\title{
Trout movement and habitat use in the upper Shavers Fork of the Cheat River, West Virginia
}

Jeff Lee Hansbarger

West Virginia University

Follow this and additional works at: https://researchrepository.wvu.edu/etd

\section{Recommended Citation}

Hansbarger, Jeff Lee, "Trout movement and habitat use in the upper Shavers Fork of the Cheat River, West Virginia" (2005). Graduate Theses, Dissertations, and Problem Reports. 2196.

https://researchrepository.wvu.edu/etd/2196

This Thesis is protected by copyright and/or related rights. It has been brought to you by the The Research Repository @ WVU with permission from the rights-holder(s). You are free to use this Thesis in any way that is permitted by the copyright and related rights legislation that applies to your use. For other uses you must obtain permission from the rights-holder(s) directly, unless additional rights are indicated by a Creative Commons license in the record and/ or on the work itself. This Thesis has been accepted for inclusion in WVU Graduate Theses, Dissertations, and Problem Reports collection by an authorized administrator of The Research Repository @ WVU. For more information, please contact researchrepository@mail.wvu.edu. 
Trout Movement and Habitat Use in the Upper Shavers Fork of the Cheat River, West Virginia

\author{
Jeff Lee Hansbarger
}

Thesis submitted to the Davis College of Agriculture, Forestry, and Consumer Sciences at West Virginia University in partial fulfillment of the requirements for the degree of

Master of Science in

Wildlife and Fisheries Resources

J. Todd Petty, Ph.D., Co-Chair

Patricia Mazik, Ph.D., Co-Chair Robert Q. Hanham, Ph.D.

Kyle Hartman, Ph.D.

Mike Shingleton, M.S.

Wildlife and Fisheries program in the Division of Forestry

Morgantown, West Virginia 2005

Keywords: Brook trout, Brown trout, Habitat use, Movement, Restoration 


\begin{abstract}
Trout Movement and Habitat Use in the Upper Shavers Fork of the Cheat River, West Virginia

By Jeff Lee Hansbarger
\end{abstract}

I quantified brook trout (Salvelinus fontinalis) and brown trout (Salmo trutta) movement and habitat use in a central Appalachian watershed, the upper Shavers Fork of the Cheat River over three seasons (spring/summer 2000-01, fall 2000) with telemetry. The objectives of my study were to: 1) quantify trout habitat use among seasons, and between the mainstem and Rocky Run (a major tributary), 2) quantify the effect of temperature extremes on habitat use by brook trout, 3) quantify trout movement among seasons and between the mainstem and Rocky Run, and 4) relate movement to variations in stream flow, water temperature, and access to cold water sources (CWSs). Habitat use analysis indicated that trout use a subset of available habitats in both the mainstem and Rocky Run. Specifically trout tended to occupy deeper and higher velocity habitats than expected by chance alone. Trout also tended to remain close to cover and in close proximity to extremely high velocity microhabitats. Finally, I consistently recorded colder trout focal point temperatures in the mainstem than near-by instream temperature loggers especially when instream levels were above $20^{\circ} \mathrm{C}$ indicating the use of mainstem CWSs (visible surface and lateral subsurface inputs through the valley alluvium, and hyporheic upwelling). Analysis of movement data indicated significant differences $(p<0.05)$ in movement rates between mainstem and Rocky Run trout with mainstem movement rates among some of the highest documented for native brook trout in an Appalachian watershed (ranging up to $6.5 \mathrm{kms}$ and up to $62 \mathrm{~m} /$ day during the spring/summer study period). Movement was strongly related to temperature and somewhat to distance to CWSs. However, mainstem trout exhibited high movement rates even when instream temperature levels were optimal suggesting other reason(s) for increased ranging. Future restoration efforts in the upper watershed should first address the overriding thermal and acid precipitation problems. The modification and/or complete replacement of all compromised culverts would be an important first step in improving water quality and habitat suitability for the highly mobile trout population in the watershed. This is a vital first step along with the continuation and possible expansion of the current WVDNR headwater liming program.

Keywords: Brook Trout, Brown Trout, Habitat use, Movement, Restoration 


\section{DEDICATION}

I dedicate this thesis to my parents and family who supported me in many ways throughout this endeavor. 


\section{ACKNOWLEDGEMENTS}

I wish to thank all committee members for their constructive comments, guidance, patience, and overall assistance in completing my thesis. A special thanks is warranted for a number of unnamed students, friends, secretaries (including Becky Nestor), and field personnel with the West Virginia Division of Natural Resources (WVDNR) who helped or aided the completion of this thesis, and anyone else I neglected to mention. I am indebted also to Kathy Fletcher and Rebecca Camper with WVU Office of Information Technology for their help with formatting, and the electronic submission of my thesis. The West Virginia Division of Natural Resources (WVDNR), United States Forest Service (USFS), United States Geological Service (USGS), Trout Unlimited (TU), and the West Virginia University Cooperative Fish \& Wildlife Research Unit all contributed to this study either financially or in some form of support. I greatly appreciate their assistance. 


\section{TABLE OF CONTENTS}

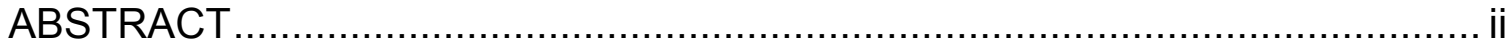

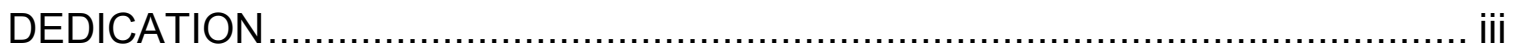

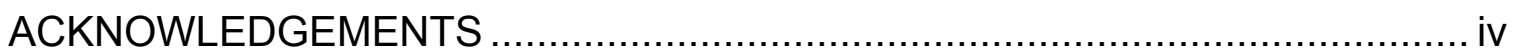

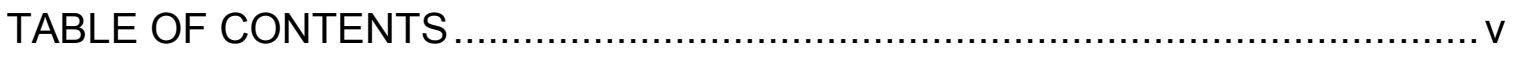

LIST OF TABLES ............................................................................ vi

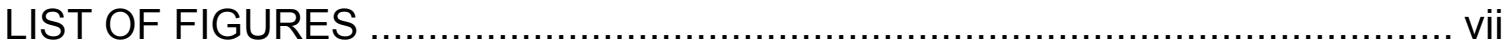

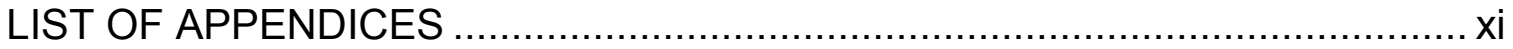

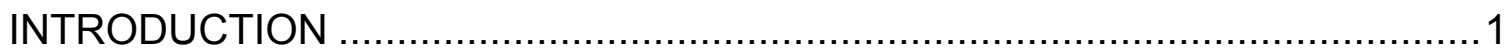

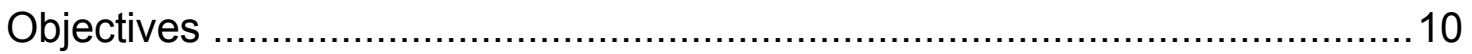

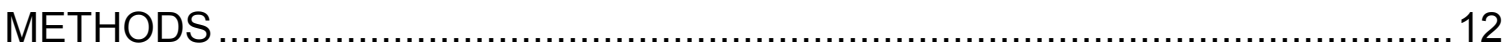

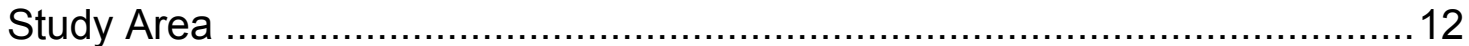

Site Selection and Mapping ............................................................. 18

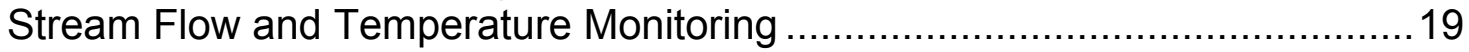

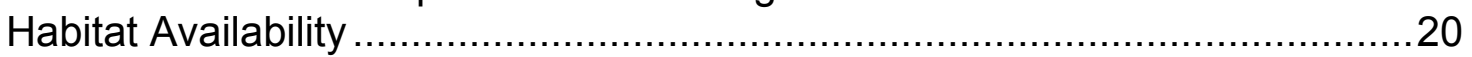

Trout Capture, Transmitter Implantation, and Tracking …...........................21

Trout Habitat Use and Movement........................................................26

Identification and Mapping of Coldwater Sources (CWSs) ..........................27

Statistical Analyses of Stream Flow and Water Temperature ........................27

Statistical Analyses of Habitat Use .......................................................28

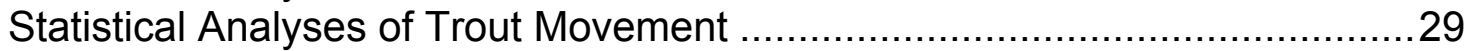

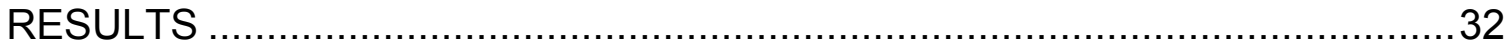

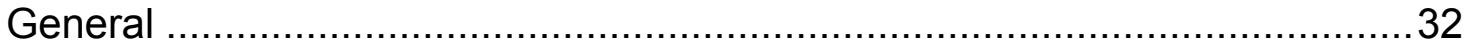

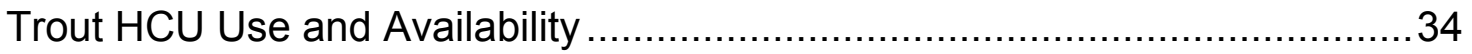

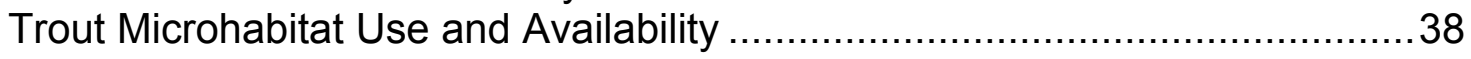

Trout Microhabitat Use and Water Temperature .........................................39

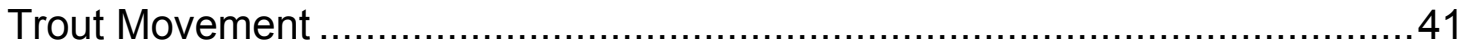

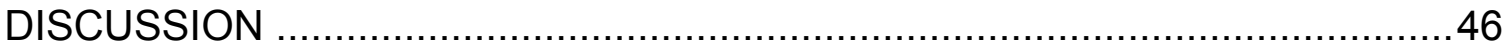

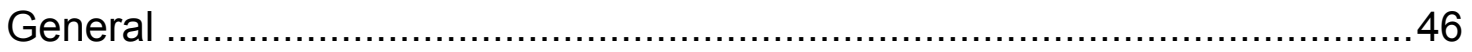

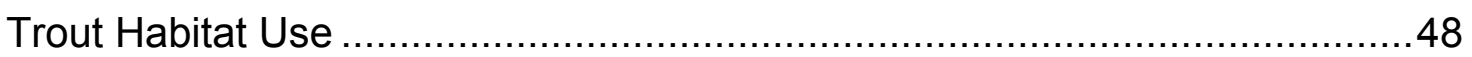

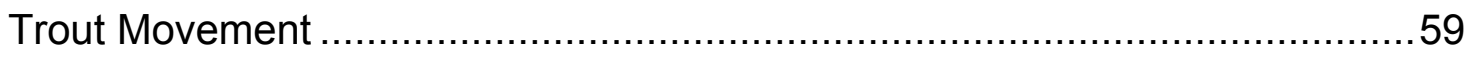

CONCLUSIONS AND MANAGEMENT IMPLICATIONS …..........................67

Classifying Warm and Coldwater Systems..............................................67

Need for Watershed Rather than Reach Scale Management Plans................71

Specific Recommendations for the Upper Shavers Fork Watershed...............72

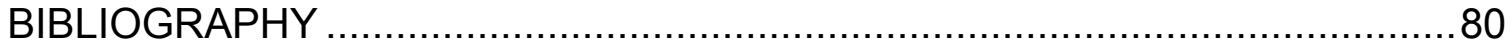




\section{LIST OF TABLES}

Table 1. General summary statistics for the mainstem of the Shavers Fork and the circumneutral focus tributary, Rocky Run

Table 2. Temperature group divisions (1-6) applied to mainstem trout observations (spring/summer 2000-01). Divisions based on recorded ambient stream temperatures, differences between ambient and focal point temperatures, and documented behavioral thresholds of trout

Table 3. Summary statistics of water temperature and flow (stage height in feet above datum) data from the Shavers Fork mainstem (SH) and Rocky Run (RR) (temperature data only). Data are from the critical spring/summer sampling period $(6 / 5-8 / 15,2000-01)$

Table 4. Summary statistics of water temperature and flow (stage height in feet above datum) data from the Shavers Fork mainstem (SH) and Rocky Run (RR) (temperature data only). Data are from the fall sampling period (9/5 - 8/15, 2000).

Table 5. Summary statistics for 9 prominent coldwater sources (CWSs) found within the Shavers Fork mainstem study area.

Table 6. Track summary table by season

Table 7. Habitat availability, and use by brook and brown trout in Rocky Run and Shavers Fork mainstem for all seasons, by stream 99

Table 8. Summary and $X^{2}$ analysis statistics for comparisons between temperature group divisions (1-6) designated for mainstem brook trout (spring/summer 2000-01

Table 9. Summary statistics of brook trout and brown trout movement in the Upper Shavers Fork watershed in spring 2000

Table 10. Summary statistics of brook trout and brown trout movement in the upper Shavers Fork watershed in spring 2001

Table 11. Summary statistics of brook trout and brown trout movement in the upper Shavers Fork watershed in fall 2000.

Table 12. Summary statistics for mean total dispersal rate comparisons by season, stream, and species 


\section{LIST OF FIGURES}

Figure 1. Map of the Shavers Fork of the Cheat River, West Virginia. The upper

Shavers Fork is denoted by the olive shading in the headwaters 105

Figure 2. Map illustrating the upper Shavers Fork watershed with the focus tributary Rocky Run and the surrounding mainstem highlighted 106

Figure 3. Map showing the circumneutral tributary Rocky Run, and surrounding mainstem of the upper Shavers Fork. Red lines represent initial upper and lower boundaries of 1-km experimental reaches on the mainstem and Rocky Run. Purple dashes represent the positioning of temperature loggers in spring/summer 2001. (1:240000 scale) 107

Figure 4. Year-to-year variation in mean daily flow of the Shavers Fork mainstem as measured at the Cheat Bridge gage station (USGS). Data is from the critical spring/summer sampling period $(6 / 5-8 / 15,2000-01)$. 108

Figure 5. Year-to-year variation in mean daily flow of the Shavers Fork mainstem as measured at the Cheat Bridge gage station (USGS). Data is from the fall sampling period $(9 / 5-11 / 15,2000)$

Figure 6. Year-to-year variation in the daily maximum water temperature measured in the Shavers Fork mainstem and Rocky Run. Data is from the critical spring/summer sampling period $(6 / 5$ - 8/15, 2000-01)

Figure 7. Year-to-year variation in the daily maximum water temperature measured in the Shavers Fork mainstem and Rocky Run. Data is from the fall sampling period $(9 / 5-11 / 15,2000)$

Figure 8. Year-to-year variation in the 7-day average maximum water temperature measured in the Shavers Fork mainstem and Rocky Run during the critical spring/summer sampling period (2000-01) ....

Figure 9. Relationship between maximum daily water temperature and mean daily flow during summer months (2000-01) for the Shavers Fork mainstem ...113

Figure 10. Imagery showing approximate locations of nine prominent CWSs within the upper Shavers Fork

Figure 11. Hydraulic channel unit (HCU) use by trout and availability in Rocky

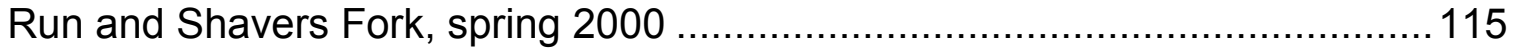

Figure 12. Figure 12. Hydraulic channel unit (HCU) use by trout and availability in Rocky Run and Shavers Fork, spring 2001 116 
Figure 13. Figure 13. Hydraulic channel unit $(\mathrm{HCU})$ use by trout and availability in Rocky Run and Shavers Fork, fall 2000

Figure 14. Microhabitat use by trout and availability of water depth (D) in Rocky Run and Shavers Fork, spring 2000

Figure 15. Microhabitat use by trout and availability of water depth (D) in Rocky Run and Shavers Fork, spring 2001

Figure 16. Microhabitat use by trout and availability of water depth (D) in Rocky Run and Shavers Fork, fall 2000.

Figure 17. Microhabitat use by trout and availability of average current velocity ACV) in Rocky Run and Shavers Fork, spring 2000

Figure 18. Microhabitat use by trout and availability of average current velocity (ACV) in Rocky Run and Shavers Fork, spring 2001

Figure 19. Microhabitat use by trout and availability of average current velocity (ACV) in Rocky Run and Shavers Fork, fall 2000

Figure 20. Microhabitat use by trout and availability of focal point current velocity (FPCV) in Rocky Run and Shavers Fork, spring 2000

Figure 21. Microhabitat use by trout and availability of focal point current velocity (FPCV) in Rocky Run and Shavers Fork, spring 2001 125

Figure 22. Microhabitat use by trout and availability of focal point current velocity (FPCV) in Rocky Run and Shavers Fork, fall 2000 126

Figure 23. Microhabitat use by trout and availability of maximum current velocity (MCV) in Rocky Run and Shavers Fork, spring 2000 127

Figure 24. Microhabitat use by trout and availability of maximum current velocity (MCV) in Rocky Run and Shavers Fork, spring 2001

Figure 25. Microhabitat use by trout and availability of maximum current velocity (MCV) in Rocky Run and Shavers Fork, fall 2000 129

Figure 26. Microhabitat use by trout and availability of distance to cover (D_cov) in Rocky Run and Shavers Fork, spring 2000

Figure 27. Microhabitat use by trout and availability of distance to cover (D_cov) in Rocky Run and Shavers Fork, spring 2001 
Figure 28. Microhabitat use by trout and availability of distance to cover (D_cov) in Rocky Run and Shavers Fork, fall 2000

Figure 29. Focal point current velocity (FPCV) versus maximum current velocity (MCV) for spring 2000.

Figure 30. Focal point current velocity (FPCV) versus maximum current velocity (MCV) for spring 2001

Figure 31. Focal point current velocity (FPCV) versus maximum current velocity (MCV) for fall 2000

Figure 32. Relationship between focal point temperature (FPT) and ambient water temperature for spring 2000-01, fall 2000

Figure 33. Variation in the difference between focal point water temperature and ambient water temperature as a function of ambient water temperature for spring/summer 2000-01.

Figure 34. Frequency histograms showing mainstem brook trout by temperature group divisions (1-6) for spring/summer 2000-01 138-140

Figure 35. Map showing representative trout movement over the spring 2001 tracking period

Figure 36. Map showing representative trout movement over the spring 2000 tracking period

Figure 37. Map showing representative trout movement over the fall 2000 tracking period

Figure 38. Frequency histograms of trout movement rates in spring 2000. ..... 144

Figure 39. Frequency histograms of trout movement rates in spring 2001 ...... 145

Figure 40. Frequency histograms of trout movement rates in fall 2000 146

Figure 41. Frequency histograms of net trout movement rates in spring 2000.

Figure 42. Frequency histograms of net trout movement rates in spring 2001.

Figure 43. Frequency histograms of net trout movement rates in fall 2000. 
Figure 44. Mean dispersal rate of brook trout and brown trout $u=i n h a b i t i n g$ Rocky Run and the mainstem of the upper Shavers Fork watershed Fork watershed

Figure 45. Relationship between brook trout movement rate and the maximum ambient water temperature of the Shavers Fork mainstem 151

Figure 46. Relationship between brook trout movement rates and distance to known CWSs in the Shavers Fork mainstem ............................................ 152 


\section{LIST OF APPENDICES}

Appendix. Summary data of implanted trout...........................153-155 


\section{INTRODUCTION}

Trout survivorship, reproduction and growth are influenced by a variety of physical, chemical, and biological factors. Dominant physical factors affecting stream-dwelling trout include water temperature, substrate composition, current velocity, and the availability of instream cover (Bjorn 1971, Meehan 1991, Behnke 1992). Instream cover is essential for protection from predators and as a refuge from high flow events (Behnke 1992, McCullough 1997, Roghair 2002). Furthermore, reproduction is strongly influenced by substrate composition. This is particularly true for many species such as brook trout (Salvelinus fontinalis) that require relatively coarse substrate with significant inputs from groundwater discharge (Meehan 1991). Brook trout are the only salmonid native to the Appalachians and West Virginia. Their preferred native habitats have been degraded or lost completely over the past century by various activities (i.e. logging, road building, agriculture) (Petty et al. 2001). Consequently brook trout are now generally restricted to headwater regions of coldwater lotic systems in the central and southern Appalachians (Marschell et al. 1996).

Many physical habitat variables are intercorrelated (Rincon et al. 1993). Current velocity and water temperature are known to have a very strong interactive affect on trout growth (Elliott 1990, Hughes 1990, 1992, 1998). Current velocity controls food delivery rates and capture success in drift-feeding fishes, and together these have a direct control on trout consumption (Hughes 1990). Net energy gain and the ability of trout to convert captured prey to biomass, however, is temperature dependent (Elliott 1990, Meehan 1991, 
Hughes 1998). Trout also need adequate flow to provide suitable water velocities and depths to access a variety of habitats and instream conditions to complete their life cycles (Meehan 1991).

Temperature is one of the most influential physical parameters that influences trout distribution. Juvenile fishes are particularly sensitive to extreme temperatures (Huey 1991). Trout and other species frequently partition themselves within habitats based more on temperature than any other habitat variables, including oxygen content (Elliott 2000). Most trout species prefer water temperatures that range between $10-19^{\circ} \mathrm{C}$ and will realize reduced growth rates when water temperature is above this range due to the increased energy demands placed on them by the higher temperature (Elliott 1990, Meehan 1991, Hartman and Sweka 2001). Bjornn (1971) reported a similar preferred temperature range of $10-14^{\circ} \mathrm{C}$, and near lethal temperatures for salmonids at 23$25^{\circ} \mathrm{C}$. Growth rapidly declines above $20^{\circ} \mathrm{C}$ for most trout (Kohler et al. 1999, Hartman and Sweka 2001) with extended periods above $25^{\circ} \mathrm{C}$ considered lethal for brook trout (Meehan 1991, Hartman and Sweka 2001). Lethal temperature levels for brown trout (Salmo trutta) vary in the current literature but are generally listed also at $25^{\circ} \mathrm{C}$ or slightly less $\left(24.7^{\circ} \mathrm{C}\right.$ ) up to $29.9^{\circ} \mathrm{C}$ (Elliott 2000 , Meehan 1991). Brown trout are usually recognized as being able to tolerate higher instream temperatures than other trout species. However, in most studies, their thermal preference is the same, if not lower than other trout species.

After a review of current literature it is apparent that researchers have reported variations in lethal (UILT - upper incipient lethal temperature, where 
$50 \%$ of individuals perish when exposed at a specified amount of time), optimal, and threshold temperature levels for trout (Power 1980, Meehan 1991, Elliott 2000, Hartman and Sweka 2001). Frequent daily instream temperature levels above $22^{\circ} \mathrm{C}$ for a stream system is considered by many to be the extreme end for classification as a coldwater system mainly due to the costs associated with activity at this temperature and above (Meehan 1991, Hartman and Sweka 2001). "Coldwater species" cannot tolerate extremely high water temperatures, including daily readings above $22^{\circ} \mathrm{C}$ and will attempt to move to more desirable habitat. For this study a threshold of $24^{\circ} \mathrm{C}$ is considered the UILT trout species can tolerate over an extended time period due to the lowest recorded lethal limits of brook and brown reported at slightly higher levels of $25.3^{\circ} \mathrm{C}$ and $24.7^{\circ} \mathrm{C}$ respectively (Power 1980, Meehan 1991, Elliott 2000, Hartman and Sweka 2001).

Designating a single (or even several) temperature threshold(s) is a difficult task. Thresholds of $22^{\circ} \mathrm{C}$ and $24^{\circ} \mathrm{C}$ were chosen for this study based on their frequency and repetition in the current literature. An alternative definition for a coldwater system is one given by Rabeni et al. (1999). They reported that warmwater streams are designated as such because temperatures are too warm to support a self-sustaining trout population. Therefore a variety of temperature thresholds need to be considered for suitable spawning, incubation of eggs, normal activity, etc. for trout before a designation can be reached. Incorporating the definition of Rabini et al. (1999) strengthens the validity of $22^{\circ} \mathrm{C}$ and $24^{\circ} \mathrm{C}$ as thermal thresholds for trout and for classification of a system as coldwater. 
Chemical habitat factors also play a part in determining trout populations' success and viability. Important factors include instream water chemistry, rainfall chemistry, residency time, the presence or absence of pollutants, and the buffering capacity of the soils and geology present in the watershed (Meehan et al. 1991, Clayton et al. 1998, Kohler and Hubert 1999). Rainfall in the eastern US is highly acidic in many mountainous areas, especially downwind of industrial areas such as the US Midwest (Kohler and Hubert 1999). The acidic precipitation released on these windward areas has a tremendous negative affect on aquatic life, especially trout. This negative effect is mainly due to the great physiological stress aquatic organisms are placed under after rainfall or snowmelt events in these affected watersheds (Menendez et al. 1976, Menedez et al. 1996, Clayton et al. 1998). The leaching of free aluminum ions from the soil into the water due to decreased $\mathrm{pH}$ levels is the main culprit in fish mortality in affected areas (Cronan and Schofield 1979).

Biological factors influencing trout growth and survivorship include food quality and availability, predation, and competition (Cada et al. 1987, Ensign et al. 1990, Meehan 1991). Productivity in most small temperate streams is low due to shading (Cada et al. 1987, Ensign et al. 1990) and low alkalinity levels (Bopp 2002). Productivity tends to increase in larger systems as a result of increased light penetration and subsequent increased levels of primary productivity and alkalinity (Giller and Malmqvist 1998, Bopp 2002). The increase is mainly due to the additions of autochthonous energy sources to the already present allochthonous energy sources. This in turn expands forage availability and quality 
to trout through increased invertebrate drift and benthic densities (Allen 1995, Bopp 2002). Predation is known to influence trout survivorship and growth both directly and indirectly. An example of an indirect effect might be a trout not occupying an optimal foraging habitat due to the possible threat of avian or mammalian predation (Fausch and White 1981, Hughes et al. 1990).

Intraspecific and interspecific competition for habitat can also act as a limiting factor. Competition potentially limits resources, which in turn could limit growth, survival and reproduction during times of stress or when low fitness becomes critical. Fausch and White (1981) demonstrated that in streams where physical conditions are suitable for both species to overlap, brook trout are outcompeted for instream resting positions by brown trout. Dewald and Wilzbach (1992) offered a similar explanation for declining brook trout numbers in the presence of hatchery raised brown trout in eastern North America. Further, Rose (1986) showed that native brook trout growth is reduced in streams where rainbows (oncorhynchus mykiss) have been introduced due to competition for both habitat and food. In comparison, brook trout out-compete various native cutthroat trout species (Oncorhynchus clarki) when stocked into watersheds in the western US and have had a negative effect on the conservation of this threatened species (Behnke 1992, Peterson et al. 2003). Whenever rainbow and or brown trout are found sympatrically with native brook trout in eastern streams, the native species is usually out-competed and realize reduced overall fitness, especially in systems with high densities of salmonids (Vincent 1987). 
The physical, chemical, and biological factors described above exist within lotic ecosystems as a complex patchwork, rather than smoothly continuous gradients of conditions often seen on land (Kotliar and Weins 1990, Giller and Malmqvist 1998). For example, depth and current velocity can vary dramatically within a relatively small area in high and intermediate gradient streams (Grossman and Petty 1996, Petty et al. 2001). Physical, chemical, and biological conditions in streams can change dramatically on a temporal basis as well (Hildrew and Giller 1994). In particular, stream flow, water temperature, and invertebrate prey densities may vary significantly on a yearly, seasonally, daily, and even hourly basis. As a consequence trout often experience optimal, suitable, and poor habitat patches within the same general area depending on the time of the year and climatic conditions. In response trout choose specific sites (microhabitats) that blend an acceptable suite of physical, chemical and biological characteristics possibly at several spatial scales (Young 1995).

Given these complexities, the ability of individuals to maximize survivorship, reproduction and growth rates in stream ecosystems is strongly dependent on their ability to respond to spatial and temporal variability in habitat conditions (Gibson 1966, Berman and Quinn 1991, Torgersen et al. 1999). Riley et al. (1992) investigated brook trout movement in Colorado streams and concluded that a high degree of movement was an adaptive response due to the heterogeneous nature of small mountain streams. Tests of optimal habitat selection by stream fishes have generally confirmed that most fishes perceive spatial variation in habitat quality and select habitats that maximize fitness or 
some immediate indicator of fitness such as feeding rates (Fausch 1984, Hill and Grossman 1993, Hughes and Dill 1990, Petty and Grossman 1996). Gilliam and Fraser (1987) demonstrated that creek chubs (Semotilus atromaculatus) select foraging patches that maximize feeding rates relative to predation risk. Other researchers have consistently found that drift feeding fishes, including salmonids select focal current velocities that maximize access to drifting prey (Fausch 1984, Hughes and Dill 1990, Hill and Grossman 1993). Hughes (1998) went on to show that the distribution of arctic grayling (Thymallus arcticus) along a river gradient was a function of both foraging site profitability and temperature.

Numerous studies of trout movements have focused on questions about how extensively trout move in streams. Early studies indicated that most trout are extremely sedentary. Gerking $(1953,1959)$ in a series of landmark papers, developed the idea that stream fishes generally lead a sedentary life style, interrupted only by unusual or specialized behaviors. These specialized behaviors as stated by Gerking (1959) are passive and active dispersal of trout fry, various ontogenic shifts related to habitat use, and small-scale diel movements between feeding and resting areas. A major tenet of this earlier literature is that fish are sedentary, and there exists the possibility of fish spending their entire lives within one pool. Bachman (1984) documented similar results while studying movement of wild brown trout in a Pennsylvania spring creek. This guiding paradigm in understanding stream fish ecology was termed by later researchers as the "restricted movement paradigm" or RMP (Gowan et al. 1994). 
Movement by stream fishes, in general, is now understood to play a larger part in their life histories allowing them to utilize a wide array of habitat types for feeding, reproduction, and refuge from predators and environmental extremes (Schlosser 1991, 1995a) on a daily and seasonal basis (Clapp 1990, Meyers et al. 1992, Brown and Mackey 1995, Gowan and Fausch 1996b,). Researchers have found that the Salmonidae family (Curry et al. 2002), and brook trout in particular (Rodriquez 2002), exhibit high levels of movement. Logan (2003) documented high mobility by brook trout in small West Virginia streams and their use of large home ranges. Using mark-recapture techniques and upstreamdownstream traps, Riley et al. (1992) found that a large proportion of brook trout in four Colorado streams were mobile. Similarly, in three radio-telemetry studies, the majority of adult brown trout were mobile, with total movements of over $90 \mathrm{~km}$ in a Wyoming drainage (Young 1994) and over $30 \mathrm{~km}$ in Michigan (Clapp et al. 1990) and Wisconsin streams (Meyers et al. 1992).

These exceptions to the RMP have become so prevalent, that they have led to a new understanding or awareness of fish ecology and fish movement, the NRMP, or "non-restrictive movement paradigm". Rodriquez (2002) determined the scale of the investigation and nature of the study often dictates what researchers record as extensive or not in terms of fish movement and/or migration. He further explained that generally movement is carried out at specific times and not year-round and that there are usually two components to most fish populations: one segment that is mobile and one that is not with both existing along a continuum. He adds that critics of the RMP may have overemphasized 
turnover rate (individuals leaving) and the proportional representation of the mobile component of a population, especially in mark-recapture studies showing high turnover rates.

Despite recent advances in our understanding of fish movements, their causal mechanisms remain largely unknown or at the least undocumented, in trout as well as in many non-game and benthic fishes (Petty and Grossman 2004). Riley et al. (1992) elaborated that movement can be affected by a number of factors, including water temperature, flow regime, fish size, local population density, winter conditions, species composition, quality of drift, and habitat characteristics. Fausch et al. (2002) have distinguished movement as a key component of "ranging behavior" by stream fishes. This term which is an important component of the theory of landscape ecology indicates movement with a purpose, which they argue should replace the term dispersal which indicates undirected movement by definition (although White (1990) defines it as one-way movement of individuals from their natal site or an area that has been occupied for a period of time). Fausch et al. (2002) define ranging behavior as long-distance movement that ceases when patches with suitable resources and/or critical habitats are encountered (Dingle 1996). For simplicity I will use fish movement and dispersal as general terms and elaborate where needed. Most researchers agree that movement/dispersal plays an important role in enabling fishes to access profitable habitats in patchy, dynamic lotic environments, and to access different required habitat types (Meehan 1991, Swanberg 1997, Fausch et al. 2002). 
A variety of quality habitat types must be present for trout to accomplish their life cycles, with a deficiency in any one type potentially limiting population levels (Behnke 1992, Matthews 1996, Swanberg 1997). These habitat types include: overwintering refuges, spawning habitat, foraging habitat, and nursery or rearing habitat (Behnke 1992, Chisholm and Hubert 1987, Cunjak 1996). Therefore the ability to assess habitat quality and to move between different habitat types as needed is critical for trout populations (Torgersen et al. 1999). Nevertheless, few studies have explicitly sought to link trout movements to spatial and temporal variability in habitat quality, especially over multiple seasons within both mainstem lotic systems and smaller associated tributaries (MakiPetays 1997, Bunnell et al. 1998, Burrell et al. 2000).

\section{Objectives}

Given the importance of movement to trout populations inhabiting spatially and temporally complex ecosystems, I conducted a study of trout movement and habitat use in the upper Shavers Fork of the Cheat River during the spring/summer 2000-01 (6/5 - 8/15), and fall 2000 (9/5 - 11/15). The overriding objective of my research was to identify the causal mechanisms underlying trout movements in this system and to possibly describe the extent to which these mechanisms change over time. Additionally I wished to determine if habitat use was influenced by these mechanisms and to what extent. Since temperature and flow impacts are at their greatest during the spring/summer periods, I chose to focus most of the analysis and discussion towards these sampling periods. I addressed the following specific objectives: 1) quantify habitat use by trout, 
comparing use between seasons, between the mainstem and Rocky Run (a major tributary of the mainstem of the Shavers Fork) and between brook trout and brown trout, 2) quantify the effect of temperature extremes on habitat use by brook trout, 3) quantify trout movement, compare among seasons, between the mainstem and Rocky Run, and between brook trout and brown trout, and 4) relate movement to variation in stream flow, water temperature, and access to cold water. 


\section{METHODS}

\section{Study Area}

The upper Shavers Fork is a large (i.e., $>100-\mathrm{km}^{2}$ basin area), high elevation (> 1000-m) watershed located in the central Appalachian Mountains of eastern West Virginia (Pocahontas and Randolph Counties) (Figure 1). The Shavers Fork is part of the Cheat River drainage flowing north to its mouth on the Monongahela River outside of Pt. Marion Pennsylvania. For purposes of this study, the area from W.Va. route 250/92 (Cheat Bridge) south to the headwaters will be considered the upper Shavers Fork watershed (Figure 2). The lower reaches of the upper Shavers Fork mainstem near Cheat Bridge average 20-25$\mathrm{m}$ in width with tributaries characteristically $5-10-\mathrm{m}$ or less in width at their mouths. Historically the watershed was known as an excellent brook trout sport fishery with such notable visitors as Thomas Edison and Henry Ford who stayed at the Cheat Mountain Lodge near Cheat Bridge at the turn of the century. Early accounts from Clarkson's Tumult on the Mountain (1964) claim that 60 "speckled beauties" or brook trout could be caught easily within 30 minutes using only "redbuds" before the area was extensively timbered in the early 1900's.

The upper Shavers Fork is very unique to the region. It originates at nearly 1500-m elevation on Thorny Flat located on Back Allegheny Mountain. The upper watershed is located atop a high plateau and has a relatively low gradient (often $<1 \%)$. Geology of the area consists primarily of sandstones and shales of the Pottsville and Mauch Chunk formations (Gaujot 2002). Streams in the watershed are generally surrounded by poorly drained, deep, strongly acidic, loam soils 
(Clayton et al. 1998). Headwater areas of the tributaries frequently consist of naturally acidic bogs and glades. Temperature within the mainstem is the most important limiting factor to the current aquatic assemblages. Researchers recorded temperature levels as high as $30^{\circ} \mathrm{C}$ immediately downstream of Cheat Bridge during the summer of 1999 (Petty, unpublished data). Daily temperature levels above $20^{\circ} \mathrm{C}$ are routinely found instream in the upper mainstem during extreme summer conditions (Petty, unpublished stream survey data).

The extreme headwaters of the upper Shavers Fork are located within the Snowshoe Ski Resort property owned by Intrawest and typically average less than 15-m wetted width during normal spring/ summer flows. A small lake and dam constructed on the extreme upper Shavers Fork in the 1970s is used for snow production by the resort. In 1999 this impoundment was enlarged with flow being mitigated in cooperation with the West Virginia Department of Environmental Protection (WVDEP). The remaining watershed downstream of the Snowshoe property to Cheat Bridge is located within the Monongahela National Forest under ownership of the United States Forest Service (USFS).

The USFS and the West Virginia Division of Natural Resources (WVDNR) cooperatively manage this area. Total area of the watershed with Cheat Bridge as the reference point is approximately $155-\mathrm{km}^{2}$. Significant tributaries in the upper Shavers Fork include First Fork, Second Fork, Beaver Creek and the Rocky Run drainage. Most tributaries enter the mainstem at right angles creating a trellised pattern (Allen 1995, Leopold 1994). Because of its potential value as a recreational fishery, this study concentrates specifically on the second order 
circum-neutral tributary Rocky Run, and mainstem reaches immediately downstream and upstream of this tributary (Figure 3).

The mainstem of the upper Shavers Fork and the circumneutral tributary Rocky Run differ physically, chemically, and biologically (Table 1). Table 1 is representative of the spring/summer study period. The mainstem is larger, more productive, and includes a more diverse fish assemblage. Rocky Run is not currently dosed by the WVDNR to mitigate acid deposition but many of the tributaries of the upper mainstem are, as is the mainstem itself in certain locations. I never sampled brown trout in Rocky Run during my study but other researchers from WVU did, therefore they are included in my Rocky Run species richness factor (Table 1). A majority of the data used in Table 1 came from, or was extrapolated from Bopp (2001) and Thorne (2004). Second Fork, a similar tributary to Rocky Run was utilized as a substitute when data specifically for Rocky Run was not available (Bopp 2001).

Intensive logging, and other man-made perturbations have all impacted the watershed. Accounts exist of the use of dynamite around Cheat Bridge to clear instream obstructions and boulders thus allowing timber to be floated downstream during the logging of the valley in the early 1900s (Clarkson 1964). The creation of the railroad grade along the upper Shavers Fork and its maintenance exists as one of the main limiting factors in the system today (S. Kite, WVU Dept. of Geography/Geology, pers. comm.). Effects from the railroad grade have created unnatural fluvial processes (deposition, scouring, and energy transfer) by altering normal flow patterns and thermal problems due to the 
removal of riparian and stream-shading vegetation (Hawkins et al. 1983, Kohler et al. 1999, Meehan, 1991). In addition, the system has not had time since the last major timber harvests (early 1900s) to allow for natural inputs of large woody debris (LWD) through deadfall and windthrow.

During pre-logging times (prior to the early 1900s) large spruce trees (Picea rubens) (and other species) in abundant supply probably contributed significant levels of LWD and structural complexity to the system. Studies have shown that the presence of LWD in quantities known to exist within the system before logging (early 1900s) have profound effects on channel morphology even in relatively low gradient systems like the upper Shavers Fork (House et al. 1986). Large amounts of instream LWD cause a stream channel to become "stair stepped", resulting in the formation of secondary channels, meanders, undercut banks, an abundance of pools, and instream rootwads (cover) (Kohler and Hubert 1999). In this pristine state prior to the early 1900s logging period, the upper Shavers Fork existed as a diverse, complex array of abundant aquatic habitat for all coldwater species, especially trout.

Other important factors potentially limiting the system include acid deposition, limited acid mine drainage (AMD), and sedimentation. Lacking adequate natural buffering capacity, the river is now dosed with limestone fines at several points within the watershed by the WVDNR to combat the effects of acid precipitation on the local aquatic communities (Jordahl 1987, Lacroix 1992, Gagen et al. 1994, Clayton et al. 1998). This successful practice started in the late 80 s in the upper watershed and will continue indefinitely. Despite these 
efforts, numerous tributaries of the Shavers Fork mainstem remain acid impaired mainly due to their remoteness and lack of access by the WVDNR for limestone fine additions, inhibiting recruitment and overall survival of trout (Lamothe 2002). Future work in the watershed will possibly incorporate improved methods to deliver limestone to the watershed directly benefiting brook trout and other impacted species by increasing levels of available suitable habitat (Petty and Thorne 2005).

Sediment loads within the river channel downstream from the reservoir to approximately Beaver Creek have notably increased in the past few years. Fine sediments can negatively impact brook trout reproductive success and recruitment and instream invertebrate assemblages (Angradi 1999, Hakala 2000). Increased sediment loads also raise the energy costs associated with trout actively feeding, therefore potentially reducing their overall growth and fitness, which can potentially affect reproductive success and species persistence indirectly (Burrell et al. 2000). Response times are reduced and trout are required to swim and seek out prey costing them more energy under turbid instream conditions (Sweka and Hartman 2001). The increased sediment loads can be attributed mainly to the reservoir's enlargement in 1999 and subsequent development of Snowshoe's property by Intrawest over the past few years. Recent developments by Intrawest within the upper drainage include a new golf course, summer homes, water parks, and new access roads.

Fish assemblages in the upper Shavers Fork and its tributaries are typical for large, Appalachian streams. A self-sustaining native brook trout population 
exists in most tributaries and the upper mainstem. Reproducing brown trout and rainbow trout (Onchorynchus mykiss) are also present in the upper reaches of the Shavers Fork, with numerous large brown trout present (>18") (Petty, unpublished stream survey data). Additional species present include the rosyface shiner (Notropis rubellus), rosy side dace (Clinostomus funduloides), blacknose dace (Rhinicthys atralatus), longnose dace (Rhinicthys cataractae), central stoneroller (Campostoma anomalum), fantail darter (Etheostoma flabellare), mottled sculpin, Northern hog sucker (Campostoma nigicans), creek chub (Semotilus atromaculatus), and other various Cyprinids and Catastomids (Lamothe 2002, Petty, unpublished stream survey data).

Conditions within the mainstem of the Shavers Fork and its tributaries fluctuate in terms of fish survivorship, reproduction and growth. The mainstem in the summer, for example, is characteristically high in productivity while the tributaries are generally less productive, mainly due to their heavy shading and lower alkalinities (Bopp 2002). Yet, these tributaries and/or their outflows may serve as coldwater refuges (i.e. CWSs) when water temperatures in the majority of the mainstem reach stressful levels. Furthermore, the tributaries also may act as "warm" refuges in the winter due to point sources of groundwater recharge (Chisolm and Hubert 1987, Brown and Mackey 1995, Cunjak 1996, Boulton et al. 1998). The hyporheic upwelling of groundwater present in the tributaries creates a relatively stable cool temperature regime almost year-round and one that is usually slightly above extreme winter instream temperatures found in the mainstem (Boulton et al. 1998). A study investigating fluctuations in instream 
conditions while identifying trout movement would be extremely relevant for the system.

Despite the problems and the unique characteristics of the system, Shavers Fork is still in a relatively pristine state capable of supporting a productive fishery. Some of the most impressive remaining stands of red spruce located on USFS land in West Virginia are found within the upper watershed of the Shavers Fork (Hornbeck and Kochenderfer 1998). The USFS has designated this watershed a model watershed to be included in a national program to facilitate improved land practices and stewardship on USFS land (T. Cain, USFS Monongahela National Forest, personal communication). The local goal of this extensive national plan is to facilitate the restoration of the native red spruce ecosystem and its associated aquatic environment. In addition the WVDNR has designated this watershed as a major area of focus into the future for restoration/enhancement efforts. It is from these higher goals that this particular project was derived.

\section{Site Selection and Mapping}

To quantify movement patterns, it is important to include accurate forms of mapping. Large-scale topographical maps (1:5000 scale and 1:10000 scale) and digital imagery downloaded to Arcview $8^{\mathrm{TM}}$ and ArcGIS ${ }^{\mathrm{TM}}$ (Environmental Systems Research institute (ESRI) software, Redlands, California) were used as base maps. Points corresponding to natural features within the upper Shavers Fork served as reference points noted on the base maps. Stakes with fluorescent tips were placed along the study reaches every $50-\mathrm{m}$ on the mainstem, and 
every $25-m$ on the focus tributary Rocky Run. I determined placement by walking the middle of the thalweg. The first stake that all others are measured from was located on the base maps using a GPS unit, at the mouth of Rocky Run. I used a Bushnell ${ }^{\mathrm{TM}}$ laser rangefinder to determine placement of all other stakes based on the original stake at the mouth of Rocky Run to ensure a high level of accuracy and precision while measuring trout movement within the study reaches. Study reaches initially consisted of four 1-km reaches of the mainstem, and a 1-km reach on Rocky Run (Figure 3).

\section{Stream Flow and Temperature Monitoring}

Shavers Fork stream flow was monitored using the USFS gaging station online website. The station used for reference was located at Cheat Bridge on West Virginia route 250/92, which is approximately $25-\mathrm{km}$ below our study area on the Shavers Fork mainstem. Stream flow is given online for this site as a stage height above a datum (confirmed standard level) each hour along with graphic representation. A rough relationship between stage height and flow volume was used as an index for this study (Petty, unpublished data). For later reference, stage heights of $4.5-\mathrm{ft}, 5.0-\mathrm{ft}$, and 5.5 -ft are approximately $40-\mathrm{cfs}$, 90 cfs, and 200-cfs, respectively.

Continuous temperature loggers $\left(\mathrm{HOBO}^{\mathrm{TM}}\right.$, Onset Computer Corporation, Bourne, Massachusetts) anchored within the study reaches allowed the instream thermal regime to be captured over the period of our study $\left( \pm 0.1^{\circ} \mathrm{C}\right)$. A total of seven loggers were spaced throughout the study reaches for the spring/summer and fall tracking periods of 2000 (Figure 3). This number was reduced to three 
critical locations in 2001. This arrangement captured the thermal regime as well as the larger number used the previous seasons. Temperature information was downloaded at intervals throughout the study periods and used to construct temperature profiles and calculate various temperature regime statistics for the upper Shavers Fork watershed.

\section{Habitat Availability}

I sampled habitat availability of the upper Shavers Fork and Rocky Run using protocols from Simonson et al. (1994) and Petty et al. (2001). Instream sampling was taken at one representative flow to document habitat availability. Other than a few thunderstorms that caused short-lived spikes shown on the USGS online stream hydrograph, instream flows averaged between 4.85 to 5.3 feet above the datum ( 43.1 - cfs to 47.1 - cfs respectively) for the majority of the time tagged trout were monitored for movement and habitat use. Consequently, all sampling for habitat availability was conducted while flows ranged between 43 - 47 cfs. Following Simonson et al. (1994) Rocky Run is considered a small tributary based on a sample of wetted stream width measurements. I established transects using a suspended flexible tape measurer on Rocky Run at positions moving upstream from a chosen representative starting point every 3 times the mean standard or wetted width (3MSW). The recommended minimal total distance sampled for small streams is $100 \mathrm{~m}$. The average wetted width sample for Rocky Run within my study reaches $(\mathrm{N}=20)$ equaled $4.79 \mathrm{~m}$, therefore I placed transects instream every 15 meters or slightly greater than 3 times the mean (3MSW). To ensure proper capture of the instream habitat variability a total of 28 
transects were sampled at 3MSW on Rocky Run or 405 meters total, well over the minimum suggested for this habitat sampling scheme (Simonson et. al. 1994).

The mainstem of the upper Shavers Fork required a slightly different approach to capture instream habitat variability. The average wetted width of the mainstem study reaches $(\mathrm{N}=20)$ equaled $14 \mathrm{~m}$, raising the classification to a larger stream. Again following Simonson et al. (1994) I located transects at approximately $2 \times \mathrm{MSW}$ on the mainstem for a total of 80 transects throughout the four 1-km study reaches. Each wetted width transect distance on both Rocky Run and the Shavers Fork was divided by six to give 5 points along the transect (not including the edges) with the following parameters taken at each: average current velocity (ACV), bottom current velocity $(B C V)$, depth (D), substrate composition, distance to cover (D_cov). Dry channel widths were recorded along with the wetted width for each transect. The Hydraulic Channel Unit (HCU) that each transect bisected was recorded as well (Petty et al. 2001). I used a meter stick, a Marsh-McBirney ${ }^{\mathrm{TM}}$ flow meter, and a plexiglass instream viewer to document habitat availability. Substrate composition was determined visually using the Wentworth scale (Allen 1995).

Trout Capture, Transmitter Implantation, and Tracking

This study was conducted over a period of 60-70 days during three separate seasons: spring/summer 2000 , fall 2000 , and spring/summer 2001 . The spring/summer sampling season continued from June 5 until around August 15 of each year. The fall 2000 season continued from September 5 until November 15. 
Trout used for the study were captured using electrofishing techniques and hook and line. In spring 2000 , only brook trout were sampled. Brown trout were added to the study design in fall 2000 and spring/summer 2001. I captured fish within the study reaches and returned them after surgery as close to their original location as possible. In spring/summer 2000, because of difficulties capturing enough large fish, seven of the tagged trout were captured from outside the study reaches and released into the immediate study area. However, we made every effort to minimize this practice, and avoided it completely in fall 2000 and spring/summer 2001.

Once captured, trout were surgically implanted with internal radio transmitters or tags using a specialized surgery table (Courtois 1981) following protocol derived from multiple sources (Hart and Summerfelt 1975, Ross and Kleiner 1982, Winter 1983, Swanberg 1997). Trout were handled according to the guidelines of the West Virginia University Animal Care and Use Committee (protocol \# 9801-12). Clove oil was used as an anesthetic and antiseptic for the surgery following the procedure outlined by Anderson et al. (1997). Some fish were held to ensure proper post-surgery recuperation, but none were held longer than a total of 24 hours after surgery. Transmitters (MBFT ${ }^{\mathrm{TM}}$ series) were from Lotek $^{\mathrm{TM}}$ Industries and weighed 2.0 grams (guaranteed 47 days) and 1.8 grams (guaranteed 34 days) respectively with signals transmitted at frequencies every $.010 \mathrm{MHz}$ between 149.540 and $150.720 \mathrm{MHz}$. Complying with the "modified Winter rule" of $2.5 \%$ body weight for maximum transmitter weight, I restricted capture to fish larger than 72 grams (approximately 175-180-mm) (Winter 1983, 
Matthews 1996). To maximize battery life, transmitters were programmed to be on one day, off the next, with alternating hours of on and off during their "on" days.

Twenty-eight trout were tagged and released each season for a total of 84 trout implanted for the study. Eight brook trout were tagged and monitored for habitat use in Rocky Run in spring/summer 2000, and twenty brook trout were tagged in the mainstem. During the 2001 spring/summer study period, five brook trout were tagged in Rocky Run, fifteen brook trout in the mainstem, and eight brown trout in the mainstem. Numbers of implanted trout chosen for each body of water were based on population estimates for particular times of the year. For example, I implanted only two brook trout in the mainstem during the fall 2000 season due to their low populations levels in the mainstem at this time. By this time the larger brook trout had generally moved into the tributaries to spawn and were not present in the mainstem in late September. Due to this, a larger number of brook trout were tagged in Rocky Run during the fall 2000 season than in the mainstem (16 brook trout in Rocky Run, 2 brook trout in the mainstem, and 10 brown trout in the mainstem).

During the spring/summer study periods I attempted to place the tagged trout within the study reaches before the descending limb of the hydrograph (USGS online data) became stable indicating summer conditions. Additionally I tried to implant the fall batch of trout in the river before the ascending limb of the hydrograph indicative of the fall season. The timing of release in the spring/summer season was to quantify fish movements and habitat use in 
response to changes in stream discharge and water temperature. The timing of release in the fall season was to quantify spawning related movements and habitat use.

To ensure full recovery and resumption of normal behaviors, official tracking of fish did not begin until one week had passed from the time individual trout were implanted with transmitters. All fish at large for each season were located using a Lotek ${ }^{\mathrm{TM}} \mathrm{SRX} 600$ Datalogger receiver at least twice per week each season between 0600 hours to 2100 hours, completing one "track". But, a track did not necessarily include all implanted fish for each season sampled. This was due to problems with equipment, weather, darkness, or because a fish could not be located on that particular day or track. An exhaustive effort was made throughout each track to locate all tagged trout throughout the watershed, walking up to $10 \mathrm{kms}$ during each tracking day during daylight hours. If all trout had still not been located for that "track" the search began for those particular trout the next time from the previous stopping point until the trout not previously found were located. If a fish was not located during three consecutive tracks it was considered lost either from predation, harvest, or emigration. If a fish was found in the same location on more than two tracks under rocks, etc., the trout was visually located by wading (Burrell et al. 2000).

To minimize the effect of the time of day on habitat use and movement, different starting points were chosen for each daily track to ensure all tagged trout were encountered at varying times throughout the day. Tagged trout were located by walking parallel to and within $50 \mathrm{~m}$ of the stream bank until a signal 
was detected (up to $400 \mathrm{~m}$ away) (Young 1995). I determined the accuracy of trout relocations by searching and finding transmitters prior to the start of implanting trout for the study. Actual distance to the transmitters during the trials $(\mathrm{N}=10)$ averaged slightly less than one meter $(0.78 \mathrm{~m})$ each time. Therefore recorded positions and movements in this study were assumed to be $\pm 1 \mathrm{~m}$ for each tagged trout. Visual recognition was achieved as much as possible especially in areas with high boulder counts which were found to increase the determined locational area due to feedback and "noise" (Todd et al. 1989). Tracking continued for up to 71-days each season. Most transmitters had "died" by day 60 .

Diel tracks of trout (both brook and brown) movement and habitat use were included to investigate possible shifting seasonal diel movement patterns (Burrell et al. 2000). Usually 3 - 4 trout were monitored over a chosen 24-period period with habitat measurements taken every other hour for each tagged trout. I executed 3 diel tracks during each season (spring/summer 2000-01, fall 2000) for each species; one near the beginning of each season, one in the middle and one near the end. To increase the content of the main movement and habitat data set, diel data was added where appropriate. To do this I inserted a single representative observation for each trout for each day observed from the diel data into the main data set. Preliminary analysis of the diel tracks failed to indicate a significant difference in movement behaviors over time. Consequently, results from the diel data sets are not included here. 


\section{Trout Habitat Use and Movement}

Upon locating each tagged trout a variety of microhabitat measurements were taken that generated microhabitat use and movement data. I used a meter stick, a Marsh-McBirney ${ }^{\mathrm{TM}}$ flow meter, a handheld $\mathrm{pH}$ meter, and a plexiglass instream viewer to record microhabitat measurements. Upon locating a tagged fish the following information was taken: 1) location based on the stakes placed along the experimental reaches and or a laser rangefinder, 2) time of day/conditions, 3) HCU type, and 4) microhabitat variables of the site where the fish was located. Microhabitat variables included focal point temperature (FPT), $\mathrm{pH}$, bottom current velocity (BCV), average current velocity (ACV), focal point current velocity (FPCV), depth (D), maximum current velocity within $60 \mathrm{~cm}(\mathrm{MCV})$ (Fausch et al. 1981), distance to cover (D_cov), cover type used (CT), and distance to a known coldwater source (CWS). Cover for this investigation consisted of undercut banks, logs and rocks, or other features including large woody debris (LWD) that might serve as instream cover for an adult trout similar to the size range I implanted with transmitters for this study (Flebbe et al. 1995). Focal point refers a position held by a drift feeding fish that is returned to after excursions to catch passing prey (Hughes 1990). These data were acquired and then analyzed concurrently with the habitat availability data.

Trout were observed for a few minutes to note their general location, activity, etc. prior to taking the habitat use measurements. Once disturbed a small painted rock placed at the first noted location of the tagged trout served as a reference for the microhabitat measurements. I substituted a reading of ten centimeters from the bottom for an adjusted focal point whenever instream 
turbidity prevented the determination of the exact location (Young 1995). Trout were apparently not bothered by the sampling procedures. Many times trout were observed re-establishing their feeding positions a short time after the series of microhabitat measurements were taken. Young (1995) noted similar behaviors by cutthroat trout, as did Bunnell et al. (1998) with brown trout.

Identification and Mapping of Coldwater Sources (CWSs)

Inputs of coldwater to the upper Shavers Fork watershed are extremely important. Without them the system could not exist as a coldwater system capable of supporting a year-round trout fishery. A number of methods were used to map CWSs and to confirm their presence in the watershed. First, major areas of possible inputs were located using field observation and topographical maps (1:24000 scale). I then used fish distributions over time and the visible persistence of flow throughout summer and fall seasons to identify the most important CWSs to the Shavers Fork mainstem reaches used for this study. The total area investigated for CWSs extended from Spruce downstream to Second Fork. Once identified, I then used ArcGIS $9^{\mathrm{TM}}$ to calculate the basin area of each CWS and calculated their distances from the mouth of Second Fork, a large tributary used for reference located near the base of our study area (Thorne 2004).

\section{Statistical Analyses of Stream Flow and Water Temperature}

I used stream flow and temperature data to calculate the following parameters: mean daily flow (stage height in feet above datum), average daily maximum temperature, average 7-day average daily maximum temperature, 
maximum 7-day average daily maximum temperature, number of days maximum temperature exceeded $18^{\circ} \mathrm{C}$, number of days maximum temperature exceeded $20^{\circ} \mathrm{C}$, and number of days maximum temperature exceeded $22^{\circ} \mathrm{C}$. Data from the 1999 drought year was included in some graphs for comparison purposes. I used Kolmogrov-Smirnov (K-S) tests for continuous data to test for significant differences in stream flow and temperatures. I tested for year-to-year differences in stream flow and temperature within the Shavers Fork mainstem and also compared water temperatures between the mainstem and Rocky Run, a small, well shaded tributary of the Shavers Fork.

\section{Statistical Analyses of Habitat Use}

My first objective was to quantify habitat use by trout and determine if they used a non-random subset of available microhabitats in Shavers Fork and Rocky Run. In addition I assessed whether changing temperature conditions influenced microhabitat use by brook trout residing in the Shavers Fork mainstem. As an initial step, I constructed frequency distribution histograms of habitat availability and use by trout separately for each microhabitat variable in each season, in each stream, and for each species. I then used $X^{2}$ analysis to test the null hypothesis of no significant differences between habitat use and availability. Significant tests enabled me to identify HCUs and specific characteristics of areas preferentially used by trout and how these preferences change seasonally and differ between species and streams (Rocky Run and the mainstem). 
My second objective was to examine the response of trout residing in the Shavers Fork mainstem to changes in water temperature, and to quantify the effects of changing conditions on microhabitat use. Ambient temperature was derived from continuous temperature loggers deployed throughout the study area. Focal water temperature was measured at the time of fish observation. I then calculated the temperature difference by subtracting ambient from the focal temperature. Positive values indicate conditions where individual trout inhabited microhabitats with warmer than ambient temperatures, whereas negative values occur when fish inhabit cooler than ambient temperatures.

Because trout residing in the mainstem exhibited a shift in temperature selection behaviors, depending on ambient water temperature, I divided all mainstem observations into one of six temperature group divisions for further analyses. Temperature groups were determined based on the relationship between temperature differences, recorded ambient temperature, and documented behavioral thresholds of trout. Distinct temperature group divisions are illustrated in Table 2. I then used $\mathrm{X}^{2}$ analysis to test for significant differences in microhabitat use among the different temperature groups. These analyses were used to test the null hypothesis of no significant effect of thermal conditions on microhabitat use by trout residing in the mainstem.

\section{Statistical Analyses of Trout Movement}

My third objective was to quantify trout movements and assess differences in movement behaviors among seasons, between the mainstem and Rocky Run, and between brook and brown trout. Movement was quantified as the distance, in 
meters, between subsequent fish locations. I arbitrarily assigned positive values to upstream movements and negative values to downstream movements. I then constructed two-tailed, frequency distributions of movement distance for each year. My analyses of these distributions followed the advection-diffusion framework described by Turchin (1998) and Skalski and Gilliam (2000), where advection refers to the direction of movement (upstream vs. downstream) and diffusion refers to variation in movement distances by individuals in the population (Petty and Grossman 2004).

Because movement distance was correlated with the number of days between capture, I converted all measurements of movement to a movement rate by dividing distance by the number of days between subsequent sightings. These data were then analyzed on a track-by-track basis by examining movement rates between subsequent sightings. I also analyzed the data on the basis of overall movement rates of each individual fish over the course of the study. Specifically, I calculated the total net movement rate (including up and downstream movements) and the total absolute movement rate for each fish each season.

I used t-tests to test the null hypothesis that overall net displacement by trout did not differ significantly from zero. Rejecting this hypothesis would suggest a directional tendency in trout movements. I tested for differences in movement rates among seasons, years, streams, and species by conducting either t-tests or ANOVAs on log-transformed movement rates. 
My fourth objective was to relate trout movements to variation in water temperature and access to cold water. I examined the effects of daily variation in temperature, flow, and access to known CWSs on trout movements during summer months. These analyses employed simple and multiple linear regression where the dependent variable (i.e., y-variable) was the log-transformed movement rate of fish on a track-to-track basis. Independent variables (i.e., xvariables) included the maximum ambient water temperature between subsequent sightings, the 7-day average maximum water temperature, maximum stream stage height, and the distance (in meters) a fish was to a known CWS prior to the movement occurring. My specific objective in this analysis was to examine the degree to which water temperature and distance to CWSs interact to determine trout movement rates during summer months. 


\section{RESULTS}

\section{General}

Flow conditions in Shavers Fork did not vary annually during spring/summer 2000-01 (average mean daily stage height $=5.1$ and 5.3 respectively) (Table 3, Figure 4). Kolmogrov-Smirnov tests further indicated that flows did not differ significantly between these years (2000 vs. $2001: D=0.03, n$ $=214, p<0.05)$. Flow during 2000 fall was characteristic of coldwater systems like the upper Shavers Fork under fall conditions and had an average mean daily stage height of 4.85 respectively (Table 3 , Figure 5).

Water temperature varied from year-to-year in the Shavers Fork mainstem during the spring/summer sampling periods. (Table 3, Figure 6,7). As expected in the drought year (1999) the mainstem experienced extremely high summer temperatures, the 7 -day average maximum temperature peaked at $25.5^{\circ}$ C around July 9 . This value is well above the widely recognized threshold of $22^{\circ}$ $\mathrm{C}$ for coldwater fisheries, and above the UILT (roughly $25^{\circ} \mathrm{C}$ ) for both brook and brown trout. Comparing the summer 1999 values to those observed in 2000 and 2001 further illustrates the extreme conditions present in 1999 that provided the impetus for this study (Table 3, Figure 6,7). Values for the 7-day average maximum temperatures peaked only at $21.6^{\circ} \mathrm{C}$ in 2000 and $23.0^{\circ} \mathrm{C}$ in 2001.

Both spring/summer study periods (2000-01) experienced temperature peaks near or above the threshold of $22^{\circ} \mathrm{C}$, but at slightly different times and in duration (Figure 6,7). In 2000, the warmest conditions occurred early, whereas higher instream temperature levels were recorded near the end of the tracking 
period in 2001 (Figure 6,7). Conditions overall were wetter and cooler in 2000 than 2001 , as exhibited by the ratios of "\# of days max. temperature was greater than $22^{\circ} \mathrm{C}$ " for the two years (6 days for 2000,10 days for 2001) (Table 3 ). Additionally the "\# of days max. temperature exceeded $20^{\circ} \mathrm{C}$ " was greater for the year 2001 than $2000(30$ days $=2001,24$ days $=2000)($ Table 3$)$.

I found a consistent, albeit weak, relationship between maximum daily water temperature and stream flow during the critical summer months in the Shavers Fork mainstem (Figure 8). The strength of this relationship varied between the two spring/summer study periods (2000-01) (Figure 8). The general pattern observed was that trout likely experience extremely warm temperatures only when flow levels in the river are below $5-5.5 \mathrm{ft}$. Thermal conditions in the fall sampling periods were expectedly consistent of a coldwater system ranging in values from $2.9^{\circ} \mathrm{C}$ to $15.7^{\circ} \mathrm{C}$ in Rocky Run and $2.7^{\circ} \mathrm{C}$ to $20.3^{\circ} \mathrm{C}$ in the mainstem (Table 3, Figure 9). Neither Rocky Run nor the mainstem came close to the threshold of $22^{\circ} \mathrm{C}$ during the fall tracking period (Table 3, Figure 9). Early in the sampling period was the only time the mainstem exceeded a threshold with a recorded maximum daily temperature value of $20.3^{\circ} \mathrm{C}$. Throughout the study in both spring/summer (2000-01) and fall sampling periods (2000), Rocky Run was consistently lower in temperature than the mainstem and never approached $22^{\circ}$ C threshold in any of the three tracking periods (Table 3,4, Figure 6,7,9).

Based on map features, distribution of fish, and visible persistence of flow throughout the summer and fall seasons, nine CWSs were noted from the base of my study area upstream to Spruce (Table 5, Figure 10). I included the 
forested watershed above the railroad bridge at Spruce as the uppermost CWS on the upper Shavers Fork. Unnamed CWSs 1,2,3 exist as one drainage basin with three distinct delivery points or seeps into the mainstem as noted (Figure 10). Unnamed CWS \#5 exists as two connected drainage basins entering the mainstem as one main input or seep. Unnamed CWS \#7 was not determined to be a separate drainage basin from CWS \#6 yet two outputs or seeps of coldwater to the mainstem were noted in the field. For the purposes of this study these distinctions were based on field observations topographical map comparisons, and ArcGIS $9^{\mathrm{TM}}$.

\section{Trout HCU Use and Availability}

To reiterate I implanted a total of 84 trout (brook and brown trout) with transmitters and monitored them for habitat use and movement using telemetry over the spring/summer 2000-01, and fall 2000 in the upper Shavers Fork (28 per season) (Appendix 1). All tagged trout were tracked and observed for habitat use and movement with some providing information longer than others during the tracking periods (8 - 71 days). As mentioned, during each study period tracks were taken that comprised documenting all trout at large for that season. A complete listing of all tracks by season with the number of trout observed for each track is given in Table 6. There was no large-scale mortality associated with the initial implantation. I did find two transmitters during the first week of the spring/summer 2000 study period that were presumed to be lost due to surgery mortality, or transmitter expulsion. 
Over the course of each season a progressive number of transmitters died, were depredated (one tag found in the spring/summer 2000 tracking season was visibly chewed), or were presumed caught by anglers. Other researchers in the watershed confirmed talking to fishermen who had caught and creeled transmitter-equipped trout. Similarly to Swanberg (1997), I spoke to fishermen who caught and released 2 tagged trout documenting they were feeding after surgery/implantation. I documented movement and habitat use data until all transmitters had expired or were recovered. A transmitter was considered "expired" only after unsuccessfully making three attempts over a period of days to locate that particular tagged trout. Many times this included walking and searching the entire length of the upper river between designated tracks until a signal was found for a particular trout at large. By the end of each study period I expected to have a constant decrease in active tags due to the natural loss of battery life in the transmitters. Regardless, I made every effort to make sure each trout was observed for as long as possible.

A number of diverse HCUs were documented in both Rocky Run and the mainstem of the upper Shavers Fork (Figure 11,12,13). Habitat units included known HCUs and ones somewhat specific to the upper Shavers Fork watershed (Gaujot 2002, Petty et al. 2001). The watershed specific HCUs included a number of complexes, or units that contain characteristics of two or more established habitat types. Complexes generally offer a greater range of microhabitat variables and complexity to trout. Bluff pool complexes (BPC) and riffle/run complexes (RRC) were the two I identified in the mainstem (Table 6). 
BPCs are associated with bends in the river due to extremely-slow eroding bedrock bluffs constricting and redirecting the main current. This creates HCUs that vary greatly in depth, current, and substrate (see Gaujot (2001) and Petty et al. (2001)) for further explanation of specific habitat units). RRCs show combined characteristics of riffles and runs. Pocket water (PW) exhibits characteristics of a glide with pockets of varying increased depth, a characteristic normally not found in glide habitat, making it somewhat of a complex as well.

A total of five HCUs were documented in Rocky Run, with 6 documented in the mainstem (Figure 11,12,13). Spring/summer 2000 results showed a higher availability and utilization of pools by brook trout in Rocky Run than the mainstem. This HCU was utilized the most in Rocky Run by brook trout in spring/summer 2000 followed by riffles. This is consistent with pool use by brook trout in small streams documented by other researchers (Logan 2002). However, pools were not prevalent in the mainstem and their use by trout was noted as being only slightly higher than their availability. RRCs were available and utilized the most by brook trout in the mainstem for spring/summer 2000. PW surprisingly was used by brook trout at higher levels than their actual availability in the mainstem during spring/summer 2000 (Figure 11). Subsequent seasons showed decreased use of PW by all species in all streams, with no use of pocket water documented for either species during fall 2000 (Figure 12,13). Riffles were surprisingly used less than their availability by mainstem brook trout during the spring/summer study periods while BPC and RRC use was consistently higher than their availability (Figure 11,12). $X^{2}$ analysis revealed that in spring/summer 
2000 brook trout HCU use in Rocky Run did not differ significantly from availability $\left(X^{2}=4.5\right.$, d.f. $\left.=4, p<.34\right)$, whereas $\mathrm{HCU}$ use by trout residing in the mainstem differed significantly from availability $\left(X^{2}=18.9\right.$, d.f. $\left.=5, p<0.002\right)$ (Figure 11).

Spring/summer 2001 showed somewhat different results of trout habitat use when compared to spring/summer 2000. High pool use by brook trout in Rocky Run was again documented but riffle use by brook trout was visibly less than in the previous spring/summer season of 2000 (Figure 11,12). Mainstem brook trout in 2001 again greatly utilized RRCs with increased levels of use in spring/summer 2001 (Figure 11,12). Brown trout in spring/summer 2001 in the mainstem utilized these HCUs heavily as well and underutilized glide habitats, as did all brook trout in the mainstem and Rocky Run in both spring/summer seasons (2000-01). In fact, during spring/summer 2001 and fall 2000 no glide habitat use was ever documented by brook trout in Rocky Run. Brook and brown trout use of HCUs was significantly different than their availability for both streams during spring/summer 2001, differing from the previous spring/summer season (2000) in which only mainstem brook trout used significantly different habitat than what was available (Figure 11, 12).

Sixteen brook trout were tagged in Rocky Run in the fall of 2000. Habitat use by brook trout in Rocky Run in fall 2000 consisted mainly of runs and pools, with the tail ends of pools being utilized extensively for spawning with overall habitat use significantly different than availability $\left(X^{2}=37.7\right.$, d.f. $\left.=4, p<0.0001\right)$. Only two brook trout were ever located and implanted in the mainstem during fall 
2000. They exclusively chose RRCs over any other HCU available to them obviously reflecting significantly different use than availability $\left(X^{2}=17.5\right.$, d.f. $=5$, $p<0.004)$ (Figure 13).

Ten brown trout tagged in the mainstem in the fall of 2000 showed similar results to their habitat use in the spring/summer 2001 season. Brown trout demonstrated a high use of RRCs with increased use in the fall 2000 season (Figure 13). Brown trout underutilized riffle habitat and consistently used BPCs close to but slightly below their availability in the fall 2000 , compared to higher than available use of this complex HCU in spring/summer 2001 (Figure 12,13). Glides were under utilized by brown trout in the fall 2000, confirming a consistent pattern of underutilization of these habitat units by all trout in both the mainstem and particularly Rocky Run, for all seasons. Brook and brown trout in both the mainstem and Rocky Run used significantly different habitats than what were available to them for fall 2000 .

\section{Trout Microhabitat Use and Availability}

Brook and brown trout consistently used a subset of available microhabitats, regardless of season, or stream type (i.e. mainstem vs tributary) (Figure 14-28). First, trout consistently avoided extremely shallow microhabitats and were overrepresented in deeper microhabitats, a pattern that was consistent from season to season, between brook trout residing in the mainstem and tributaries, and between trout species (Figure 14-16). Second, brook and brown trout tended to avoid microhabitats with low average current velocity and preferred microhabitats with moderate to high velocities (Figure17-19). The only 
time this pattern was not observed was in spring/summer 2000 in Rocky Run, where brook trout use of AVCV did not differ significantly from availability (Figure 17). Third, there was a general tendency for FPCV to be slightly lower than the AVCV at microhabitats used by trout in all seasons and sites (Figure 20-22). In contrast there was a general tendency for brook trout to occupy microhabitats in close proximity to high velocity areas (Figure 29-31). In fact, in nearly every case the current velocity at the focal point of a brook trout was $>10 \mathrm{~cm} / \mathrm{s}$ lower than velocities nearby (Figure 29-31). This pattern suggests that trout select focal points with relatively low current velocities that are near to high velocity microhabitats.

Cover was determined to be any instream rock, boulder, or LWD that supplied shade and/or cover from predation and some relief from the current to adult sized-trout. Distance to cover was utilized disproportionately to its availability for the most part by all species, for all seasons in both Rocky Run and the Shavers Fork mainstem (Figure 26,27,28). A maximum distance of twenty meters to cover from any point was documented in the mainstem with a maximum of eight meters for Rocky Run (Figure 26,27,28). Distances to cover noted were greater in the spring/summer of 2000 than in the spring/summer of 2001 for brook trout in the mainstem.

\section{Trout Microhabitat Use and Water Temperature}

My analysis of water temperatures at the focal position of trout and comparisons to nearby ambient temperature levels revealed several important patterns (Figure 32). Ambient water temperatures in Rocky Run at the time of 
fish observations never exceeded $16^{\circ} \mathrm{C}$, and consequently the focal point temperatures were always within $1-2^{\circ} \mathrm{C}$ of ambient, regardless of the season. A similar pattern was observed for brook and brown trout residing in the Shavers Fork mainstem in the fall 2000 , but a very different pattern emerged in spring/summer 2000-01 (Figure 32). During the spring/summer study periods focal point temperatures never exceeded $20^{\circ} \mathrm{C}$ despite frequent periods when ambient temperatures exceeded this threshold (Figure 32). In addition I observed trout choosing to inhabit slightly warmer than ambient water temperatures when ambient levels dropped below $13^{\circ} \mathrm{C}$ (Figure 32). Between $13-17^{\circ} \mathrm{C}$, however, focal point temperatures were always within one degree of ambient.

Given the relationships observed in Figure 32, I calculated the temperature difference as the focal point temperature minus the nearby ambient temperature and plotted this value as a function of ambient temperature (Table 2, Figure 33). Doing so enabled me to identify 4 temperature zones, within which I observed different behavioral responses by trout to temperature. Zone 1 (i.e. "cold zone") where ambient temperature $<13^{\circ} \mathrm{C}$, I observed a tendency for some individuals to seek and inhabit significantly warmer habitats (i.e. temperature difference $>1^{\circ} \mathrm{C}$ ). In zone 2 , the focal point temperature never differed significantly from ambient. I refer to this zone as the ideal temperature zone for trout in the Shavers Fork. Zone 3 (i.e. warm zone) includes a range of temperatures between 17 and $20^{\circ} \mathrm{C}$ where there is increasing tendency for trout to seek out microhabitats with significantly cooler temperature levels. Finally zone 4 , or the hot zone, is the range of temperatures above $20^{\circ} \mathrm{C}$ that apparently 
are too warm for any individuals to inhabit, and therefore all trout must select coldwater refuges (i.e. microhabitats with water temperatures less than $20^{\circ} \mathrm{C}$ ) (Figure 33).

Because of the known and observed effects of temperature on trout behaviors, I tested the hypothesis that changing water temperatures would influence the types of physical microhabitats used by trout residing in the Shavers Fork mainstem. As an initial step, I used $\mathrm{X}^{2}$ analysis to test for differences in microhabitat use among the four ambient temperature zones (i.e. cold, ideal, warm, hot). I then tested for differences in microhabitat use between trout that tended to occupy microhabitats with temperature levels similar to the surrounding ambient and those that occupied locations with significantly cooler temperature levels (temperature difference $>1^{\circ} \mathrm{C}$ ). Results from these comparisons showed similar use between the temperature group divisions in all microhabitat variables except distance to cover (D_cov) (Table 8, Figure 33,34). Trout exhibited a tendency to stay very close to cover during extremely warm to hot periods. Distance to cover was utilized significantly different by tagged trout under these conditions.

\section{Trout Movement}

Figures 35-37 illustrate variations of three common themes in the movement behaviors of brook trout in the upper Shavers Fork watershed. First, brook trout residing in the Shavers Fork mainstem were highly mobile, and over time tended to accumulate near CWSs. A small number of tagged trout actually entered tributaries after spending time in their outflows in the mainstem (only four 
tagged trout ever abandoned the mainstem for the tributaries, the majority of tagged trout chose the CWS outflows over actually entering the tributaries) (Figure 35). Second, brook trout residing in Rocky Run were highly sedentary in both spring/summer study periods (Figure 36), and third, this pattern was repeated in the fall (Figure 37). In these figures the mainstem is shown as colored polygons relating to an $\mathrm{Arc}^{\mathrm{TM}}$ habitat unit stream coverage or shape file. Yellow points indicate a fish's location for a specific track. Some numbers are missing in the sequence of tracks due to those numbers either representing diel tracks, the fish not being located on that particular track, or due to unfavorable tracking conditions for that corresponding date. The highest track number in sequence represents the final location noted.

Total movement rates of brook trout and brown trout varied as a function of season, stream, and species (Table 9,10,11, Figure 38,39,40). Brook trout residing in Rocky Run were generally sedentary, with a median movement rate ranging from $0.1-\mathrm{m} /$ day in fall 2000 to $2.1-\mathrm{m} /$ day in spring/summer 2000 (Table $9,10,11)$. ANOVA's conducted on total movement rates indicated that brook trout overall movements in Rocky Run were highly consistent from season to season $(F=1.02, p=0.35)$

Analysis of net movement rates by brook trout and brown trout indicated that there was a general tendency for individuals to move upstream over time during the spring/summer study periods. However, the extent of this depended strongly on the time of year and the stream inhabited (Table 9,10,11, Figure $41,42,43)$. Specifically, I found that brook trout inhabiting Rocky Run did not 
exhibit significant tendencies in upstream or downstream movement in any season (Table 9,10,11, Figure 41,42,43). In contrast, brook trout residing in the Shavers Fork mainstem exhibited dramatic upstream movement tendencies in spring/summer 2000 and 2001 (Table 9,10, Figure 41,42). For example, several individuals moved more than $6.5-\mathrm{km}$ over the course of the spring/summer 200001 seasons (Table 9,10). Brown trout exhibited an upstream movement tendency similar to brook trout in spring/summer 2001 with one individual moving as much as $2.6 \mathrm{~km}$ upstream and many others moving $1.0-1.5-\mathrm{km}$ in a 65 day period (Table 10, Figure 42) (no data exists for brown trout in spring/summer 2000). Interestingly, this pattern of upstream movement was not evident for brook and brown trout in the Shavers Fork mainstem in fall 2000 (Table 10, Figure 43). In contrast to Rocky Run, trout inhabiting the Shavers Fork mainstem exhibited extremely high rates of mobility in spring/summer 2000 and 2001 (Table 9,10). Brook trout in the mainstem were observed to move as much as 100-150 m/day and exhibited median movement rates from 40.3-m/day in spring/summer 2001 to 57.8 -m/day in spring/summer 2000 (Table 9,10). A similar rate was observed for brown trout in spring/summer 2001 (median dispersal rate $=25.5-\mathrm{m} /$ day $)($ Table 10$)$. High rates of overall movement by brook and brown trout residing in the mainstem were not observed in the fall 2000 season (Table 11, Figure 43). For example, median movement rates by brook trout fell from 57.8-m/day in spring/summer 2000 to $0.4-\mathrm{m} /$ day in fall 2000 (Table $9,10)$. Likewise, the median movement rate by brown trout in fall 2000 was $0.3-$ m/day (Table 11). 
Trout movement rates differed significantly between seasons, and streams. Seasonal and spatial variation in trout movement rates are summarized in Figure 44, which illustrates the results of ANOVA's on mean movement rates for brook trout and brown trout in the study area (Table 12). Trout in Rocky Run moved at a significantly lower rate than trout in Shavers Fork in spring/summer 2000 and 2001, but not in fall 2000. Furthermore, trout movement rates in Shavers Fork were significantly lower in fall 2000 than in either spring/summer 2000 or 2001 . Finally, I observed no significant differences in the overall movement rates of brook trout and brown trout inhabiting the Shavers Fork mainstem (Figure 44).

Given the high rates of overall movement by brook trout in the Shavers Fork mainstem, I examined the effects of temperature, stream flow, and distance to CWSs on brook trout movement during the spring/summer 2000 and 2001 seasons. Brook trout movement rates were significantly related to maximum water temperature in both spring/summer 2000 and 2001 (Figure 45). In spring/summer 2000, movement rates decreased significantly as maximum temperature increased from $12^{\circ} \mathrm{C}$ to $18^{\circ} \mathrm{C}$. In contrast, movement rates increased as a function of maximum temperature when temperatures exceeded $18^{\circ} \mathrm{C}$ (Figure 45 - top panel).

I observed significant relationships between brook trout movement rates and distance to a known CWS (Figure 46). In both spring/summer 2000 and 2001 there was a tendency for movement rates to increase with increasing distance from cold water or CWSs. This was especially true in spring/summer 
2001 (Figure 46 - bottom panel). Multiple regression analyses further clarified the interactive effects of water temperature and distance to CWSs on brook trout ranging behavior. Inclusion of both maximum temperature and distance to a CWS in regression models produced significantly better power to predict trout movement rates $\left(F=4.7, p=0.001, R^{2}=0.26\right)$. 


\section{DISCUSSION}

\section{General}

Temperatures observed in 2000 and 2001 indicate that thermal stress and low flows influenced trout populations inhabiting the mainstem. Summer 2000 was one of the coolest, wettest summers on record, and yet the 7-day average maximum temperature was very near to the recognized thermal limit of $22^{\circ} \mathrm{C}$ for coldwater fisheries (Figure 7) (Petty, unpublished data). Likewise, trout inhabiting the mainstem in summer 2000 and 2001 had to endure three to four weeks (24-30 days) where the maximum daily temperature exceeded $20^{\circ} \mathrm{C}$ (Table 3). Nevertheless, compare this to the eight-week period in 1999 where temperatures exceeded this critical threshold over 55 days or 7-8 weeks.

Rocky Run on the other hand exists as a true coldwater stream due to its yearly thermal regime (Table 2, Figure 6,7). In summer 2001, water temperatures never exceeded $20^{\circ} \mathrm{C}$ in Rocky Run (Table 2, Figures 6,7). Furthermore the maximum 7-day average maximum temperature of $18.2^{\circ} \mathrm{C}$ clearly places this tributary in the category of a coldwater fishery. I have presented data for summer 2001 only, due to the consistency of the tributary thermal regimes in the basin from year to year (Petty, unpublished stream survey data). In fact, temperature data for Second Fork and First Fork, which are more than twice the size of Rocky Run, are nearly identical to Rocky Run, even during the drought year of 1999.

The temperature and flow tables and figures (Table 1,2,3, Figure 4-9) confirm that the upper Shavers Fork exists as a highly dynamic system in terms of conditions for growth, survival, and reproduction of resident trout. In this 
system trout (and other fishes) must be mobile and be ready to act on changing instream conditions as quick as possible to ensure optimal growth and survival (Torgersen et al. 1999). Some reaches utilized by trout in the mainstem during fall for example were found to not hold trout during the spring/summer sampling periods. Additionally many areas are devoid of water at low flows and without movement, trout would find themselves high and dry if they did not vacate these habitats prior to their dewatering. Many of these conditions (flow and thermal conditions) can be improved through restoration efforts and/or other means. The "Specific recommendations for the upper watershed" section further elaborates on some of these options for the system.

The mainstem is a much more productive stream than Rocky Run, with higher invertebrate and prey fish densities (Table 1). But, the mainstem heats up too much in the summer due its lesser canopy cover (and railroad grade), creating inhospitable areas to trout residing there somewhat negating its potential. There are larger individuals and less trout overall in the mainstem as reflected by the size ranges and density measurements found in each stream (Table 1). This is to be expected as the mainstem acts as a "sink" in the system compared to the tributary "sources" (Schlosser 1991, 1995a). Once spawning season (late August) approaches it is apparent from my study and others (Lamothe 2002) that most sexually mature brook trout abandon the mainstem for the upper tributary reaches and extreme upper reaches of the mainstem (Intrawest property - Snowshoe Mountain 
I had mixed results in mapping the locations of CWSs within the upper watershed. In a few cases the exact number of visible inputs and where they entered the mainstem was disputable. Using field observations and noting locations of tagged fish, some CWSs appeared to have a different number of inputs to the mainstem than what was determined using ArcGIS $9^{\mathrm{TM}}$ and topographical maps. There was also evidence that hyporheic upwelling supplied additional sources of coldwater to the system (Boulton et al. 1998). By using a hand-held thermometer I was able to verify trout were congregating at certain instream locations in colder water than surrounding habitat. Additionally there were no visible seeps or tributaries entering within 50 meters upstream or downstream of these areas. While I am confident of the general location and overall effect of the identified CWSs, further research in this area would aid in understanding how these smaller drainage basins interface with the mainstem of the Shavers Fork and supply cold water. This is also an important topic for other large, alluvial trout fisheries in West Virginia (i.e., Dry Fork, Gandy Creek, Potomac River, and Cranberry River).

\section{Trout Habitat Use}

Three major findings can be gleaned from the habitat use results in this study. First, trout used a subset of available habitats in both the mainstem and Rocky Run (tributaries). There was also a consistent, significant difference in habitat use between mainstem trout and trout occupying Rocky Run (Figure 11,12,13). Use of important pool HCUs was above their availability levels in Rocky Run and above their extremely low levels of availability in the mainstem 
during spring/summer 2000-01 (Figure 11,12). This use pattern is consistent with trout habitat use documented by other researchers during spring/summer conditions (Herger et al. 1996, Logan 2002, Roghair 2002, Young 1995). In contrast, high levels of use of PW and glide HCUs documented during the spring/summer 2000 was something I could not find in current literature, and was not documented in the subsequent spring/summer season of 2001. I hypothesize that these habitats (PW, glide) in the upper Shavers Fork when used offer areas of low velocity, which serve as "resting positions" to trout after high levels of movement from downstream reaches and/or possibly offer microhabitats influenced by CWSs. The spring/summer 2000 season was characterized by slightly higher and more variable levels of flow, which could have indirectly influenced the use of this HCU by trout, but this is unsubstantiated.

Trout during fall 2000 used habitats based on their ability to serve as spawning sites (Figure 13). Brook trout habitat use in the fall in the mainstem was dominated by RRC use, mainly due to the only fish tagged in the mainstem were two small adults using RRCs throughout the fall study period (Figure 13). Many attempts were made to locate adult brook trout in the mainstem but all efforts were unsuccessful other than the two found that were large enough to implant with transmitters. This snapshot of habitat use for the entire population is speculative at best due to the low number of trout (2) observed in the mainstem for fall 2000 habitat use. Habitat use by brook trout in fall 2000 in Rocky Run showed surprisingly little use of riffle areas for spawning. One possible explanation is the lack of overall depth in Rocky Run (during the fall especially) 
making these HCUs inferior to deeper HCUs such as pools and runs for spawning, which were utilized at higher levels during the fall (Figure 13). Increased protection from various potential predators in the form of greater depth might also be an important factor in this difference.

The thermal constraints trout face in the Shavers Fork mainstem during the spring/summer study periods are not as critical during the fall (Table 3 ). The factors most likely to affect the fishery at this time are non-accessible spawning areas (extreme headwaters) due to low water or barriers, low invertebrate densities, lack of adequate spawning locations, and/or competition for these locations (Meehan 1991, Behnke 1992). In the fall overall movement was less and habitat use restricted to the tail ends of pools and runs of adequate flow and substrate for spawning.

By the time I implanted trout in early September I missed the brook trout's spawning migration to the extreme headwaters of the system (tributaries and upstream reaches on Snowshoe property). I waited too long to implant the trout prior to their spawning migration. Therefore my recorded behaviors are of brook trout after an upstream spawning migration while brown trout finished their spawning near the end of the fall study period. Optimally I would have preferred implanting trout prior to their spawning migration in early September in an attempt to capture any change in habitat use and movement.

Habitat use by brown trout during the fall showed a similar trend to brook trout with high use of habitats such as pools, BPCs, and low levels of glide and surprisingly little riffle use. For whatever reason riffles were not utilized in the fall 
in the mainstem very much by brown trout either. I would have expected trout to choose these habitats at higher levels overall due to their potential for spawning sites (Meehan 1991, Behnke 1992). Perhaps due to the low gradient of this system and overall shallow depth, HCUs with more depth like BPCs were chosen for spawning by brown trout in the mainstem rather than riffle habitat due to possibility of predation. A total of 10 brown trout were implanted in the fall 2000 .

I observed three pairs of (at least one implanted) brown trout spawning in the mainstem during the study. Two pairs were spawning in BPCs and the third pair was located at the tail-end of a pool near the end of the study period in late October. Brook trout utilized similar HCUs for spawning sites in Rocky Run (Figure 13). I observed five pairs of (at least one implanted) spawning brook trout within Rocky Run, three at the tail ends of pools and two within runs. Microhabitat variables in the fall were utilized by trout in an even narrower range of values than in the spring/summer seasons (Figure 14-25) and can be attributed to the specific requirements of spawning habitat by stream-dwelling trout.

Fish abundance can be related to specific types of HCUs or instream fish habitat, and their abundance (Cunjak 1996). For example, Hankin et al. (1988) found that fish densities were 5-10 times greater in pools than in riffles in Cummings Creek, Oregon. Many subsequent authors have noted a high use of pool habitat by trout due to their flexibility in fulfilling a trout's daily needs (feeding, resting, etc.) (Meehan 1991, Elliott 2000, Logan 2002). A low number of pools in the mainstem and even Rocky Run could be limiting the trout fishery of the upper Shavers Fork, along with the other problems of the system. Pool use 
was consistently at or above the available levels in both the mainstem and Rocky Run, especially if it had LWD associated with it (Young 1996). If the system existed in a more natural, unaltered state with large amounts of instream LWD as before major logging in the system, a greater number of pools (and total diverse habitats) would exist but this is not the case presently.

Higher levels of LWD present in the Rocky Run watershed have increased the availability of pools and total HCUs associated with LWD compared to the mainstem (Figure 11,12,13). This is a positive attribute of systems close to equilibrium and associated with stable age structured forests (Flebbe and Dolloff 1995). Due to a higher gradient one would expect Rocky Run to naturally exist with a higher number of pools than the mainstem. It is obvious upon walking the stream bank of both streams and from the habitat availability data that LWD exists in greater, more natural densities in the smaller tributary Rocky Run than the mainstem. This is consistent with other research done in small forested watersheds showing tributaries of major coldwater rivers in the eastern US exist in a more native or recovered state while the mainstem reaches exists in a more impacted or un-recovered state due to a lack of complete recovery from major logging events in the early 1900s (Flebbe and Dolloff 1995). The railroad grade and its maintenance add to this problem by deterring the growth of large trees along the track right of way. If in the future LWD is added naturally or artificially, one would expect to see a rise in trout densities, and not just purely due to immigration from surrounding reaches (Gowan et al. 1996a). The additions would add energy to the system and enrich the invertebrate 
communities, creating a positive cascading effect through the aquatic community over time (Meehan 1991, Flebbe and Dolloff 1995).

Trout (especially brown trout) during the entire study chose habitats whenever possible close to or near cover, which is consistent with findings by other researchers (Clapp et al. 1990, Meyers et al. 1992, Young 1995, Burrell et al. 2000) (Figure 26, 27,28). Distance to cover varied over the two spring/ summer seasons, a surprising finding. My only explanation for this can possibly be attributed to two factors. One reason is the higher levels of turbidity in the system during the spring/summer 2000 season due to construction in the extreme headwaters on Intrawest's Snowshoe property. Under turbid conditions trout do not hold as tight to structure as under clearer conditions due to the cryptic effect offered by the turbidity in the water column. Secondly, despite nonsignificant differences in flow during both spring/summer seasons, the tracks taken in 2000 were done under generally higher levels of flow than in 2001. I did not test for significance but many times tracks were taken after storm events and elevated flows in 2000. Other than these reasons I can find no other reason as to why I recorded varying distances to cover between the spring/summer seasons (2000-01). Distance to cover increased slightly during fall 2000 for all trout but was expected as trout chose habitats based more on flow and substrate rather than cover in the fall (Figure 26,27,28).

The second major finding and related to the first is that temperature is the most important habitat variable for trout in determining habitat use in the upper Shavers Fork during the critical spring/summer study periods (Wootton 
1990). Given the extreme thermal conditions experienced by trout residing in the Shavers Fork mainstem, an important objective of my study was to quantify the water temperature at locations inhabited by trout (FPT) and compare them to ambient water temperatures in the river. Consequently I produced scatter graphs relating FPT to ambient water temperature (i.e., temperature recorded by a nearby temperature logger at the same time that the fish was located) (Figure 32). I found during the fall 2000 season, trout tended to occupy positions with water temperatures similar to ambient conditions. In other words they did not exhibit evidence of selecting microhabitats that were either warmer or cooler than nearby ambient temperatures (Figure 32 - lower panel). This pattern was consistent for both brook and brown trout in Rocky Run and the Shavers Fork mainstem (Figure 32 - lower panel).

The pattern observed during spring/summer 2000-01, however, was far more complex and demonstrated the importance temperature plays in habitat selection (Figure 32 - upper panel). Brook trout residing in Rocky Run exhibited no evidence of preferential temperature selection. Focal water temperature of Rocky Run trout was always very close to the temperature recorded by a nearby temperature logger (Figure 32 - upper panel). In contrast, brook trout and brown trout residing in the Shavers Fork mainstem exhibited preferences for temperatures cooler and warmer than ambient, depending on the overall thermal conditions at the time (Figure 32,33). Specifically, I found that when ambient temperatures were less than $13^{\circ} \mathrm{C}$, there was as tendency for trout to occupy microhabitats with slightly warmer temperatures (Figure 32,33). And during warm 
to hot periods trout found and used habitat that was cooler than surrounding habitat. In fact, I found individuals in water that was as much as almost four degrees cooler than the ambient water temperature during extremely warm instream conditions (Figure 33).

When ambient water temperature ranged between 13 and $17^{\circ} \mathrm{C}$ (temp. group \#2) (Figure 33), I observed no evidence of preferential selection for warmer or cooler microhabitats. Ambient temperature levels exceeding $17-18^{\circ} \mathrm{C}$, however, appeared to elicit a behavioral shift in brook trout (Figure 33). At temperatures between 17 and $20^{\circ} \mathrm{C}$ (temp. groups \#3,5), brook trout exhibited a tendency to select microhabitats that were slightly cooler than the ambient temperature. Significant levels of microclimate selection were not evident in brown trout at this temperature range (Figure 33). However, when ambient temperatures reached levels exceeding $20^{\circ} \mathrm{C}$ (temp. group \#4,6) brook and brown trout moved, found, and occupied microhabitats that possessed temperatures between $2-4^{\circ} \mathrm{C}$ degrees cooler than ambient temperatures (Figure 33).

As a result of the preferential selection of warmer or colder microhabitats, I found that brook trout residing in the Shavers Fork mainstem tended to occur in a relatively narrow range of water temperatures, even though ambient temperatures ranged widely. In fact, despite ambient temperatures that often exceeded $23^{\circ} \mathrm{C}$, I never observed brook trout or brown trout to in water temperatures above $19.5^{\circ} \mathrm{C}$ (Figure 32 - upper panel, 33), indicating that trout were actively choosing habitats with cooler thermal regimes (Torgersen et al. 
1999, Elliott 2000). Clearly, tagged trout in the Shavers Fork mainstem were able to survive extended periods of warm weather by locating and preferentially utilizing areas of significant inputs of cold water or CWSs (Kaeding 1996, Swanberg 1997). As expressed by Togersen et al. (1999), pockets exhibiting preferred thermal regimes allow many fishes to survive in an otherwise inhospitable area, especially for species existing at the margin of their environmental tolerances. In the upper Shavers Fork mainstem, these "pockets" during critical instream thermal periods are the tributary outflows and areas of hyporheic upwelling instream.

When choosing habitats during critical thermal periods, trout are able to respond behaviorally and find suitable habitat with a preferred thermal regime and preferred microhabitat variable suite similar to what they would normally use under preferred conditions. This is demonstrated by the lack of significance in comparing the microhabitat variables between the different temperature group designations based on Figure 33 (Table 8; Figure 34). The only microhabitat variable to show significant difference between the groups is D_cov (Table 8; figure 34). Temperature groups 5 and 6 showed the closest distances to cover compared to the other designated temperature group divisions (Figure 33). This is explained by the fact that cover is used extensively by trout and other stream fishes to hold under for shade and to reduce metabolic costs, further minimizing potentially inhospitable thermal conditions. Cover also supplies overhead protection to trout during resting or inactive periods protecting them from 
predation at a time when they are usually for the most part motionless and vulnerable.

The third trend found was that trout utilized productive habitats in the mainstem during the critical spring/summer study periods despite documented unfavorable instream temperature levels. This was done despite tributaries close - by (such as Rocky Run) that had optimal instream temperature levels. Trout utilized mainstem habitats mainly due to the increased productivity, and their ability to utilize CWS confluences close-by, enabling them to persist in the mainstem despite areas with overall intolerable temperature levels. Another undocumented reason for trout using these CWS outflows could be their use for feeding stations by trout in the upper watershed. Development in the upper watershed at times creates high levels of turbidity in the mainstem. Many authors have shown that turbidity increases the bioenergetic costs associated with foraging by trout (Sweka and Hartman 2001). To take full advantage of the productivity in the mainstem, trout possibly utilize the outflows "clearing" effect on the suspended sediments and feed in outflow areas and margins allowing them to utilize their sight for optimal feeding.

My findings are similar to those of Kaya et al. (1977) and Kaeding (1996) who found that brown and rainbow trout utilized the Firehole River in Wyoming, which is warmed by geothermal springs in a similar fashion to what I observed in the upper Shavers Fork. Kaya et al. (1977) and Kaeding (1996) discovered that both rainbow and brown trout utilized coldwater inputs in conjunction to mainstem habitat. Fish stayed close to or within the CWSs but ranged into the warmer 
mainstem to utilize the productive areas of the mainstem for feeding. Even though the mainstem presented potentially lethal thermal conditions, access to CWSs made it possible for trout to maintain access to the productive mainstem (Kaya 1977, Kaeding 1996). Many recent authors have documented the use of cold water tributaries as thermal refuges in both lotic and lentic habitats by trout and have highlighted the importance of their interconnectivity, parallel to my findings (Garrett et al. 1995, Curry et al. 1997, Swanberg 1997, Torgersen, et al. 1999, Bramblett et al. 2002).

Microhabitat use by trout in the upper Shavers Fork is obviously highly affected by temperature. My findings highlight a reoccurring theme in current literature that maximum water temperature is the single most important factor limiting the geographic distribution of brook trout presently, and into the future (McRae et al. 1994). If overall temperature levels are reduced to more appropriate levels of a classic coldwater system (historical levels) through restoration efforts in the future, habitat use by trout will more than likely be altered due to temperature playing less of a role in determining habitat selection and use. This is extrapolated from findings by Baltz et al. (1987) who discovered that when creating models for microhabitat choice in stream fishes, temperature was the single most important factor but ceased to be so at lower temperature levels.

Total depth, and focal point elevation surprisingly were found to be the two most important factors overall in Baltz et al.'s (1987) models of habitat use by stream fishes followed closely by temperature. But, in contrast the system they 
studied was not as severely impacted by summer high water temperature levels as the upper Shavers Fork. Nonetheless Baltz et al. (1987) highlighted the importance of temperature in trout HCU and microhabitat choices. This theme is reiterated again in the findings of Kaeding et al. (1996), Torgersen et al. (1999), and others who have shown the use of CWSs during critical thermal periods by trout and other stream fishes.

\section{Trout Movement}

Three major findings were extrapolated from the overall movement results of this study. The first is that a major difference in overall movement rates was noted between mainstem and Rocky Run tagged trout, especially during the critical spring/summer study periods (Table 9,10; figure 44). Rocky Run trout moved very little and mainstem fish moved extensively during this period. In fact, movement rates by brook trout in the mainstem of the Shavers Fork are some of the highest ever recorded in an Appalachian watershed (Table 9,10). Movement by trout during the spring/summer study periods was mostly upstream, similar to other documented cases of brook trout overall movement (Riley et al. 1992, Gowan et al. 1996b, Curry et al. 2002, Lenormand et al. 2004). In comparison movement rates between species and between streams were similar in the fall (this is due in some part to missing the upstream surge of spawning movements), and overall significantly lower than in the spring/summer study periods (Table 11; Figure 44).

A major reason for this as noted in the habitat section is the effect of temperature on habitat selection. Trout used movement to locate, and use 
microhabitat exhibiting suitable thermal regimes especially in the mainstem, something that was not required by trout in the fall. Results from the fall study period were consistent with some studies of brook trout overall movements in small Appalachian streams and indicated very low levels of mobility and high residency rates of trout inhabiting small tributaries (Roghair et al. 2002). However, recent work in similar watersheds close by (Logan 2002) have shown somewhat different results with larger home ranges noted and larger pulses of daily movement in brook trout residing in small Appalachian streams.

High rates of movement by trout in the mainstem allow trout to vacate inhospitable or poor habitat and find optimal habitat. This allows trout to adjust to the ever-changing conditions, and to reach spawning areas (Torgersen et al. 1999, Fausch et al. 2002). Rocky Run on the other hand exists as a stable coldwater refuge that despite fluctuating conditions in the mainstem, remains constant for the most part (Table 2,3). Therefore the impetus to move for trout residing in the mainstem is absent in Rocky Run and is reflected in the lack of movement documented there. Although cooler, the tributaries offer less to eat to trout that reside there and are less profitable, reflected in lower invertebrate density and diversity (Table 1). Despite less productivity, there are more individuals present in Rocky Run. The fact that vacated holding locations will be quickly used and potentially difficult to obtain again also plays a part in the determining if ranging behavior by Rocky Run trout.

A second major finding is that movement by mainstem trout was strongly related to temperature and somewhat to distance to CWSs. These findings are 
similar to the research done by Kaya (1977) and Kaeding et al. (1996) highlighting trout movement and habitat use in a geothermally heated stream with coldwater tributaries. Given the high rates of overall movement by brook trout in the Shavers Fork mainstem, I examined the effects of temperature, stream flow, and distance to CWSs on brook trout ranging behavior during the critical spring/summer 2000-01 study periods. Brook trout movement rates were significantly related to maximum water temperature in both spring/summer study periods (2000-01) (Figure 45). In spring 2000, movement rates decreased significantly as maximum temperature increased from $12^{\circ} \mathrm{C}$ to $18^{\circ} \mathrm{C}$. In contrast, movement rates increased as a function of maximum temperature when temperatures exceeded $18^{\circ} \mathrm{C}$ (Figure 45 - top panel). A similar pattern was observed in spring 2001, although the relationship was much weaker $\left(R^{2}=0.02\right)$ and there was no "cool" period (Figure 45 - bottom panel). The overall relationship is $\mathrm{U}$-shaped with increased movement rates under cold $\left(<13^{\circ} \mathrm{C}\right)$ and hot $\left(>17^{\circ} \mathrm{C}\right)$ conditions, but very low RB rates under ideal temperature levels $\left(13-17^{\circ} \mathrm{C}\right)$.

I also observed significant relationships between brook trout movement rates and distance to a known CWS (Figure 46). In both spring 2000 and 2001 study periods there was a tendency for movement rates to increase with increasing distance from cold water or CWSs. This was especially true in the spring/summer of 2001 (Figure 46 - bottom panel). Multiple regression analyses further clarified the interactive effects of water temperature and distance to CWSs on brook trout ranging behavior. Inclusion of both maximum temperature 
and distance to a CWS in regression models produced significantly better power to predict trout movement rates $\left(F=4.7, p=0.001, R^{2}=0.26\right)$.

The third major finding of this section is that movement by mainstem trout is higher than trout residing in the tributaries even when temperature levels are low and close to optimal. This suggests there is some other undetected or undocumented reason(s) why mainstem trout are more mobile than tributary residing trout. One reason might be that trout in the mainstem have more room to move (less individuals), so they do. Bachman (1984) in a landmark study documented somewhat different results to mine by brown trout residing in a Pennsylvania stream. The system he studied was extremely productive, exhibited a favorable temperature regime, and was close to if not over the carrying capacity for the system. Therefore to move meant to give up a highly competed for resource. Therefore his results showed trout holding to one pool or $\mathrm{HCU}$, which in the upper Shavers Fork would be highly unprofitable if not deadly to most trout due to the drastically changing conditions that exist in the mainstem over the course of a year.

Another possible reason for trout to adopt high rates of movement within their adult life strategy could be based on a behavior pattern of all trout as discussed earlier. To be a mainstem trout, individuals must move extensively throughout the system, or to stay in the tributaries in Rocky Run, moving very little. "Movers" possibly represent bold individuals that are able to move and take advantage of scarce resources. In comparison "shy" individuals represent individuals that are trapped by larger conspecifics and suffer reduced growth, a 
condition exacerbated by periods of low stream flow (Fraser et al. 2001, Petty and Grossman 2004).

Trout in the mainstem clearly fall under the new understanding within current literature that stream fishes move more extensively throughout their range than previously thought This is in direct conflict with the former RMP, or restricted movement paradigm. As discussed by Rodriguez (2002), a variety of views exist currently on whether the RMP is dead or alive in explaining and understanding stream fish life histories and strategies. Rodriguez (2002) has attempted to dispel recent findings by claiming many accounts of high mobility are nothing more than the overrepresentation of the mobile component of a population. Additionally he claimed that many papers documenting large overall movement rates and distances by brook trout for example are the exception rather than the rule. He stressed that restricted movement is the norm during non-migratory periods for salmonids in stream systems, ultimately reflecting Gerking's $(1953,1959)$ understanding of restricted overall movement except for specialized behaviors, or purposes.

Many western researchers have documented extensive rates and distances covered through movement and/or migrations by stream fishes. Swanberg (1997) documented mean spawning migration distances at $63 \mathrm{~km}$ $( \pm 21 \mathrm{~km})$ for Montana bull trout based on temperature and photoperiod from telemetry. At times though he also documented the tagged bull trout holding or concentrating activity in one general location for extended periods of time, for example during overwintering periods. Bjornn et al. (1964) documented 
migrations of over $200 \mathrm{~km}$ for bull trout in Idaho river systems. On the other extreme of the continuum for western systems, Young (1996) documented a median total movement for cutthroat trout (Onchorynchus clarki pleuriticus) at only $332 \mathrm{~m}$ for a similar spring/summer study period to my study in the North Fork Little Snake River drainage in south-central Wyoming. In contrast I had trout range up to $7.5 \mathrm{~km}$ from their initial release point in the mainstem over approximately a 60-day tracking period during the spring/summer.

A combination of movement strategies by stream fishes in the eastern US has been documented in many locations. Burrell et al. (2000) recorded spawning migrations by brown trout in the Chattoooga River, South Carolina over $7.6 \mathrm{~km}$. In a corollary study Bunnell et al. (1998) found brown trout to be restricted in diel movements in the same system, showing a combination of movement strategies. In my study I documented similar findings with maximum distance covered as high as $6.5 \mathrm{~km}$, with movement rates ranging from .1 m/day in Rocky Run to $62.5 \mathrm{~m} /$ day in the mainstem during the spring/summer study periods. Petty et al. (2004) documented extremely low rates of movement in mottled sculpins (Cottus bairdi) with mean rates over a 45-day period at around $4.4 \mathrm{~m}$. Rates were determined to be mainly due to the need to conserve profitable feeding patches due to high competition for preferred patches. Bachman (1984) as mentioned earlier in an extremely informative paper recorded very low overall movement and cumulative distances covered for a number of brown trout inhabiting Spruce Creek in PA over a multi-year study. 
Salmonids are quite plastic in their habitat use, responding flexibly to seasonal variations in habitat availability and other factors through movement and/or migrations (Maki-Petays et al. 1997, Torgersen et al. 1999, Fausch et al. 2002). It is also apparent that generally impacted watersheds require greater movement by fishes residing there due to the potential for fragmentation and/or degradation of preferred habitats, like the upper Shavers Fork (Dunham et al. 1999). Additionally natural fluctuations in environmental conditions can also affect the level of movement exhibited by stream fishes from year to year within a given system (Clay et al. 1997).

The geographical characteristics of an area, its vegetative patterns, proximity of complementary fish habitats, competition, and food availability combine with other minor factors to determine to what degree fishes with a given system adopt extensive movements and migrations to complete their life histories. For example western systems are larger in scale than eastern systems and specific complementary habitats are separated by greater distances. Each system is unique, each has its own possible disturbances or impacts, and past history, all combined with limiting factors to create its physical habitat. I have proven that if needed trout in the upper Shavers Fork move and find optimal habitat. If they are already there, or there does not exist an immediate need to migrate or move for whatever reason (spawning, dewatering of habitats, etc.), then their overall movements are restricted. But, due to the impacts in the upper Shavers Fork and the history of the area, trout presently must utilize movement 
behaviors to survive and complete their life cycles or their survival will be compromised.

This study if repeated again could be improved in a number of ways. A major limitation to the study is the fact that only large, adult trout were used for the study. This limitation was mainly due to the size of the transmitters used. Transmitters currently have become smaller and offer a wider range of functions for future similar studies and will only get smaller, allowing a wider size range of animals to be monitored over longer time periods. Similar future studies documenting detailed movement and habitat use at various stages of development would be extremely important for habitat restoration efforts due to changing habitat needs of trout at different life stages (Behnke 1992).

Study periods incorporating greater spatio-temporal scales would be beneficial. A greater number of individuals tagged and followed throughout multiple areas of the watershed would strengthen trends observed due to increased sample size. For example to evaluate the fall period more comprehensively the tagging period needed to be started earlier, perhaps in early August. This would allow for the capture of many of the larger adult brook trout still in the mainstem, thus making it easier to locate adequate numbers of trout for implantation prior to the spawning migration. The use of a portable GPS unit to document linear distances and the exact location of each tagged trout during each track would also be extremely beneficial for a variety of reasons. 


\title{
CONCLUSIONS AND MANAGEMENT IMPLICATIONS
}

\author{
Classifying Warm and Coldwater Systems
}

My results provide evidence that waterbodies should be classified as cold or warmwater based not only on their local thermal regime, but also on the availability of nearby coldwater inputs to the system. In two out of the three years examined, the upper Shavers Fork mainstem alone did not classify as a coldwater system. In 2001, the maximum 7-day average maximum temperature

exceeded $22^{\circ} \mathrm{C}$. In addition the maximum summer temperature recorded in each of these years exceeded $24^{\circ} \mathrm{C}$. Furthermore, preliminary analysis of temperature data from 2002 and 2003 indicates that these critical thresholds are exceeded in most years. Both of these statistics represent well-accepted thermal thresholds for classifying the fishery potential for temperate freshwater systems, and clearly, in isolation, the upper Shavers Fork is a marginal coldwater fishery.

Nevertheless, it is difficult to deny the importance of the Shavers Fork mainstem as a wild brook, brown, and rainbow trout fishery. In my study, I found that brook trout and brown trout persist in the mainstem throughout the warm summer months, despite high ambient water temperatures. Related studies in the watershed have documented the persistence of all age classes of all species of trout in the mainstem (Petty, unpublished stream survey data). Furthermore, some of the largest brook and brown trout in the region can be found in the Shavers Fork mainstem throughout most of the year. Behavioral observations and trout population data from the Shavers Fork suggest that instead of being a marginal trout fishery, it may be among one of the most productive wild fisheries 
in the area (Petty, unpublished stream survey data). The results of my study and associated studies in the watershed indicate that the productivity of the Shavers Fork trout fishery is determined by the combined influence of high light levels, surface and subsurface inputs of coldwater to the mainstem, and the limiting factors previously discussed (Allen 1995). High light levels occur because the channel is naturally wide and because of sparse riparian vegetation in some areas. The lack of vegetation is sometimes natural and other times the result of historic land use and/or maintenance of the railroad grade.

High levels of light have positive and negative effects on the mainstem. High light levels has the positive effect of promoting high levels of primary productivity, which cascades through the invertebrate and vertebrate consumers (Bopp 2002, Lamothe 2002). Consequently, high light levels are responsible for dramatically elevated food levels in the mainstem relative to the well-shaded tributaries. In fact, Bopp (2002) determined that invertebrate biomass in the mainstem is often ten times that of nearby tributaries, especially during late spring and summer months. The negative effects of high light on the mainstem are obvious from our current study; they result in high summer water temperatures, especially during periods of low stream flow.

The behavioral response of brook and brown trout observed in this study indicate that CWSs allow them to take advantage of the high levels of productivity in the mainstem. I documented this during summer conditions despite high ambient water temperatures, similar to findings by other researchers (Kaeding 1996, Torgersen et al. 1999). As ambient water temperatures rise, trout 
exhibit ranging behavior and move to access CWSs and their outflows. However, only rarely did I observe individuals completely abandon the mainstem and move up into a cold tributary (only 4 out of 25 brook trout moved from the mainstem into a tributary in Spring 2000 or 2001, and no tagged brown trout ever abandoned the mainstem). Instead they selected cold microhabitats within the mainstem itself, thereby maintaining access to high food levels characteristic of the mainstem. These cold microhabitats were influenced by tributary outflows, seeps, and/or hyporheic upwelling through the valley alluvium.

Therefore, I propose a need to develop methods of classifying waterbodies at a spatial scale that is larger than the stream reach for West Virginia streams. I believe that an effective classification of the coldwater potential of a system must consider the types of CWSs that drain into it. For example, I would consider Rocky Run an intuitive coldwater system, because its overall thermal regime would allow coldwater resident species to persist in isolation. The Shavers Fork mainstem, in contrast, should be considered a dependent coldwater system, because its overall thermal regime would not allow coldwater residents to persist in isolation. Instead, coldwater fishes in the mainstem depend on coldwater inputs from tributaries. I believe that there are numerous watersheds in West Virginia and the central Appalachian region for which this type of classification system is relevant and would ultimately aid in their conservation.

Many new forms of technology are being integrated into fisheries management today that would aid in creating a temperature classification 
scheme for West Virginia streams (Fausch et al. 2002). One highly advanced but expensive technique that could be utilized to create an entire temperature profile of the upper Shavers Fork is the use of advance airborne thermal imaging platforms. Kay et al. (2001) utilized an advanced thermal imaging system to create maps of Cascade mountain streams in southern Washington picking up $1^{\circ}$ C temperature differences within the watershed analyzed. Their work was done to aid in preparing a classification system based on instream temperature readings due to potential global warming problems and to improve upon their current classification scheme.

The thermal images (TIRs) created by this platform have long been used to determine sea surface temperatures and are highly accurate. Variations in temperature are shown in either various colors or shades of grey within the TIRs. Torgersen et al. (2001) utilized a similar system (forward-looking infrared (FLIR) videography) to obtain continuous data on stream temperature while investigating large-scale patterns of stream temperature and pool frequency on the John Day River, Oregon. A similar system could aid in determining precise locations of CWS inputs, their points of delivery, groundwater recharge, and to define exactly where the zones are that are most inhospitable to temperature tolerant fishes such as brook trout in the upper Shavers Fork watershed. This type of spatial knowledge of the temperature regime in the watershed would also prove invaluable to any future restoration/enhancement efforts. Further incorporation of relevant remote sensing data and geographic information systems (GIS) would prove highly beneficial in dealing with the issues and 
complexities of the upper Shavers Fork watershed by helping to manage and analyze spatial data more efficiently (Welch et al. 1988, Fausch et al. 2002).

Need for Watershed Rather than Reach Scale Management Plans

This study also provides evidence that fisheries like the upper Shavers Fork need to be managed at a watershed scale rather than a stream reach or segment scale. There are two important reasons for this conclusion. First, my study indicates that brook and brown trout are highly mobile, especially in larger waterbodies like the Shavers Fork mainstem. My findings are consistent with many similar contemporary studies on salmonids (Clapp et al. 1990, Gowan and Fausch 1996b, Swanberg 1997). If management approaches are developed patchwork on a reach-by-reach basis, then individual fish are likely to move through different areas with different types of management guidelines. For example, unless catch-and-release regulations apply to two to three miles of stream at the least, most individuals within that particular reach are likely to move into reaches where harvest is not restricted and possibility be lost due to fishing. Likewise, fish located within the catch-and-release segment at any given time are likely to have come from an area outside of the special regulation reach.

Consequently, high harvest rates in nearby reaches could negatively affect trout populations within the catch-and-release reaches.

Second, small coldwater tributaries and the larger mainstem exist as complementary brook trout habitats at the watershed scale to highly mobile resident trout (Dunning et al. 1992, Schlosser 1991, 1995a, Pope et al. 2000, Bramblett et al. 2002, Petty et al. 2005). The fishery depends on fish having 
access to refuges throughout the watershed, spawning habitats in small tributaries, and productive feeding habitats in the larger mainstem. Consequently, management actions taken in ether habitat likely will affect the productivity of the other habitat. Therefore proper management is best accomplished under a watershed framework (Dunning et al. 1992, Williams et al. 1997, Pope et al. 2000).

Specific Recommendations for the Upper Shavers Fork Watershed

Highly complex interactions between riparian influences (e.g., forest stand age and density influences on in-channel large woody debris loading), stream hydraulics (e.g., flow regimes and peak flows), and geomorphic features (e.g., channel morphology, and streambed material) are responsible for the formation of stream habitat (Dolloff et al. 1997). Management practices in the watershed directed towards the promotion of these interactions in as natural a state as possible would improve the overall health of the system and have a positive cascading effect on the entire aquatic community (Schlosser 1991, 1995a). Three main problems in the system that will continue to be present in the future are the continued use and maintenance of the railroad grade in the watershed, acid deposition, and impacts from Intrawest's development of Snowshoe Mountain. The health of the upper watershed will in a way depend on how current and future impacts related to these three main issues are mitigated.

I offer three recommendations regarding the management of the upper Shavers Fork trout fishery based on this study. First small tributaries must be protected and any necessary restoration/enhancement actions be taken to re- 
connect these to the mainstem and to improve (or maintain) their water quality. Tributaries and seeps are complementary spawning habitat to the mainstem, vital cold water sources, and they increase overall habitat suitability in the system. I encourage the WVDNR to maintain and expand its current limestone fines program to reverse the effects of acid deposition and limited AMD in the watershed. The timing, delivery, and placement of future liming efforts could also be improved. Based on their models, Petty and Thorne (2005) showed that current brook trout recruitment in the system is at approximately $20 \%$ of historical levels due to the loss of spawning habitat from acid deposition. Their models have shown that this figure would increase dramatically if a number of impacted reaches not currently limed are in fact limed in the future using current rail lines in the watershed (Petty and Thorne 2005).

A survey of potential barriers between the mainstem and the tributaries is an important part of the first recommendation. If such barriers exist, then the cooling potential of the tributaries may be limited or compromised at best. Action to improve these areas and to remove anything that might impede the future delivery of cold, clean water from the tributaries and other CWSs (seeps, etc.) would benefit the system immensely. Many culverts exist presently in a state of disrepair and actually add to the thermal problems of the system in their present state by fanning out cold outflows and slowing their delivery to the system. By the time such outflows reach the mainstem they no longer act as a cooling input and in some cases possibly re-enter the system as warming inputs during critical 
periods. The culvert system at Beaver Creek is but one example presently that would benefit the system by being reworked or improved.

Access by fish into these CWSs is a critical factor limiting habitat suitability in the mainstem (Baker and Coon 1997, Fausch et al. 2002). Consequently, any actions that would increase the delivery of cold, clean water (for thermal and acidity problems) to the mainstem would ultimately supply a connection for fish movement (Schlosser 1991, 1995a). New and/or improved culverts must be placed in a manner so that they facilitate passage, not discourage it due to increased flow, etc. through the culvert (Gibson et al. 2005). As pointed out by Fausch et al. (2002), barriers to movement such as old, compromised culverts act as critical overriding factors (much like the railroad grade) to the conservation of stream fishes and if repaired would be extremely beneficial to the overall system for multiple reasons. Many of the extreme headwater areas are characterized by beaver (Castor canadansis) ponds and associated habitats shown to play an important and positive role in stream fish population dynamics (Schlosser 1995b). Restoration efforts could open up these habitats that have been previously closed off and/or under-utilized by mainstem fishes and increase the amount of suitable habitat available to brook trout and other fishes inhabiting the upper Shavers Fork (Baker and Coon 1997).

Unrestricted movement also promotes genetic diversity within the wild trout population of the upper Shavers Fork by connecting metapopulations throughout the watershed (Clay and Butland 1997, Dunham and Rieman 1999). Creating and/or maintaining a connection between the tributary headwaters 
(Beaver Creek for example) and the mainstem would connect a "source" of individuals to the larger more productive mainstem "sink" further benefiting the system as a whole (Schlosser 1991, 1995a, Pulliam 1998). One tagged brook trout last located over 2-kms downstream of Rocky Run in late spring 2000, was found later that fall in the extreme headwaters of Rocky Run, moving over $7.5 \mathrm{~km}$ to reach suitable spawning areas on its fall spawning run. Numerous brook trout tagged during stream surveys with elastic polymers have also been re-captured in different tributaries than they were originally captured and marked in (Petty et al. 2005). These examples reiterate the need for watershed scale management plans rather than reach scale management, and the need to protect interconnectivity within the upper Shavers Fork watershed (Bramblett et al. 2002, Williams et al. 1997).

The second recommendation concerns instream habitat complexity. On the topic of future restoration efforts, I believe that the importance of cold water and CWSs overrides issues of structural habitat deficiencies in the mainstem as stated repeatedly. In late summer, habitat in the upper watershed is only useful to trout if it is near to a CWS. In other words, although structural habitat complexity is generally low in the Shavers Fork mainstem (Petty et al. 2001), it probably does not currently limit the brook or brown trout fishery in this system. Consequently, any efforts to improve habitat complexity through natural stream channel design must consider how those actions relate to the distribution of CWSs. Some of the best habitat in the mainstem is underutilized because it is in areas that get too warm for trout to inhabit year-round. For example some lower 
reaches possibly used as overwintering areas by "holdover" and wild trout in the upper Shavers Fork are too warm for them during the summer. Clapp et al. (1990) documented similar seasonal habitat segregation due to thermal issues on the Au Sable River, Michigan with brown trout. I suggest that any future natural stream channel design projects focus on ways to reduce heating in specific areas of the river or improve structural complexity in areas near to CWSs.

Future instream restoration/enhancement efforts need to be well thought out and done as naturally as possible. Allowing a river or stream to find its own path and adjust itself naturally by meandering along an unrestricted floodplain over time also will put more points for groundwater recharge within reach of the ever-shifting riverbed (Wood et al. 1998). This would enhance the thermal regime in addition to benefiting the natural dynamics of the system. Obviously an expert or firm(s) with knowledge in fluvial geomorphology and stream restoration needs to be heavily involved if steps are undertaken to improve the instream habitat of the upper Shavers Fork and restore it to a close approximation of its former self (Rabeni and Sowa 1993, Shields et al. 2003). Care must be taken to make the areas that are "enhanced" or "restored" as indiscernible and natural as possible.

I would caution, however, that the Shavers Fork is a good example of a system where structural habitat improvement projects might actually produce a negative effect on trout populations by attracting fish and anglers, thereby increasing angling related mortality (a similar situation can occur with catch \& release regulated streams) (M. Shingleton, WVDNR, Elkins West Virginia, pers. 
comm.). Habitat improvement projects are only beneficial when improved habitat can be expected to increase the overall productivity of the fishery (Gowan and Fausch 1996a). The Shavers Fork fishery is limited more severely by thermal conditions and loss of spawning habitat from acid deposition than by structural habitat quality (Petty and Thorne 2005). Consequently, habitat improvement projects are unlikely to produce increased trout productivity in the near term unless they are designed to offset problems associated with thermal conditions and acid deposition (Rabeni and Sowa 1996).

To realize the productivity potential of the trout fisheries in the upper Shavers Fork watershed will probably require a non-traditional approach to controlling harvest. This is the third recommendation offered. The high rates of movement exhibited by trout within the Shavers Fork mainstem potentially make them extremely vulnerable to harvest. In addition, the tendency for large brook trout to use the mainstem as a feeding habitat in the spring/summer and tributaries as spawning habitat in the fall makes it difficult to manage the mainstem and tributaries in isolation. As pointed out by Gowan et al. (1994), good management depends upon correct assessment of the extent to which fish move. I strongly encourage the WVDNR to consider developing a harvest control plan that recognizes the spatial complexities of trout populations in the watershed that I have outlined here.

In closing, a major topic in my opinion that needs to be addressed in conjunction with the other issues of the watershed is winter mortality of trout. Overwintering areas exhibit increased habitat volume, reduced flow velocity, and 
increased habitat complexity (Schlosser 1995a). Current literature suggests the lack of overwintering habitat can have a profound negative impact on a trout fishery (Chisolm and Hubert 1987, Berg 1994, Cunjak 1996), and that further studies need to be done to understand this limiting factor to trout fisheries (Brown and Mackay 1995). As noted previously, overwintering habitat is a major type of habitat required by trout to survive (Behnke 1992), and is probably lacking in the upper Shavers fork mainstem.

Streams such as the upper Shavers Fork that are shallow and wide not only lack suitable winter cover, but also promote subsurface ice formation (Cunjak 1996). Subsurface ice can block intragravel flow and creates anchor ice dams, which can dewater downstream habitats (Berg 1994), a common problem I personally have observed on the upper Shavers Fork. Fish perish for a variety of reasons related to this change in their physical habitat under winter conditions from abrasions to their gills from frazile ice, to anchor ice which limits instream habitat in winter and kills invertebrates (Chisolm and Hubert 1987, Berg 1994). The total area of habitat available to trout from season to season has been shown to be a major influence in dictating trout population dynamics and ultimately abundance and overall survival (Cunjak 1996). Additionally, winter mortality in conjunction with slow growth of older fish, could potentially limit trout entering the fishery of a size-limited trout fishery in the upper Shavers Fork (Whitworth and Strange 1983).

Winter mortality as a limiting factor can be mitigated through sound natural restoration practices along with many of the other watershed-scale 
problems covered. Preliminary research has shown that in degraded areas activities that moderate fluctuations in winter stream temperature (i.e. riparian vegetation restoration) and that create deep water habitats (i.e. natural stream restoration principles) may help alleviate poor winter conditions (Jakober et al. 1998). The fact that there is a lack of instream structure to help break up ice jams during the spring thaw compounds the problem in the upper Shavers Fork. Despite the difficulties in carrying out such a study in this remote system in winter, I highly recommend this aspect of the system be fully understood due to the potential of winter mortality to limit the trout fishery of the upper Shavers Fork.

I recommend all actions possible be taken by the WVDNR to incorporate my findings into the management of the upper Shavers Fork to promote, restore, and/or enhance its trout fishery. A management plan that incorporates thinking at a larger scale in terms of management objectives and possible influences (both negative and positive) to the system would be extremely beneficial (Cooper et al. 1998, Huston 1999). Ultimately my study and all related work falls under and meshes with the overriding USFS goal mentioned in the introduction of restoring the native red spruce ecosystem to the upper Shavers Fork watershed and its associated aquatic assemblages. This study, direct results/findings, and subsequent work in the watershed will also benefit "Back the Brookie", a TU National grassroots environmental campaign (McCoy 2004). 


\section{BIBLIOGRAPHY}

Allen, J.D. 1995. Stream Ecology. Kluwer Acedemic Publishers.

Anderson, W.G., S.R. McKinley, and M. Colavecchia. 1997. The use of clove oil as an anesthetic for rainbow trout and its effects on swimming performance. North American Journal of Fisheries Management 17:301307.

Angradi, T.R. 1999. Fine sediment and macroinvertebrate assemblages in Appalachian streams: a field experiment with biomonitoring applications. Journal of the North American Benthological Society 18(1):49-66.

Bachman, R.A. 1984. Foraging behavior of free-ranging wild and hatchery brown trout in a stream. Transactions of the American Fisheries Society 113:132.

Bahr, M.A., and J.M. Shrimpton. 2004. Spatial and quantitative patterns of movement in large bull trout (salvelinus confluentus) froma watershed in north-western British Columbia, Canada, are due to habitat selection not differences in life history. Ecology of Freshwater Ecology 13:294-304.

Baltz, D.M., B. Vondracek, L.B. Brown, and P.B. Moyle. 1987. Influence of temperature on microhabitat choice by fishes in a California stream. Transactions of the American Fisheries Society 116:12-20.

Baltz, D.M., B. Vondracek, L.R. Brown, and P.B. Moyle. 1991. Seasonal change in microhabitat selection by rainbow trout in a small stream. Transactions of the American Fisheries Society 120:166-176.

Baker, E.A., and T.G. Coon. 1997. Development and evaluation of alternative habitat suitability criteria for brook trout. Transactions of the American Fisheries Society 126:65-76.

Behnke, R.J. 1992. Native trout of western North America. American Fisheries Society Monograph 6. Bethesda, Maryland.

Berg, N.H. 1994. Ice in stream pools in California's central Sierra Nevada: Spatial and temporal variability and reduction in trout habitat availability. North American Journal of Fisheries Management 14:372-384.

Berman, C.H., and T.P. Quinn. 1991. Behavioral thermoregulation and homing of spring chinook salmon, Oncorhynchus tshawytscha (Walbaum) in the Yakima River. Journal of Fish Biology 39:301-312. 
Bjorn, T.C. 1971. Trout and salmon movements in two Idaho streams as related to temperature, food, stream flow, cover, and population density.

Transactions of the American Fisheries Society 100:423-438.

Bjornn, T.C. and J. Mallet. 1964. Movement of planted and wild trout in an Idaho river system. Transactions of the American Fisheries Society 93:70-76.

Bopp, J.A. 2002. Combined effects of water chemistry, canopy cover, and stream size on benthic macroinvertebrates along a Central Appalachian stream continuum. M.Sc. Thesis. West Virginia University. 104 pgs.

Boulton, A.J., S. Findlay, P. Marmonier, E.H. Stanley, and M. Valett. 1998. The functional significance of the hyporheic zone in streams. Annual Review of Ecology and Systematics 29:59-81.

Bramblett, R.G. M.D. Bryant, B.E. Wright, and R.G. White. 2002. Seasonal use of small tributary and main-stem habitats by juvenile steelhead, coho salmon, and dolly varden in a southeastern Alaska drainage basin. Transactions of the American Fisheries Society 131:498-506.

Brown, R.S. and W.C. Mackay. 1995. Fall and winter movements of and habitat use by cutthroat in the Ram River, Alberta. Transactions of the American Fisheries Society 124:873-885.

Bunnell Jr., D.B., J.J. Isely, K.H. Burrell, and D.H. Van Lear. 1998. Diel movements of brown trout in a southern Appalachian river. Transactions of the American Fisheries Society 127:630-636.

Burrell, K.H., D.H. Van Lear, D.B. Bunnell, and C.A. Dolloff. 2000. Seasonal movements of brown trout in a southern Appalachian river. Transactions of the American Fisheries Society 129:1373-1379.

Cada, G.F., J.M. Loar, and M.J. Sale. 1987. Evidence of food limitations of rainbow and brown trout in southern Appalachian soft-water streams. Transactions of the American Fisheries Society 116:692-702.

Calvin, M.K., L.R. Kaeding, and D.E. Burkhalter. 1977. Use of a cold-water refuge by rainbow and brown trout in a geothermally heated stream. Progressive Fish Culturist 39(1)37-38.

Chisolm, I.M., and W.A., Hubert. 1987. Winter stream conditions and use of habitat by brook trout in high-elevation Wyoming streams. Transactions of the American Fisheries Society 116:176-184. 
Clapp, D.F., R.D. Clark, and J.S. Diana. 1990. Range, activity, and habitat of large, free-ranging brown trout in a Michigan stream. Transactions of the American Fisheries Society 119:1022-1034.

Clay, D. and S. Butland. 1997. Population and movement of brook trout in a small forest stream. Greater Fundy Environmental Report No. 35444.

Clarkson, R.B. 1964. Tumult on the mountain, lumbering in West Virginia, 17701920. McClain Printing Company.

Clayton, J.L., E.S. Dannaway, R. Menendez, H.W. Rauch, J.L. Renton, S.M. Sherlock, and P.E. Zurbuch. 1998. Application of limestone to restore fish communities in acidified streams. North American Journal of Fisheries Management 18:347-360.

Courtois, L.A. 1981. Lightweight, adjustable, and portable surgical table for fisheries work in the field. Progressive Fish-Culturist 43:55-56.

Cooper, S.D., S. Diehl, K. Kratz, and O. Sarnelle. 1998. Implications of scale for patterns and processes in stream ecology. Australian Journal of Ecology 23:27-40.

Cronan, C.S., and C.L. Schofield. 1979. Aluminum leaching response to acid precipitation: effects on high-elevation watersheds in the northeast. Science 204(4390):304-306.

Cunjak, R.A. 1996. Winter habitat of selected stream fishes and potential impacts from land - use activity. Canadian Journal of Fisheries and Aquatic Sciences 53(Suppl 1):267-282.

Curry, R.A., C. Brady, D.L.G. Noakes, and R.G. Danzmann. Use of small streams by young brook trout spawned in a lake. Transactions of the American Fisheries Society 126:77-83.

DeWald, L., and M.A. Wilzbach. 1992. Interactions between native brook trout and hatchery brown trout: effects on habitat use, feeding, and growth. Transactions of the American Fisheries Society 121:287-296.

Dingle, H. 1996. Migration: the biology of life on the move. Oxford (UK): Oxford University Press.

Dolloff, C.A., H.E. Jennings, and M.D. Owens. 1997. A comparison of basinwide and representative reach habitat survey techniques in three southern Appalachian watersheds. North American Journal of Fisheries Management 17:339-347. 
Dunham, J.B. and B.E. Rieman. 1999. Metapopulation structure of bull trout: influences of physical, biotic, and geometrical landscape characteristics. Ecological Applications 9(2) 642-655.

Dunning, J. B., B. J. Banielson, and H. R. Pulliam. 1992. Ecological Processes that affect population in complex landscapes. Oikos 65:169175.

Elliott, J.M. 1990. Mechanisms responsible for population regulation in young migratory trout, Salmo trutta. III. The role of territorial behavior. Journal of Animal Ecology 59:803-818.

Elliott, J.M. 2000. Pools as refugia for brown trout during two summer droughts: trout responses to thermal and oxygen stress. Journal of Fish Biology 56:938-948.

Ensign, W.E., R.J. Strange, and S.E. Moore. 1990. Summer food limitation reduces brook and rainbow trout biomass in a southern Appalachian stream. Transactions of the American Fisheries Society 119:894-901.

Fausch, K.D. 1984. Profitable stream positions for salmonids: relating specific growth rate to net energy gain. Canadian Journal of Zoology 66:441-451.

Fausch, K.D., and R.J. White. 1981. Competition between brook trout and brown trout for positions in a Michigan stream. Canadian Journal of Fisheries and Aquatic Sciences 38:1220-1227.

Fausch, K.D., C.E. Torgersen, C.V. Baxter, and H.W. Li. 2002. Landscape to riverscapes: bridging the gap between research and conservation of stream fishes. Bioscience 52(6):483-498.

Flebbe P.A., and C.A. Dolloff. 1995. Trout use of woody debris and habitat in Appalachian wilderness streams of North Carolina. North American Journal of Fisheries Management 15:579-590.

Forseth, T., and B. Jonsson. 2000. The growth and food ration of piscivorous brown trout (Salmo trutta). Functional Ecology 8:171-177.

Fraser, D.F., G.T. Skalski, and J.F. Gilliam. 2001. Explaining leptokurtic movement distributions: intrapopulation variation in boldness and exploration. American Naturalist 158:124-135.

Gagen, C.J., W.E. Sharpe, and R.F. Carline. 1994. Downstream movement and mortality of brook trout (Salvelinus fontinalis) exposed to acidic episodes in streams. Canadian Journal of Fisheries and Aquatic Science 51:16201629. 
Garrett, J.W., and D.H. Bennett. 1995. North American Journal of Fisheries Management 15:480-487.

Gaujot, R. 2002. Surface hydrology, and fish habitat relationships in the upper Shavers Fork drainage basin. Thesis. West Virginia University. 91 pgs.

Gerking, S.D. 1953. Evidence for the concepts of home range and territory in stream fishes. Ecology 34(2):347-365.

Gerking, S.D. 1959. The restricted movement of fish populations. Biological Review 34:221-242.

Gibson, R.J. 1996. Some factors influencing the distribution of brook trout and young Atlantic salmon. Journal of Fisheries Research Board of Canada 23:1977-1980.

Gibson, R.J., R.L. Haedrich, and C.M. Wernerheim. 2005. Loss of fish habitat as a consequence of inappropriately constructed stream crossings. Fisheries $30(1): 10-16$.

Giller, P.S., and B.Malmqvist. 1998.The biology of streams and rivers. Oxford University Press.

Gilliam, J.F., and D.F. Fraser.1987. Habitat selection under predation hazard: a test of a model with foraging minnows. Ecology 68:1856-1862.

Gowan, C., M.K. Young, K.D. Fausch, and S.C. Riley. 1994. Restricted movement in resident stream salmonids: a paradigm lost? Canadian Journal of Fisheries and Aquatic Science 51: 2626-2635.

Gowan C., and K.D. Fausch. 1996a. Long-term demographic responses of trout populations to habitat manipulations in six Colorado streams. Ecological Applications 6(3)931-946.

Gowan, C., and K.D. Fausch. 1996b. Mobile brook trout in two high elevation Colorado streams: re-evaluating the concept of restricted movement. Canadian Journal of Fisheries and Aquatic Science 53:1370-1381.

Grossman, G.D., and J.T. Petty. 1995. Observations on habitat structure, population regulation, and habitat use in evolutionary significant units: a landscape approach. American Fisheries Society Monograph Series 17:381-391.

Hakala, J.P. Factors influencing brook trout (Salvelinus fontinalis) abundance in Forested headwater streams with emphasis on fine sediment. M. Sc. Thesis. West Virginia University. 166 pgs. 
Hankin, D.G., and G.H. Reeves. 1988. Estimating total fish abundance and total Habitat area in a small stream based on visual estimation methods. Canadian Journal of Fisheries and Aquatic Sciences 45:834-844.

Hart, L.G., and R.C. Summerfelt. 1975. Surgical procedures for implanting ultrasonic transmitters into flathead catfish (Pylodictis olivaris). Transactions of the American Fisheries Society 104:56-59.

Hartman, K.J. and J.A. Sweka. 2001. Development of a bioenergetics model for Appalachian brook trout. Proceedings of the Annual Conference of the Southeast Association of Fish \&Wildlife Agencies 55:38-51.

Hawkins, C.P., M.L. Murphy, N.H. Anderson and M.A. Wilzbach. 1983. Density of fish and salamanders in relation to riparian canopy and physical habitat in streams of the northwestern United States. Canadian Journal of Fisheries and Aquatic Sciences 40:1173-1185.

Helfrich, L.A., and W.T. Kendall. 1982. Movements of hatchery-reared rainbow, brook, and brown trout stocked in a Virginia mountain stream. Progressive Fish-Culturist 44(1) 3-7.

Herger, L.G., W.A. Hubert, and M.Y. Young. 1996. Comparison of habitat composition and cutthroat trout abundance at two flows in small mountain streams. North American Journal of Fisheries Management 16:294-01.

Hill, J. and G.D. Grossman. 1993. An energetic model of microhabitat use for rainbow trout and rosyside dace. Ecology 74:685-698.

Hildrew, A.G., and P.S. Giller. 1994. Patchiness and species interactions and disturbance in the stream benthos: Aquatic ecology, scale, pattern, process (34th Symposium of the British Ecological Society) (eds Giller P.S.., A.G. Hildrew and D.G. Raffaelli ), p21-62. Blackwell Publications, London.

Hornbeck, J.W., and J. N. Kochenderfer. 1998. Growth trends and management implications for West Virginia's red spruce forests. Journal of Applied Forestry Vol. 15, No. 4:197-202.

House, R.A., and P.L. Boehne. 1986. Effects of instream structures on salmonid habitat and populations in Tobe Creek, Oregon. North American Journal of Fisheries Management 6:38-46.

Huey, R.B. 1991. Physiological consequences of habitat selection. American Naturalist 137:90-115. 
Hughes, N.F. 1998. A model of habitat selection by drift-feeding stream salmonids at different scales. Ecology 79(1):281-294.

Hughes, N.F. 1992. Selection of positions by drift feeding salmonoids in dominance hierarchies: model and test for arctic grayling (Thymallus arcticus) in subarctic mountain streams, interior Alaska. Canadian Journal of Fisheries and Aquatic Sciences 49:1999-2008.

Hughes, N.F., and L.M. Dill. 1990. Position choice by drift-feeding salmonids: model and test for arctic grayling (thymallus artcticus) in subarctic mountain streams, interior Alaska. Canadian Journal of Fisheries and Aquatic Sciences 47:2039-2048.

Huston, M.A. 1999. Local processes and regional patterns:appropriate scales for understanding variation in the diversity of plants and animals. Oikos 86:393-401.

Jakober, M.J., T.E. McMahon, R.F. Thurow, and C.G. Clancy. Role of stream ice on fall and winter movements and habitat use by bull trout and cutthroat trout in Montana headwater streams. Transactions of the American Fisheries Society 127:223-235.

Jordahl, D.M. 1987. Effects of low pH on survival of brook trout embryos and yolk-sac larvae in West Virginia streams. Transactions of the American Fisheries Society 116:807-816.

Kaeding, L.R. 1996. Summer use of coolwater tributaries of a geothermally heated stream by rainbow and brown trout, Onchorynchus mykiss and Salmo trutta. American Midland Naturalist 135(2):283-292.

Kay, J., R.N. Handcock, A Gillespie, C. Konrad, S. Burges, N. Naveh,and D. Booth. 2001. Proceedings of the International Geoscience and Remote Sensing Symposium (IGRSS), July 9-13, 2001.

Kohler, C.C., and W.A. Hubert, editors. 1999. Inland fisheries management in North America, 2nd Edition, American Fisheries Society, Bethesda, Maryland.

Kotliar N.B., and J.A. Weins. 1990. Multiple scales of patchiness and patch structure: a hierarchical framework for the study of heterogeneity. Oikos 59:253-260.

Lacroix, G.L. 1992. Mitigation of low stream pH and its effect on salmonids. Environmental Pollution 78:157-164. 
Lamothe, P.J. 2002. Spatial population dynamics of brook trout (Salvelinus fontinalis) in a central Appalachian watershed. M.Sc. Thesis. West Virginia University. 118 pgs.

Lenormand, S., J.J. Dodson, and A Menard. 2004. Seasonal and ontogenic patterns in the migration of anadromous brook charr (Salvelinus fontinalis). Canadian Journal of Fisheries and Aquatic Science 61:54-67.

Leopold, L.B. 1994. A view of the river. Harvard University Press, Cambridge, Massachusetts, 298 pgs.

Logan, M. 2002. Brook trout movement and habitat use in a headwater stream of the central Appalachian Mountains of West Virginia. M.Sc. Thesis. West Virginia University. 70 pgs.

Maki-Petays, A., T. Muotka, A. Huusko, P. Tikkanen, and P. Kreivi. 1997. Seasonal changes in habitat use and preference by juvenile brown trout in a northern boreal river. Canadian Journal for Fisheries and Aquatic Sciences 54:520-530.

Marschall, E.A., and L.B. Crowder. 1996. Assessing population responses to multiple anthropogenic effects: a case study with brook trout. Ecological Applications 6(1):152-167

Matthews, K.R. 1996. Habitat selection and movement patterns of California golden trout in degraded and recovering stream sections in the golden trout wilderness, California. North American Journal of Fisheries Management 16:579-590.

McCoy, J. 2005. Backing the brookie, in Sunday Gazette Mail (January 16, 2005).

McCullough, B.J. Effects of floods on brook trout populations in the Monongahela National Forest. M.Sc. Thesis. Penn State University. 100pgs.

McRae, G., and C.J. Edwards. Thermal characteristics of Wisconsin headwater streams occupied by beaver: implications for brook trout habitat. Transactions of the American Fisheries Society 123:41-656.

Meehan, W.R., editor. 1991. Influences of forest and rangeland management on salmonid fishes and their habitat. American Fisheries Society, Bethesda, Maryland.

Menendez, R. 1976. Chronic effects of reduced pH on brook trout. Journal of Fisheries Research Board of Canada 33(1) 118-122. 
Menendez, R., J.L. Clayton, and P. Zurbuck. 1996. Chemical and fishery responses to mitigative liming of an acidic stream, Dogway Fork, West Virginia. Restoration. Ecology 4(3):220-233.

Meyers, L.S.,T.F. Thuemler, and G.W. Kornely. 1992. Seasonal movements of brown trout in northeast Wisconsin. North American Journal of Fisheries Management 12:433-441.

Peterson, D.B. 2003. Upstream movement by nonnative brook trout (Salvelinus fontinalis) promotes invasion of native cutthroat trout (Oncorhynchus clarki) habitat. Canadian Journal of Fisheries and Aquatic Sciences 60:1502-1516.

Petty, J.T. 1999-2002. Unpublished stream survey data.

Petty, J.T., and G.D. Grossman. 1996. Patch Selection by mottled sculpin (Pisces: Cottidae) in a southern Appalachian stream. Freshwater Biology 35:261-276.

Petty, J.T., J. Freund, P. Lamothe, P. Mazik. 2001. Quantifying instream habitat in the upper Shavers Fork basin at multiple spatial scales. Proceedings of the Southeastern Association of Fish and Wildlife Agencies 55:81-94.

Petty, J.T., and G.D. Grossman. 2004. Restricted movement by mottled sculpin (pisces:cottidae). Freshwater Biology 49(5):631-645.

Petty, J.T., P.J. Lamothe, and P. Mazik. 2005. Spatial and Seasonal Dynamics of brook trout populations inhabiting a central Appalachian watershed. Transactions of the American Fisheries Society 134:572-587.

Petty, J.T. and D. Thorne. 2005. An ecologically based approach to identifying Restoration Priorities in an acid impacted watershed. Restoration Ecology.

Pope, S. E., L. Fahrig, and H. G. Merriam. 2000. Landscape complementation and metapopulation effects on leopard frog populations. Ecology 81:2498-2508.

Power, G. 1980. The brook charr, Salvelinus fontinalis. In Balon 141-203.

Pulliam, H. R. 1988. Sources, sinks, and population regulation. American Naturalist 132:652-661.

Rabeni, C.F., and R.B. Jacobson. 1993. The importance of fluvial hydraulics to fish -habitat restoration in low-gradient alluvial streams. Freshwater Biology 29:211-220. 
Rabeni, C.F., and S.P. Sowa. 1996. Integrating biological realism into habitat restoration and conservation strategies for small streams. Canadian Journal of Fisheries and Aquatic Sciences 53(1);252-259.

Rabeni, C.F., and R.B. Jacobson. 1999. Warmwater streams. Pages 505-525 in C.C. Kohler and W.A. Hubert, editors. Inland fisheries management in North America, $2^{\text {nd }}$ edition. American Fisheries Society, Bethesda, Maryland.

Riley, S.C., K.D. Fausch, and C. Gowan. 1992. Movement of brook trout (Salvelinus fontinalis) in four small subalpine streams in northern Colorado. Ecology of Freshwater Fish 1:112-122.

Rincon, P.A., and J. Lobon Cervia. 1993. Microhabitat use by stream-resident brown trout: bioenergetics consequences. Transactions of the American Fisheries Society 122:575-587.

Roghair, C.N., C.A. Dolloff, and M.K. Underwood. 2002. Response of a brook trout population and instream habitat to a catastrophic flood and debris flow. Transactions of the American Fisheries Society 131:718-730.

Roper, B.B., D.L. Scarnecchia, and T.J. La Marr. 1994. Summer distribution of and habitat use by Chinook salmon and steelhead within a major basin of the south Umpqua River. Transactions of the American Fisheries Society 123:298-308.

Rose, G.A. 1986. Growth decline in sub-yearling brook trout (Salvelinus fontinalis) after the emergence of rainbow trout (Salmo gairdneri). Canadian Journal of Fisheries and Aquatic Science 43:187-193.

Ross, M.J. and C.F. Kleiner. 1982. Shielded needle technique for surgically implanting radio-frequency transmitters in fish. Progressive Fish-Culturist 44:41-43.

Rodriquez, M.A. 2002. Restricted movement in stream fish: the paradigm is incomplete, not lost. Ecology 83(1):1-13.

Schlosser, I.J. 1991. Stream fish ecology: a landscape perspective. Bioscience 41(10):704-712.

Schlosser, I.J. 1995a. Critical landscape attributes that influence fish population dynamics in headwater streams. Hydrobiologia 303:71-81.

Schlosser, I.J. 1995b. Dispersal, boundary processes, and trophic-level interactions in streams adjacent to beaver ponds. Ecology 76(3):908-925. 
Shields Jr., F.D., R.R. Copeland, P.C. Klingman, M.W. Doyle, and A. Simon. 2003. Design for stream restoration. Journal of Hydraulic Engineering August:575-584.

Simonson, T.D., J. Lyons, and P.D. Kanehl. 1994. Quantifying fish habitat in streams: transect spacing, sample size, and a proposed framework. North American Journal of Fisheries Management 14:605-617.

Skalski, G. T. and J. F. Gilliam. 2000. Modeling diffusive spread in a heterogeneous population: a movement study with stream fish. Ecology 81:1685-1700.

Swanberg, T.R. 1997. Movement of and habitat use by fluvial bull trout in the Blackfoot river, Montana. North American Journal of Fisheries Management. 126:735-746.

Sweka, J. and K.J. Hartman. 2001. Effects of turbidity on prey consumption and growth in brook trout and implications for bioenergetics modeling. Canadian Journal of Fisheries and Aquatic Sciences 58:386-393.

Thorne, D. 2004. Spatial and seasonal variation in brook trout diet, growth, and consumption in a complex Appalachian watershed. M.Sc. Thesis. West Virginia University.

Todd, B.L., and C.F. Rabini. 1989. Movement and habitat use by smallmouth bass. Transactions of the American Fisheries Society 118:229-242.

Torgersen, C.E., D.M. Price, H.W. Li, and B.A. McIntosh. 1999. Multiscale thermal refugia and and stream habitat associations of Chinook salmon in northeastern Oregon. Ecological Applications 9(1):301-319.

Torgersen, C.E., R.N. Faux, B.A. Mclntosh, N.J. Paoge, and D.J. Norton. 2001. Airborne thermal remote sensing for water temperature assessment in rivers and streams. Remote Sensing of the Environment 76:386-398.

Turchin, P. 1998. Quantitative Analysis of Movement. Sunderland, MA, Sinauer Associates, Inc.

Vincent, E.R. 1987. Effects of stocking catchable-size rainbow trout in two wild trout species in the Madison River and O'Dell Creek, Montana. North American Journal of Fisheries Management 7:91-105.

Young, M.K. 1994. Brown trout mobility in south-central Wyoming streams. Canadian Journal of Zoology 72:2078-2083. 
Young, M.K. Telemetry-determined diurnal positions of brown trout (Salmo trutta) in two south-central Wyoming streams. 1995. American Midland Naturalist 133:264-273.

Young, M.K. 1996. Summer movements and habitat use by Colorado River cutthroat trout (Oncorhynchus clarki pleuriticus) in small, montane streams. Canadian Journal of Fisheries and Aquatic Sciences 53:14031408.

Welch, R., and M.M. Remillard. 1988. Remote sensing and geographic information system techniques for aquatic resource evaluation. Photogrammetric Engineering and Remote Sensing 54(2):177-185.

Welsh, H.H., G. R. Hodgson, and B.C. Harvey. 2001. Distribution of juvenile coho salmon in relation to water temperature in tributaries in the Mattole River, California. North American Journal of Fisheries Management 21:461-470.

West Virginia Department of Natural Resources Public Document. 2004. West Virginia Fishing Regulations for 2004.

White, G.C. and R.A. Garrott. 1990. Analysis of wildlife radio-tracking data. Academic Press.

Whitworth, W.E. and R.J. Strange. 1983. Growth and production of sympatric brook and rainbow trout in an Appalachian stream. Transactions of the American Fisheries Society 112:469-475.

Williams, J.E., C.A. Wood, and M.P. Dombeck, editors. 1997. Watershed restoration: principles and practices. AFS publication.

Winter, J.D. 1983. Underwater Biotelemetry in Fisheries Techniques. American Fisheries Society, Bethesda, Maryland.

Wootton, R.J. 1990. Ecology of teleost fishes. Chapman and Hall, London. 
Table 1. General summary statistics for the mainstem of the Shavers Fork and the circumneutral focus tributary, Rocky Run (Cheat Bridge served as the reference point for the mainstem, the mouth of Rocky Run served as its reference point for basin area calculations).

\begin{tabular}{|c|c|c|}
\hline Parameters & Rocky Run & Shavers Fork \\
\hline Basin Area $\left(\mathrm{km}^{2}\right)$ & 6.7 & 156 \\
\hline Wetted Width (m) & $8.3 \pm 1.6$ & $21.2 \pm 5.0$ \\
\hline Canopy cover (\%) & $70 \pm 3$ & $24 \pm 3$ \\
\hline $\mathrm{pH}$ & $6.4(5.6-7.2)$ & $6.7(6.2-7.4)$ \\
\hline $\begin{array}{c}\text { Alkalinity } \\
\text { (mg/L CaCO3) }\end{array}$ & $11.2(4-22.8)$ & $51.1(22-136)$ \\
\hline $\begin{array}{c}\text { Benthic Macroinvertebrate } \\
\text { Density }\left(\mathrm{m}^{2}\right)\end{array}$ & $2770(1800-3750)$ & $4866(2900-6100)$ \\
\hline $\begin{array}{l}\text { Benthic Macroinvertebrate } \\
\text { Biomass }\left(\mathrm{mgDM} / \mathrm{m}^{2}\right)\end{array}$ & $220(80-550)$ & $493(300-700)$ \\
\hline $\begin{array}{c}\text { Brook Trout Density } \\
\qquad \# / m\end{array}$ & $0.60(0.23-1.02)$ & $0.06(.025-0.10)$ \\
\hline $\begin{array}{l}\text { Brook trout } \\
\text { age structure - } \\
\text { YOY }(\%)\end{array}$ & & \\
\hline Small adults $(<150 \mathrm{~mm}, \%)$ & $\begin{array}{l}30 \% \\
54 \%\end{array}$ & $\begin{array}{l}14 \% \\
46 \%\end{array}$ \\
\hline Large adults $(>150 \mathrm{~mm}, \%)$ & $16 \%$ & $40 \%$ \\
\hline Fish Species Richness & 6 & 18 \\
\hline
\end{tabular}


Table 2. Temperature group divisions (1-6) applied to mainstem trout observations (spring/summer 2000-01). Divisions based on recorded ambient stream temperatures, differences between ambient and focal point temperatures, and documented behavioral thresholds of trout.

\begin{tabular}{ccc}
\hline Category & Ambient Temp & Focal Temp Difference \\
\hline${ }^{*}$ Not included & Cool $\left(<13^{\circ} \mathrm{C}\right)$ & $>1^{\circ} \mathrm{C}$ (positive) \\
1 & Cool $\left(<13^{\circ} \mathrm{C}\right)$ & $-1^{\circ} \mathrm{C}<$ difference $<1^{\circ} \mathrm{C}$ \\
2 & Ideal $\left(13.1-17^{\circ} \mathrm{C}\right)$ & $-1^{\circ} \mathrm{C}<$ difference $<1^{\circ} \mathrm{C}$ \\
3 & Warm $\left(17.1^{\circ} \mathrm{C}-20^{\circ} \mathrm{C}\right)$ & $-1^{\circ} \mathrm{C}<$ difference $<1^{\circ} \mathrm{C}$ \\
4 & Hot $\left(20.1^{\circ} \mathrm{C}-24^{\circ} \mathrm{C}\right)$ & $-1^{\circ} \mathrm{C}<$ difference $<1^{\circ} \mathrm{C}$ \\
5 & Warm $\left(17.1^{\circ} \mathrm{C}-20^{\circ} \mathrm{C}\right)$ & $>-1^{\circ} \mathrm{C}$ (negative) \\
6 & Hot $\left(20.1^{\circ} \mathrm{C}-24^{\circ} \mathrm{C}\right)$ & $>-1^{\circ} \mathrm{C}$ (negative) \\
\hline
\end{tabular}


Table 3. Summary statistics of water temperature and flow (stage height in feet above datum) data from the Shavers Fork mainstem (SH) and Rocky Run (RR) (temperature data only). Data are from the critical spring/summer sampling period $(6 / 5-8 / 15,2000-01)$. The drought year 1999 is included for comparison $(\mathrm{ND}=$ no data).

\begin{tabular}{lcccc}
\hline & RR 2001 & SH 1999 & SH 2000 & SH 2001 \\
\hline Avg Daily Max Temp ${ }^{\circ} \mathrm{C}$ & 15.2 & 21.5 & 19.0 & 19.2 \\
Max Recorded Ambient Temp ${ }^{\circ} \mathrm{C}$ & 18.7 & 27.8 & 23.3 & 24.4 \\
Avg 7-day Avg Daily Max Temp ${ }^{\circ} \mathrm{C}$ & 15.3 & 21.6 & 19.1 & 19.3 \\
Max 7-day Avg Daily Max Temp ${ }^{\circ} \mathrm{C}$ & 18.2 & 25.5 & 21.8 & 23 \\
\# Days Max Temp > $18^{\circ} \mathrm{C}$ & 5 & 63 & 51 & 48 \\
\# Days Max Temp > 20 ${ }^{\circ} \mathrm{C}$ & 0 & 55 & 24 & 30 \\
\# Days Max Temp $>22^{\circ} \mathrm{C}$ & 0 & 31 & 6 & 10 \\
Mean Daily Flow (ft above datum) & ND & 4.2 & 5.1 & 5.3 \\
\hline
\end{tabular}


Table 4. Summary statistics of water temperature and flow (stage height in feet above datum) data from the Shavers Fork mainstem (SH) and Rocky Run $(R R)$ (temperature data only). Data are from the fall sampling period $(9 / 5-11 / 15$, 2000) (ND = no data).

\begin{tabular}{lcc}
\hline & RR 2000 & SH 2000 \\
\hline Avg Daily Max Temp ${ }^{\circ} \mathrm{C}$ & 9.9 & 12.3 \\
Max Recorded Ambient Temp ${ }^{\circ} \mathrm{C}$ & 15.7 & 20.3 \\
Avg 7-day Avg Daily Max Temp ${ }^{\circ} \mathrm{C}$ & 10 & 12.4 \\
Max 7-day Avg Daily Max Temp ${ }^{\circ} \mathrm{C}$ & 15.1 & 18.2 \\
\# Days Max Temp $>18^{\circ} \mathrm{C}$ & 0 & 5 \\
\# Days Max Temp $>20^{\circ} \mathrm{C}$ & 0 & 1 \\
\# Days Max Temp $>22^{\circ} \mathrm{C}$ & 0 & 0 \\
Mean Daily Flow (ft above datum) & $\mathrm{ND}$ & 4.85 \\
\hline
\end{tabular}


Table 5. Summary statistics for nine prominent coldwater sources (CWSs) found within the Shavers Fork mainstem study area. The tributary Second Fork is included mainly as a reference for distance. Riverside reference is based on facing upstream (see Figure 8 to view the approximate locations of these nine CWSs on a map of the upper Shavers Fork drainage).

\begin{tabular}{ccccc}
\hline CWS \# & Name & $\begin{array}{c}\text { Distance from } \\
\text { Second Fork }(\mathrm{m})\end{array}$ & Riverside & $\begin{array}{c}\text { Basin area } \\
\left(\mathrm{km}^{2}\right)\end{array}$ \\
\hline- & Second Fork & 0 & Left & $12.5 \mathrm{~km}^{2}$ \\
1 & Unnamed CWS 1 & 2805 & Right & $0.63 \mathrm{~km}^{2}$ \\
2 & Unnamed CWS 2 & 2215 & Right & Part of \#1 \\
3 & Unnamed CWS 3 & 3005 & Right & Part of \#1 \\
4 & Rocky Run & 4195 & Right & $6.7 \mathrm{~km}^{2}$ \\
5 & Unnamed CWS 5 & 4788 & Right & $0.39 \mathrm{~km}^{2}$ \\
6 & Unnamed CWS 6 & 5111 & Left & $0.63 \mathrm{~km}^{2}$ \\
7 & Unnamed CWS 7 & 5385 & Left & Part of \#6 \\
8 & Unnamed CWS 8 & 6687 & Left & $0.34 \mathrm{~km}^{2}$ \\
9 & Shavers Fork & 8295 & mainstem & $22.5 \mathrm{~km}^{2}$ \\
\hline
\end{tabular}


Table 6. Track summary table by season $(B R K=$ brook trout, $B R N=$ brown trout).

\begin{tabular}{|c|c|c|c|c|}
\hline & Track & & No. of Fish Observed/Total & \\
\hline Season & No. & Date & Tagged & Locational or Diel \\
\hline \multirow[t]{16}{*}{ Spr./Summer 2000} & 1 & $6 / 15,16$ & $21 / 25$ (rain) & $\mathrm{L}$ \\
\hline & 2 & $6 / 19,20$ & 16/27 (rain) & L \\
\hline & 3 & $6 / 23,24$ & $24 / 28$ & $\mathrm{~L}$ \\
\hline & 4 & $6 / 26,27$ & $3 / 28$ & diel BRK \\
\hline & 5 & $7 / 1,2$ & $17 / 28$ & L \\
\hline & 6 & $7 / 5,6$ & $24 / 28$ & $\mathrm{~L}$ \\
\hline & 7 & $7 / 9,10$ & $26 / 28$ & $\mathrm{~L}$ \\
\hline & 8 & $7 / 13,14$ & $25 / 28$ & $\mathrm{~L}$ \\
\hline & 9 & $7 / 17,18$ & $3 / 28$ & diel BRK \\
\hline & 10 & $7 / 21,22$ & $20 / 28$ & $\mathrm{~L}$ \\
\hline & 11 & $7 / 25,26$ & $18 / 28$ & L \\
\hline & 12 & $7 / 29,30$ & $12 / 28$ & L \\
\hline & 13 & $8 / 2,3$ & $3 / 28$ & diel BRK \\
\hline & 14 & $8 / 6,7$ & $4 / 28$ & L \\
\hline & 15 & $8 / 10,11$ & $3 / 28$ & L \\
\hline & 16 & $8 / 15,16$ & $1 / 28$ & L \\
\hline \multirow[t]{26}{*}{ Spr./Summer 2001} & 1 & $6 / 8$ & $23 / 23$ & L \\
\hline & 2 & $6 / 12$ & $23 / 23$ & L \\
\hline & 3 & $6 / 16$ & $28 / 28$ & L \\
\hline & 4 & $6 / 18$ & $28 / 28$ & $\mathrm{~L}$ \\
\hline & 5 & $6 / 20$ & $28 / 28$ & L \\
\hline & 6 & $6 / 26$ & $27 / 28$ & L \\
\hline & 7 & $6 / 28$ & $27 / 28$ & L \\
\hline & 8 & $6 / 30$ & $4 / 28$ & diel BRK \\
\hline & 9 & $7 / 2$ & 0 (rained out) & L \\
\hline & 10 & $7 / 4$ & $4 / 28$ & diel BRN \\
\hline & 11 & $7 / 10$ & $26 / 28$ & L \\
\hline & 12 & $7 / 12$ & $26 / 28$ & L \\
\hline & 13 & $7 / 14$ & $25 / 28$ & $\mathrm{~L}$ \\
\hline & 14 & $7 / 16$ & $4 / 28$ & diel BRK \\
\hline & 15 & $7 / 18$ & $3 / 28$ & diel BRN \\
\hline & 16 & $7 / 20$ & $20 / 28$ & L \\
\hline & 17 & $7 / 24$ & $19 / 28$ & L \\
\hline & 18 & $7 / 26$ & $3 / 28$ & diel BRK \\
\hline & 19 & $7 / 28$ & $2 / 28$ & diel BRN \\
\hline & 20 & $7 / 30$ & 0 (rained out) & L \\
\hline & 21 & $8 / 1$ & $5 / 28$ & L \\
\hline & 22 & $8 / 3$ & $4 / 28$ & L \\
\hline & 23 & $8 / 5$ & $2 / 28$ & L \\
\hline & 24 & $8 / 11$ & $2 / 28$ & L \\
\hline & 25 & $8 / 13$ & $1 / 28$ & L \\
\hline & 26 & $8 / 15$ & $1 / 28$ & $\mathrm{~L}$ \\
\hline
\end{tabular}


Table 6. (cont'd)

\begin{tabular}{ccccc}
\hline Fall 2000 & 1 & $9 / 19,20$ & $28 / 28$ & $\mathrm{~L}$ \\
& 2 & $9 / 23,24$ & $3 / 28$ & diel BRK \\
3 & $9 / 28,29$ & $28 / 28$ & $\mathrm{~L}$ \\
4 & $10 / 3,4$ & $3 / 28$ & diel BRN \\
& 5 & $10 / 10,11$ & $28 / 28$ & $\mathrm{~L}$ \\
6 & $10 / 13,14$ & $28 / 28$ & diel BRK \\
7 & $10 / 16,17$ & $3 / 28$ & diel BRN \\
8 & $10 / 19,20$ & $3 / 28$ & $\mathrm{~L}$ \\
9 & $10 / 23,24$ & $28 / 28$ & $\mathrm{~L}$ \\
10 & $10 / 28,29$ & $20 / 28$ & diel BRK \\
11 & $11 / 3,4$ & $3 / 28$ & diel BRN \\
12 & $11 / 6,7$ & $2 / 28$ & $\mathrm{~L}$ \\
\hline
\end{tabular}


Table 7. Mean $( \pm$ SE) habitat availability and use by brook and brown trout in Rocky Run and Shavers Fork for all seasons, by stream. No brown trout were implanted with transmitters in spring/summer 2000, and none were ever tagged or located in Rocky Run during this study (ND = no data).

\begin{tabular}{|c|c|c|c|c|c|c|}
\hline & $\begin{array}{l}\text { Depth } \\
\mathrm{cm}\end{array}$ & $\begin{array}{l}\text { Avg. Current } \\
\text { Velocity } \\
\mathrm{cm} / \mathrm{s}\end{array}$ & $\begin{array}{c}\text { Focal Point } \\
\text { Current Velocity } \\
\mathrm{cm} / \mathrm{s}\end{array}$ & $\begin{array}{c}\text { Maximum } \\
\text { Current Velocity } \\
\mathrm{cm} / \mathrm{s}\end{array}$ & $\begin{array}{c}\text { Distance to } \\
\text { Cover } \\
\text { m }\end{array}$ & $\begin{array}{c}\text { Cover Type } \\
\text { B, W, B/W } \\
\%\end{array}$ \\
\hline \multicolumn{7}{|l|}{ Rocky Run } \\
\hline Availability & $11(0.9)$ & $15(1.3)$ & ND & ND & $1.0(0.7)$ & $65,23,12$ \\
\hline Brook Trout Spring 2000 & $15(0.8)$ & $19(1.6)$ & $16(1.2)$ & $38(1.5)$ & $1.8(0.3)$ & $79,18,3$ \\
\hline Brook Trout Spring 2001 & $18(0.9)$ & $26(1.0)$ & $23(1.0)$ & $36(1.2)$ & $0.3(0.1)$ & $67,5,28$ \\
\hline Brook Trout Fall 2000 & $17(0.4)$ & $23(0.6)$ & $19(0.4)$ & $29(0.4)$ & $0.8(.06)$ & $80,8,12$ \\
\hline \multicolumn{7}{|l|}{$\underline{\text { Shavers Fork }}$} \\
\hline Availability & $17(0.6)$ & $22(0.7)$ & ND & ND & $2.0(0.1)$ & $82,12,6$ \\
\hline Brook Trout Spring 2000 & $23(1.1)$ & $25(1.2)$ & $21(0.9)$ & $39(1.5)$ & $4.5(0.4)$ & $86,9,5$ \\
\hline Brook Trout Spring 2001 & $22(0.7)$ & $26(0.8)$ & $24(0.9)$ & $36(0.8)$ & $0.5(0.1)$ & $79,6,15$ \\
\hline Brook Trout Fall 2000 & $20(0.6)$ & $25(1.1)$ & $20(0.9)$ & $31(1.5)$ & $0.6(0.3)$ & $100,0,0$ \\
\hline Brown Trout Spring 2000 & ND & ND & ND & ND & ND & ND \\
\hline Brown Trout Spring 2001 & $23(1.2)$ & $24(1.2)$ & $20(1.11)$ & $35(1.11)$ & $0.6(0.1)$ & $90,0,10$ \\
\hline Brown Trout Fall 2000 & $19(0.6)$ & $24(0.7)$ & $19(0.7)$ & $30(0.8)$ & $1.0(0.2)$ & $100,0,0$ \\
\hline
\end{tabular}


Table 8. Summary and $X^{2}$ analysis statistics for temperature group divisions designated for mainstem brook trout (spring/summer 2000-01). Figures in temperature group cells represent the average followed by the standard error in parenthesis (NA = not applicable).

\begin{tabular}{ccccccc}
\hline $\begin{array}{c}\text { Temp. } \\
\text { group }\end{array}$ & $\begin{array}{c}\text { Sample } \\
\text { Size }\end{array}$ & Depth & $\begin{array}{c}\text { Avg. } \\
\text { Current } \\
\text { Velocity } \\
\text { cm/s }\end{array}$ & $\begin{array}{c}\text { Focal Point } \\
\text { Current } \\
\text { Velocity } \\
\text { cm/s }\end{array}$ & $\begin{array}{c}\text { Maximum } \\
\text { Current } \\
\text { Velocity } \\
\text { cm/s }\end{array}$ & $\begin{array}{c}\text { Distance to } \\
\text { Cover }\end{array}$ \\
\hline 1,2 & 85 & $22.4(0.9)$ & $26.6(1.1)$ & $21.9(0.8)$ & $38.9(1.3)$ & $3.2(0.4)$ \\
3,4 & 55 & $21.4(1.3)$ & $25.8(1.4)$ & $20.7(1.2)$ & $37.3(1.6)$ & $2.0(0.4)$ \\
5,6 & 25 & $20.3(2.0)$ & $24.3(1.7)$ & $19.9(1.6)$ & $34.4(2.0)$ & $1.6(0.4)$ \\
$X^{2}$ & NA & 5.4 & 2.5 & 9.5 & 5.1 & $24.8^{* *}$ \\
d.f. & NA & 8 & 6 & 6 & 8 & 6 \\
\hline$* *=p<0.01$ & & & & & &
\end{tabular}


Table 9. Summary statistics of brook trout and brown trout movement in the upper Shavers Fork watershed in Spring 2000. "Disp" is an abbreviation for dispersal. "Net Disp" considers movements up and downstream and is in meters. "Total Disp" is calculated on the basis of the absolute value of movement distance and is in meters. "Net Disp Rate" and "Tot Disp Rate" are in meters/day. "Days at Large" refers to the total number of days that an individual was known to persist in the study area. The $t$ - and $p$-values are statistics from tests for whether trout exhibited a tendency to move up or down stream. Significant values (i.e., $p<0.05$ ) indicate a tendency to move upstream.

\begin{tabular}{lcccccccc}
\multicolumn{1}{l}{ Brook Trout in Rocky Run } & N & Mean & SE & Median & Min & Max & t-value & p-value \\
\hline Length & 9 & 199 & 6.2 & 196 & 174 & 225 & & \\
Net Disp & 9 & 41 & 37 & 32 & -154 & 272 & & \\
Net Disp Rate & 9 & 1.0 & 1.0 & 0.6 & -3.9 & 7.6 & 0.97 & 0.36 \\
Tot Disp & 9 & 133 & 30.4 & 76.0 & 39.0 & 278.0 & & \\
Tot Disp Rate & 9 & 3.3 & 1.0 & 2.1 & 1.0 & 7.7 & & \\
Days at Large & 9 & 42 & 4.0 & 40 & 23 & 65 & & \\
\hline
\end{tabular}

Brook Trout in Shavers Fork

\begin{tabular}{lcccccccc}
\hline & $\mathrm{N}$ & Mean & SE & Median & Min & Max & t-value & p-value \\
\hline Length & 14 & 197 & 3.6 & 195 & 174 & 224 & & \\
Net Disp & 14 & 2,318 & 458 & 2,122 & 31 & 6,489 & & \\
Net Disp Rate & 14 & 62 & 11 & 57 & 0.6 & 143 & 5.6 & .0001 \\
Tot Disp & 14 & 2,362 & 449 & 2,142 & 219 & 6,515 & & \\
Tot Disp Rate & 14 & 63 & 11 & 58 & 6 & 143 & & \\
Days at Large & 14 & 38 & 2.8 & 38 & 20 & 61 & & \\
\hline
\end{tabular}


Table 10. Summary statistics of brook trout and brown trout movement in the upper Shavers Fork watershed in Spring 2001. "Disp" is an abbreviation for dispersal. "Net Disp" considers movements up and downstream and is in meters. "Total Disp" is calculated on the basis of the absolute value of movement distance and is in meters. "Net Disp Rate" and "Tot Disp Rate" are in meters/day. "Days at Large" refers to the total number of days that an individual was known to persist in the study area. The $t$ - and $p$-values are statistics from tests for whether trout exhibited a tendency to move up or down stream. Significant values (i.e., $\mathrm{p}<0.05$ ) indicate a tendency to move upstream.

\begin{tabular}{lcccccccc}
\multicolumn{1}{l}{ Brook Trout in Rocky Run } & $\mathrm{N}$ & Mean & SE & Median & Min & Max & t-value & p-value \\
\hline Length & 4 & 198 & 6.7 & 200 & 180 & 212 & & \\
Net Disp & 4 & 158 & 106 & 58 & 39 & 478 & & \\
Net Disp Rate & 4 & 3.2 & 1.6 & 1.8 & 1.0 & 8.0 & 1.95 & 0.15 \\
Tot Disp & 4 & 175 & 121 & 62 & 39 & 538 & & \\
Tot Disp Rate & 4 & 3.5 & 1.9 & 2.0 & 1.0 & 9.0 & & \\
Days at Large & 4 & 41 & 7 & 38 & 28 & 60 & & \\
\hline
\end{tabular}

Brook Trout in Shavers Fork

\begin{tabular}{lcccccccc}
\hline & $\mathrm{N}$ & Mean & SE & Median & Min & Max & t-value & p-value \\
\hline Length & 13 & 189 & 6.1 & 191 & 137 & 222 & & \\
Net Disp & 13 & 1,226 & 308 & 1,273 & -254 & 2,780 & & \\
Net Disp Rate & 13 & 26.6 & 6.4 & 28.1 & -5.5 & 57.9 & 4.12 & 0.001 \\
Tot Disp & 13 & 1,723 & 342 & 1,856 & 84 & 3,654 & & \\
Tot Disp Rate & 13 & 39.0 & 7.3 & 40.3 & 1.5 & 76.7 & & \\
Days at Large & 13 & 45 & 3.0 & 46 & 20 & 64 & & \\
\hline
\end{tabular}

Brown Trout in Shavers Fork

\begin{tabular}{lcccccccc}
\hline & N & Mean & SE & Median & Min & Max & t-value & p-value \\
\hline Length & 8 & 238 & 11 & 237 & 184 & 279 & & \\
Net Disp & 8 & 808 & 233 & 798 & -5.0 & 2,051 & & \\
Net Disp Rate & 8 & 18.9 & 4.5 & 20.4 & -0.1 & 36.6 & 4.19 & 0.004 \\
Tot DIsp & 8 & 1,274 & 345 & 1,119 & 13.0 & 2,688 & & \\
Tot Disp Rate & 8 & 29.8 & 8.06 & 25.5 & 0.4 & 74.7 & & \\
Days at Large & 8 & 42 & 3.9 & 44 & 20 & 56 & & \\
\hline
\end{tabular}


Table 11. Summary statistics of brook trout and brown trout movement in the upper Shavers Fork watershed in Fall 2000. "Disp" is an abbreviation for dispersal. "Net Disp" considers movements up and downstream and is in meters. "Total Disp" is calculated on the basis of the absolute value of movement distance and is in meters. "Net Disp Rate" and "Tot Disp Rate" are in meters/day. "Days at Large" refers to the total number of days that an individual was known to persist in the study area. The $t$ - and $p$-values are statistics from tests for whether trout exhibited a tendency to move up or down stream. Significant values (i.e., $\mathrm{p}<0.05$ ) indicate a tendency to move upstream.

\begin{tabular}{lcccccccc}
\multicolumn{1}{l}{ Brook Trout in Rocky Run } & N & Mean & SE & Median & Min & Max & t-value & p-value \\
\hline Length & 16 & 199 & 6.8 & 190 & 169 & 285 & & \\
Net Disp & 16 & 194 & 129 & 3.0 & -2.0 & 2,000 & & \\
Net Disp Rate & 16 & 5.4 & 3.7 & 0.1 & -0.1 & 58.8 & 1.45 & 0.17 \\
Tot Disp & 16 & 202 & 129 & 5.0 & 1.0 & 2,000 & & \\
Tot Disp Rate & 16 & 5.6 & 3.7 & 0.1 & 0 & 58.8 & & \\
Days at Large & 16 & 38 & 2 & 38 & 26 & 52.0 & & \\
\hline
\end{tabular}

Brook Trout in Shavers Fork

\begin{tabular}{lcccccccc}
\hline & N & Mean & SE & Median & Min & Max & t-value & p-value \\
\hline Length & 2 & 162 & 1.0 & 162 & 161 & 163 & & \\
Net Disp & 2 & 4.0 & 3.0 & 4.0 & 1.0 & 7.0 & & \\
Net Disp Rate & 2 & 0.1 & 0.1 & 0.1 & 0.01 & 0.2 & 1.33 & 0.41 \\
Tot Disp & 2 & 21 & 12 & 21 & 9.0 & 33 & & \\
Tot Disp Rate & 2 & 0.4 & 0.2 & 0.4 & 0.2 & 0.6 & & \\
Days at Large & 2 & 47 & 7 & 47 & 40 & 54 & & \\
\hline
\end{tabular}

Brown Trout in Shavers Fork

\begin{tabular}{lcccccccc}
\hline & $\mathrm{N}$ & Mean & SE & Median & Min & Max & t-value & p-value \\
\hline Length & 10 & 169 & 13 & 158 & 119 & 231 & & \\
Net Disp & 10 & 4.9 & 2.7 & 4.5 & -6.0 & 21.0 & & \\
Net Disp Rate & 10 & 0.1 & 0.1 & 0.1 & -0.2 & 0.6 & 1.53 & 0.16 \\
Tot Disp & 10 & 10.1 & 2.0 & 9.5 & 0.0 & 21.0 & & \\
Tot Disp Rate & 10 & 0.3 & 0.1 & 0.3 & 0.0 & 0.6 & & \\
Days at Large & 10 & 37 & 3 & 34 & 24 & 54 & & \\
\hline
\end{tabular}


Table 12. Summary statistics for mean total dispersal rate comparisons by season, stream, and species (RR=Rocky Run, $\mathrm{SF}=$ Shavers Fork mainstem (BRK=Brook trout, $\mathrm{BRN}=$ Brown trout).

\begin{tabular}{cccc}
\hline Comparison & F & d.f. & p \\
\hline RR vs SF (Spr./Summer 00) & 58.22 & 1,22 & 0.0001 \\
RR vs SF (Spr./Summer 01) & 13.06 & 1,16 & 0.003 \\
RR vs SF (Fall 00) & 0.2 & 1,17 & 0.66 \\
BRK vs BRN (Spr./Summer 01) & 0.38 & 1,20 & 0.54 \\
BRK vs BRN (Fall 00) & 0.78 & 1,11 & 0.40 \\
Among Seasons (BRK/RR) & 1.13 & 2,28 & 0.34 \\
Among Seasons (BRK/SF) & 12.1 & 2,28 & 0.002 \\
Among Seasons (BRN/SF) & 53.09 & 1,17 & 0.0001 \\
\hline
\end{tabular}


Figure 1. Map of the Shavers Fork of the Cheat River, West Virginia. The upper Shavers Fork is denoted by the olive shading in the headwaters.

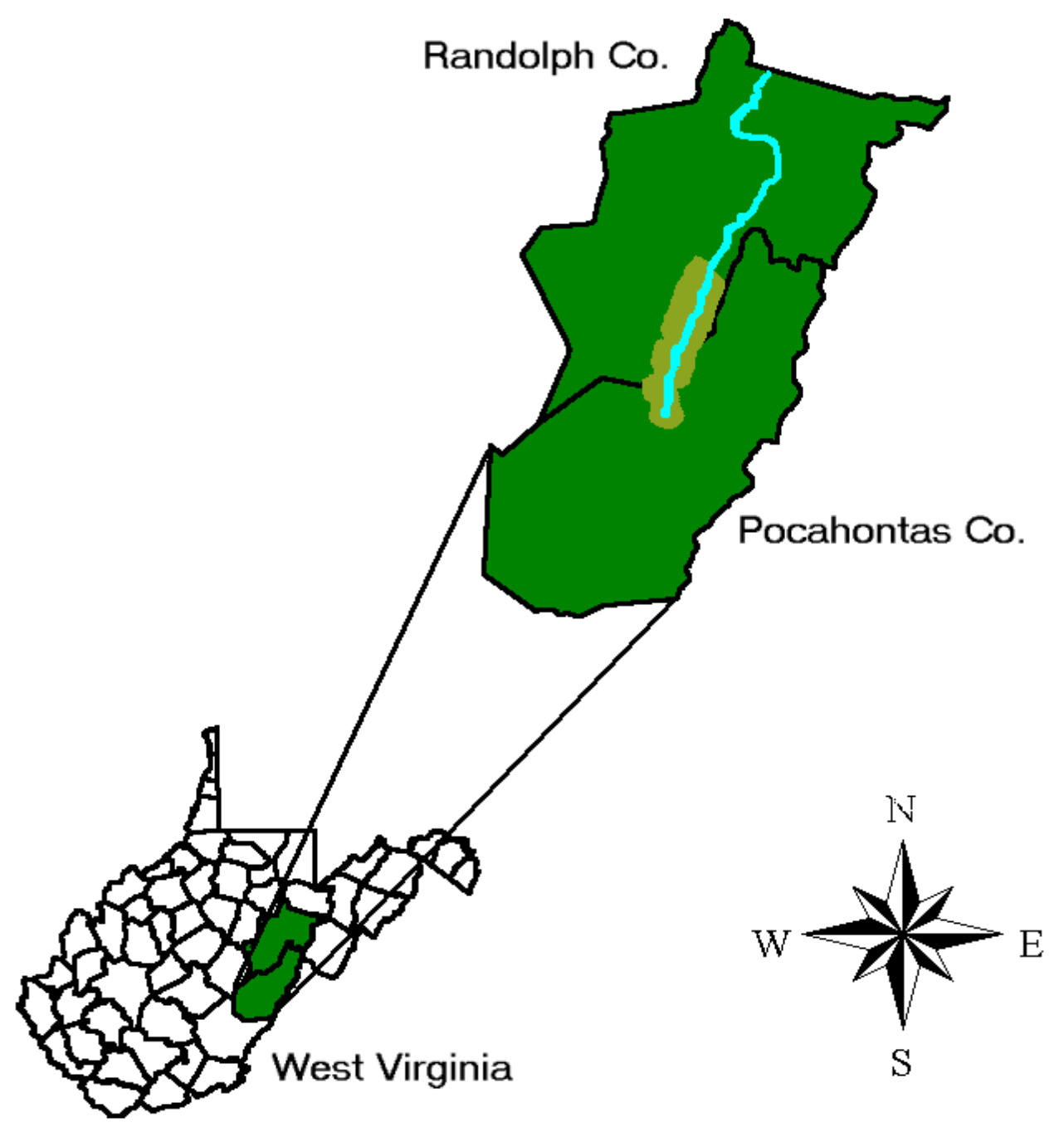


Figure 2. Map illustrating the upper Shavers Fork watershed with the focus tributary Rocky Run and the surrounding mainstem highlighted.

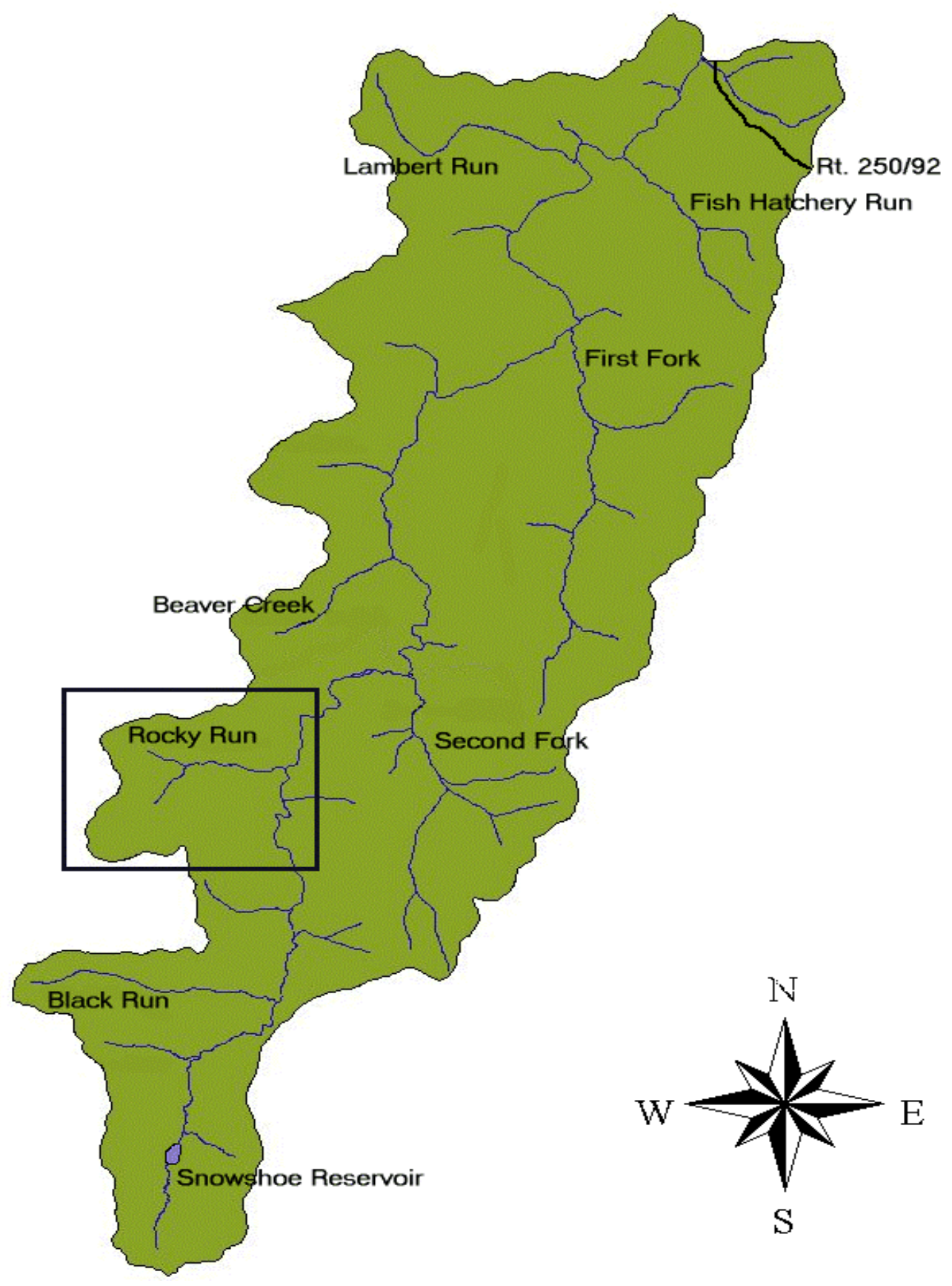


Figure 3. Telemetry study sites on Rocky Run, and the mainstem of the upper Shavers Fork of the Cheat River, West Virginia. Red lines represent upper and lower boundaries of 1-km experimental reaches on the mainstem and Rocky Run. These reaches are where fish were initially captured, tagged, and released. Subsequent tracking extended well outside of this area when necessary, especially upstream on the Shavers Fork mainstem. Purple dashes represent the positioning of temperature loggers in Spring 2001. (1:24000 scale)

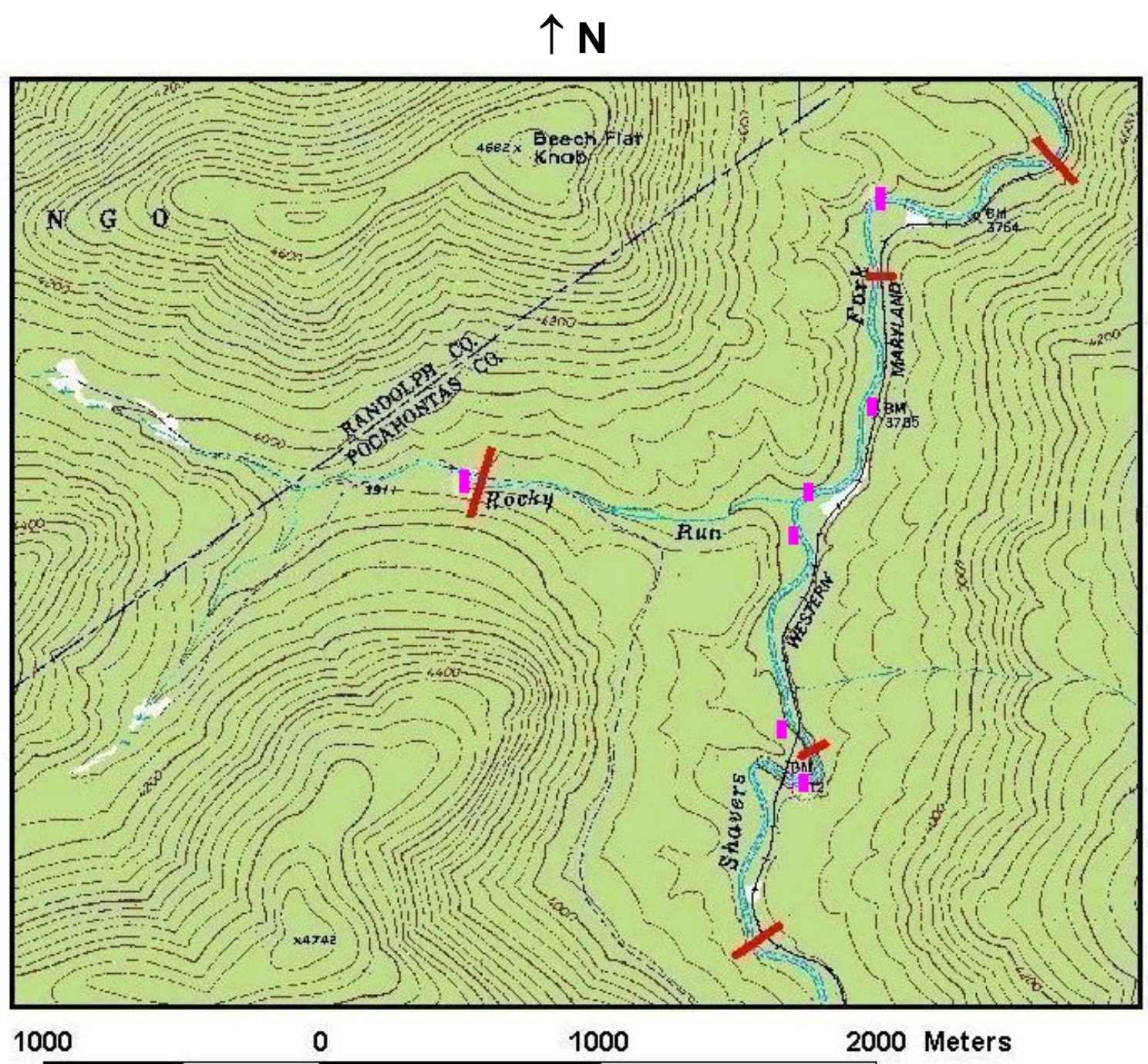


Figure 4. Year-to-year variation in mean daily flow of the Shavers Fork mainstem as measured at the Cheat Bridge gage station (USGS). Data are from the critical spring/summer sampling periods $(6 / 5-8 / 15,2000-01)$.

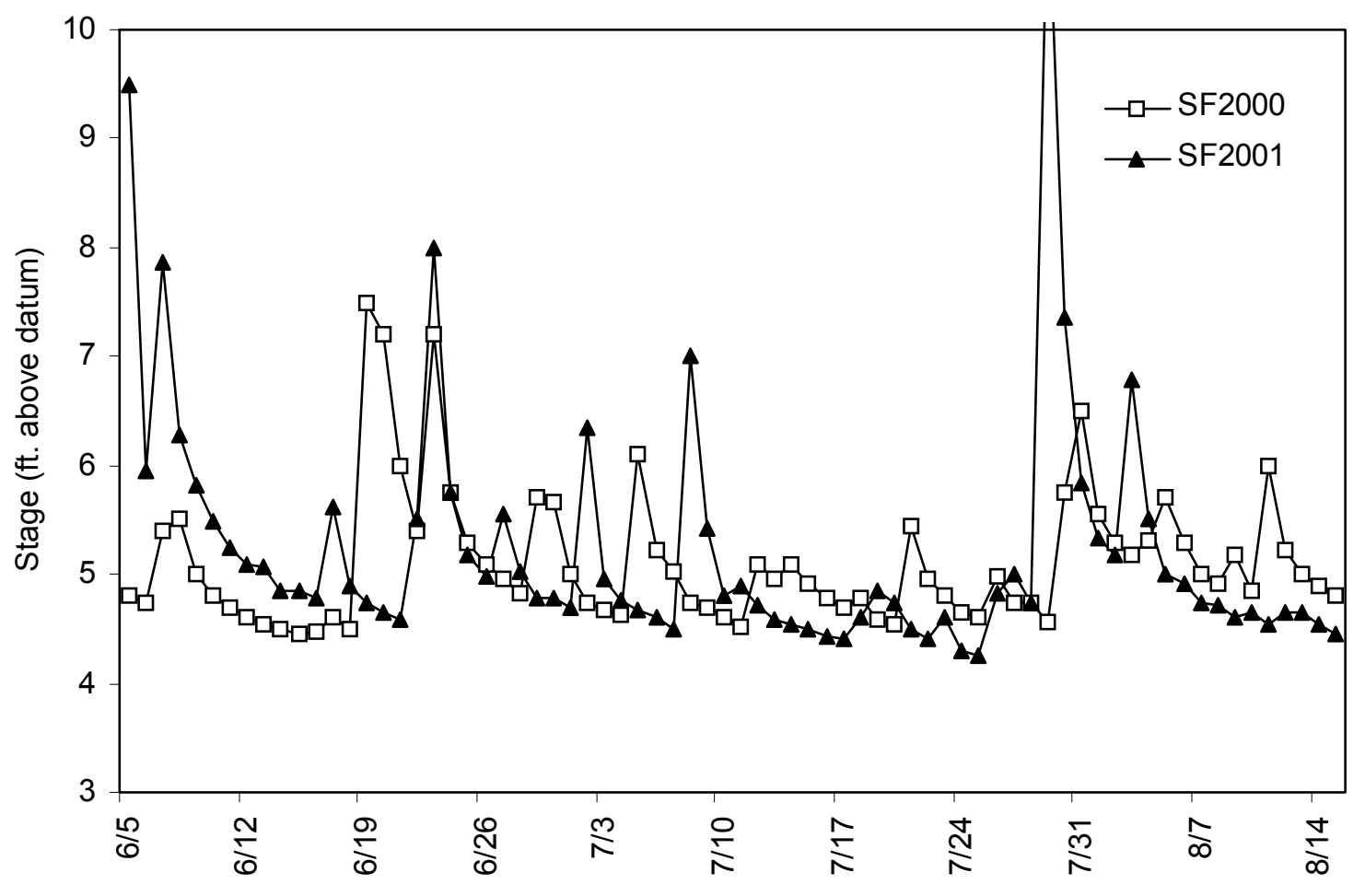


Figure 5. Year-to-year variation in mean daily flow of the Shavers Fork mainstem as measured at the Cheat Bridge gage station (USGS). Data are from the fall sampling period $(9 / 5-11 / 15,2000)$.

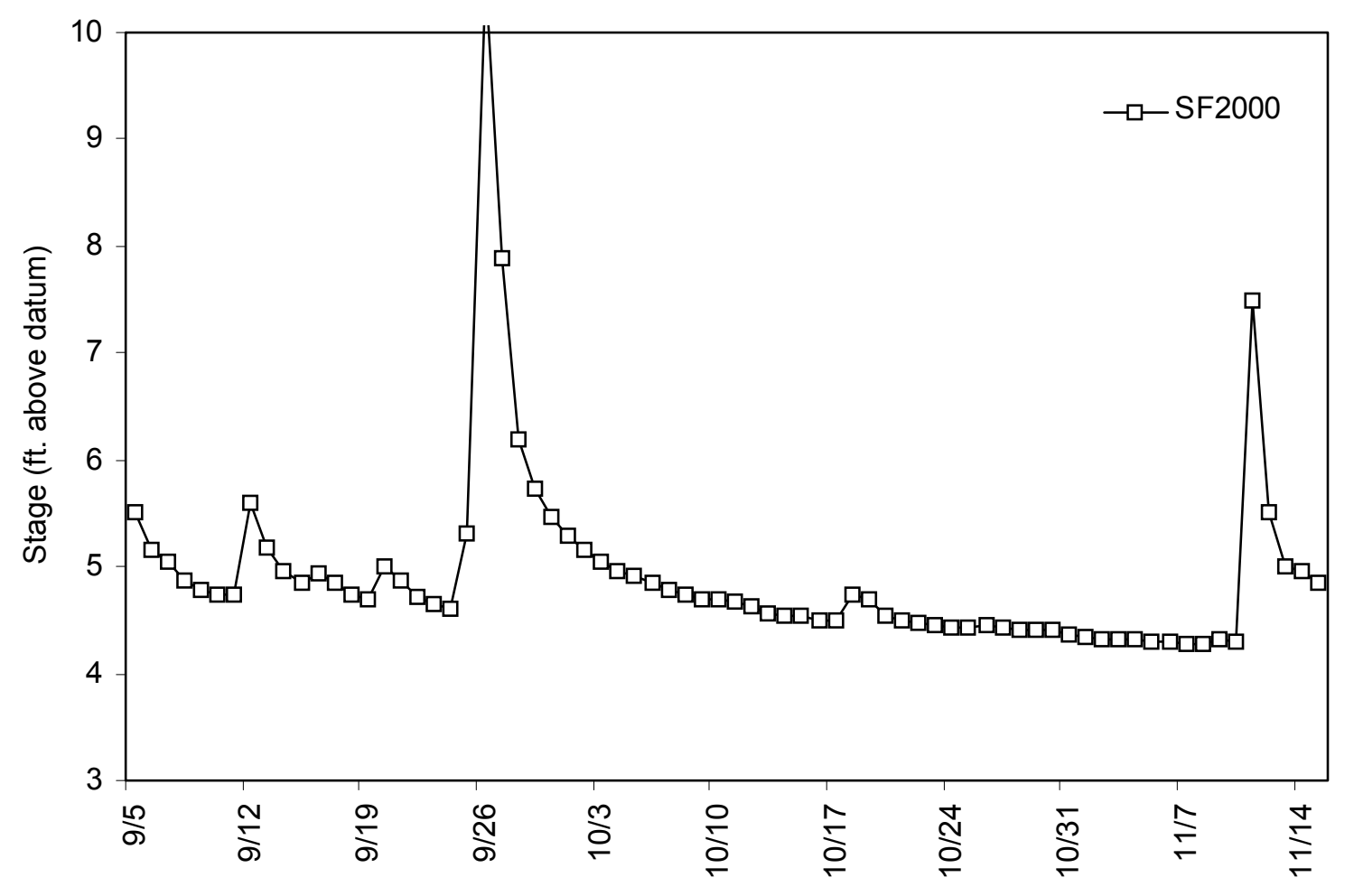


Figure 6. Year-to-year variation in the daily maximum water temperature measured in the Shavers Fork mainstem and Rocky Run. Data are from the critical spring/summer sampling periods $(6 / 5-8 / 15,2000-01)$. The dashed line indicates an important threshold temperature $\left(22^{\circ} \mathrm{C}\right)$ delineating intuitive coldwater systems from cool and warmwater systems.

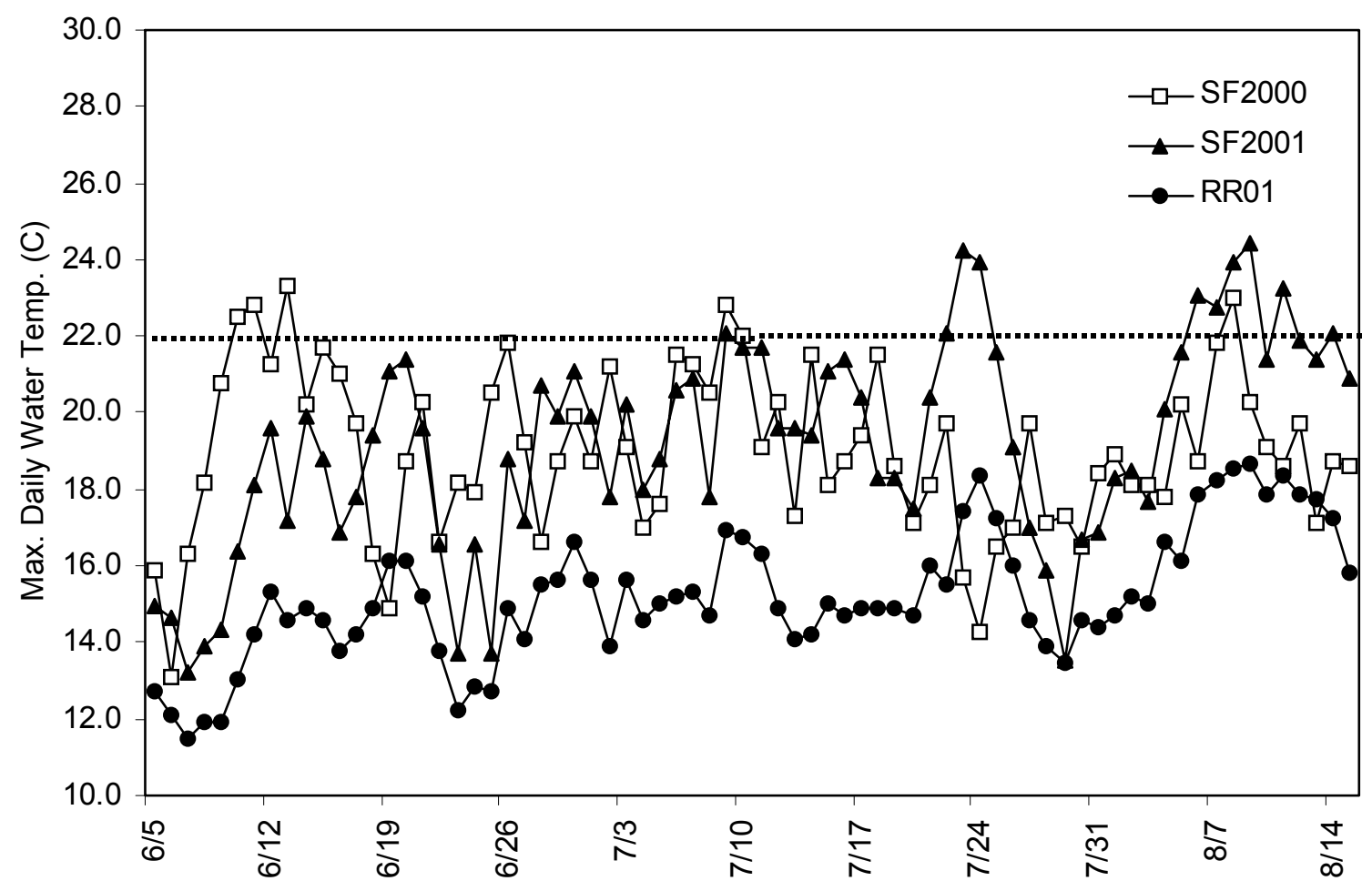


Figure 7. Year-to-year variation in the 7-day average maximum water temperature measured in the Shavers Fork mainstem and Rocky Run during the critical spring/summer sampling periods (2000-01). The dashed line indicates an important threshold temperature $\left(22^{\circ} \mathrm{C}\right)$ delineating intuitive coldwater systems from cool and warmwater systems. The drought year of 1999 is included for comparison purposes.

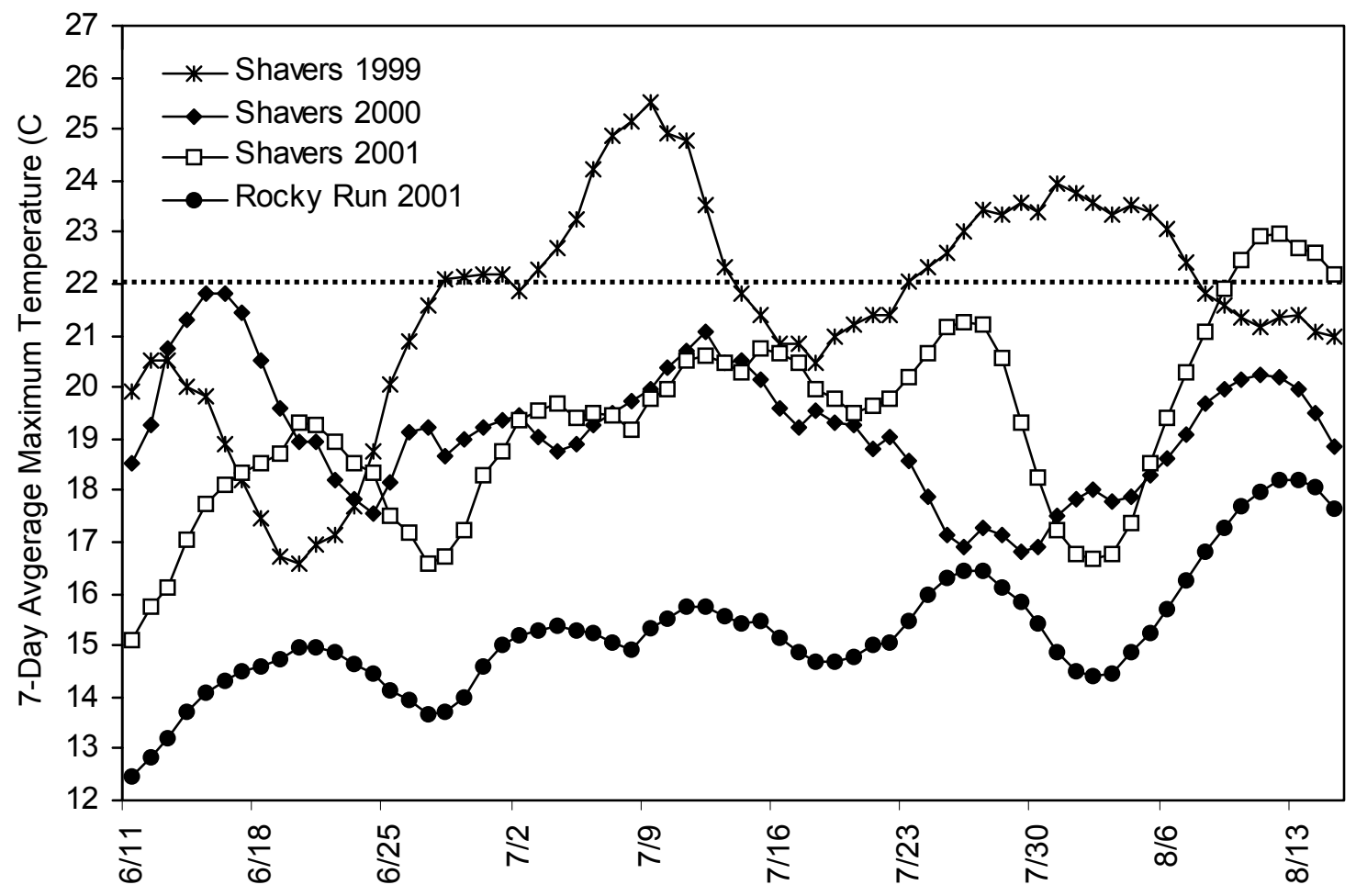


Figure 8. Relationship between maximum daily water temperature and mean daily flow during summer months for the Shavers Fork mainstem. The dashed line represents a temperature $\left(20^{\circ} \mathrm{C}\right)$ above to which trout showed a strong behavior response. This temperature occurs regularly at flows $<5.5 \mathrm{ft}$. The drought year 1999 is included for comparison purposes.
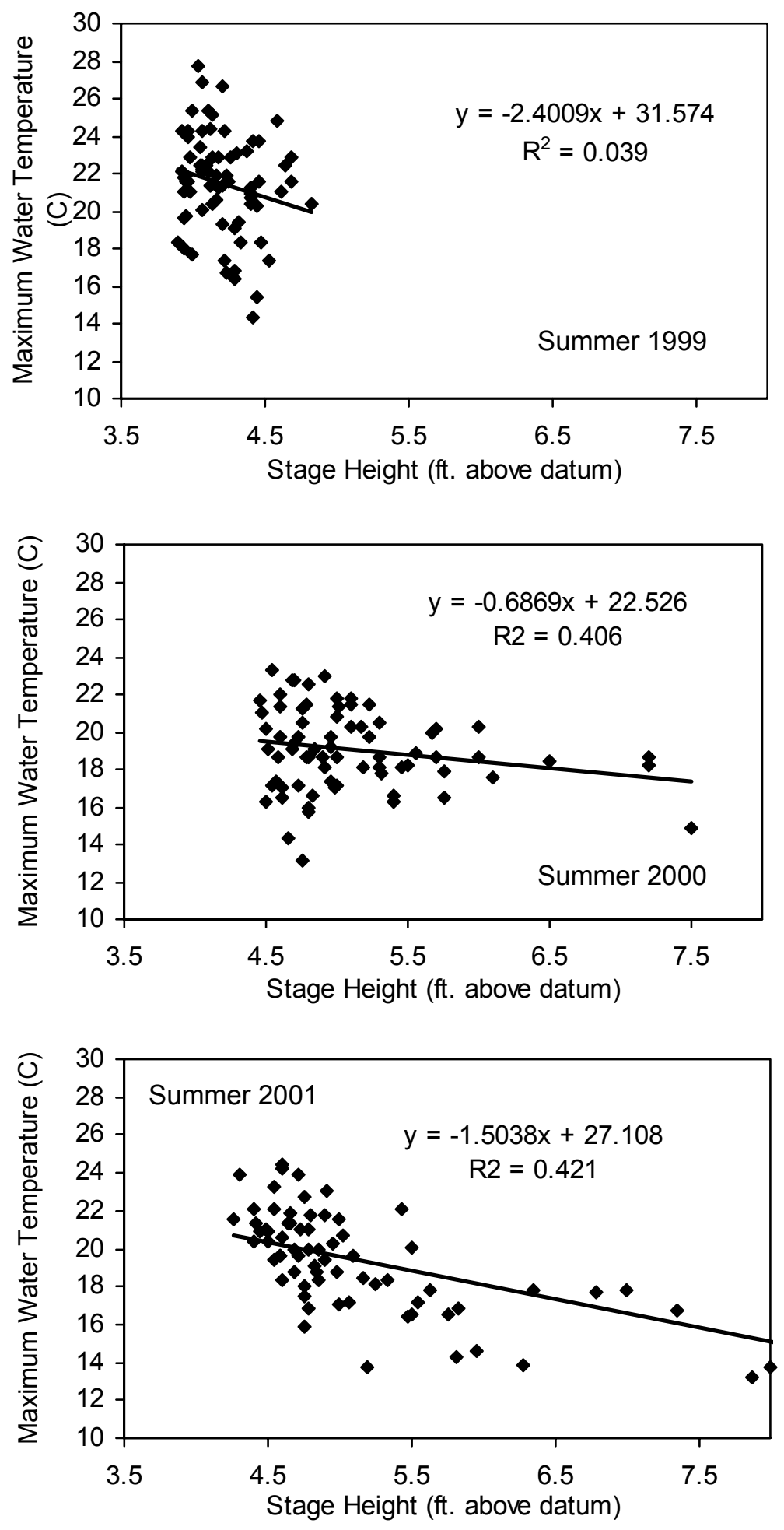
Figure 9. Year-to-year variation in the daily maximum water temperature measured in the Shavers Fork mainstem and Rocky Run. Data are from the fall sampling period $(9 / 5-11 / 15,2000)$.

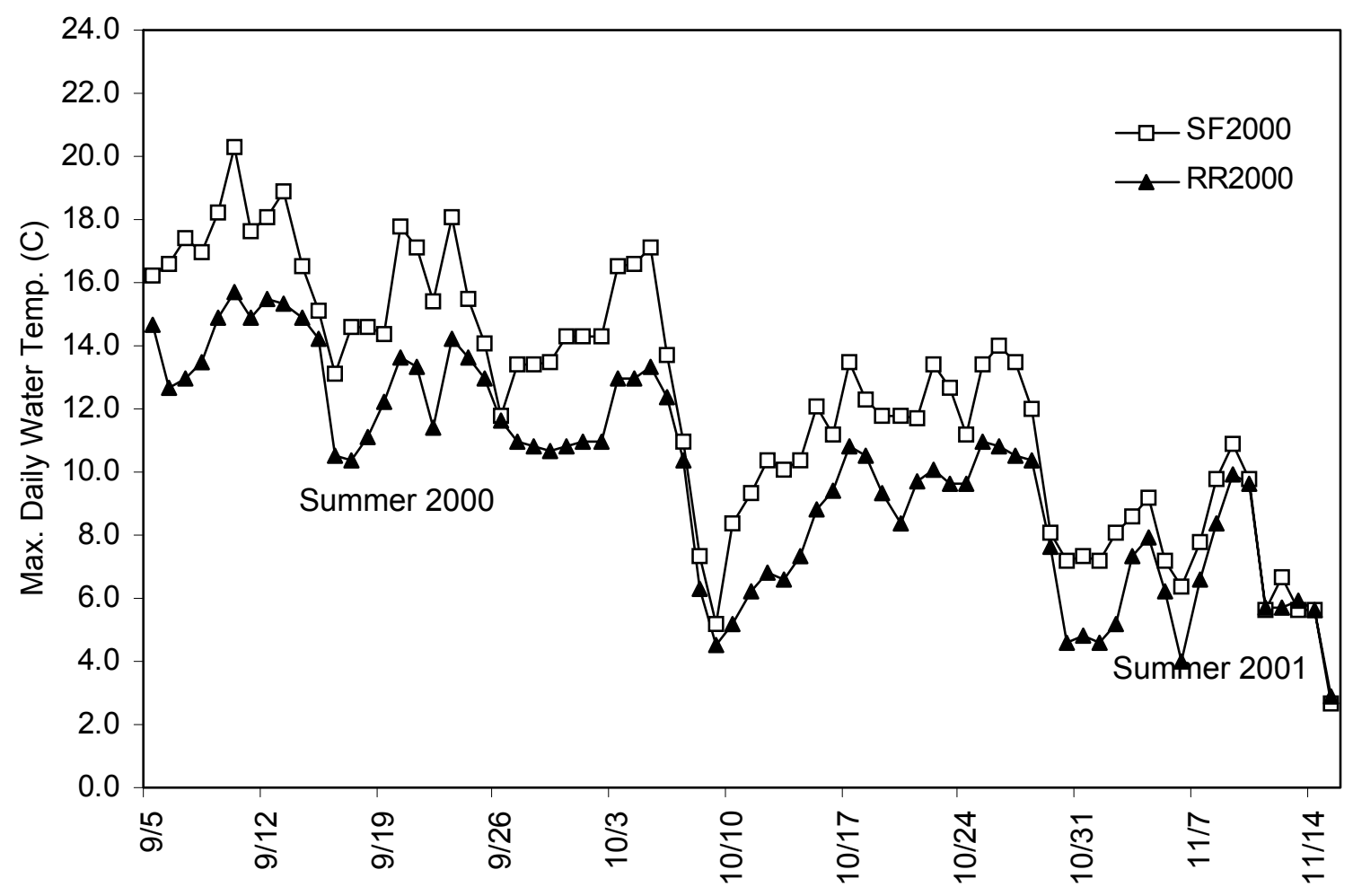


Figure 10. Imagery showing approximate locations of nine prominent CWSs within the upper Shavers Fork determined through field observations and arcGIS. Numbers on the map corresponds to the side of the river the CWS enters the mainstem (except for \#9 which is the mainstem of the Shavers Fork above Spruce. See Table 4 for further statistics on these CWSs. (1:20000 scale)

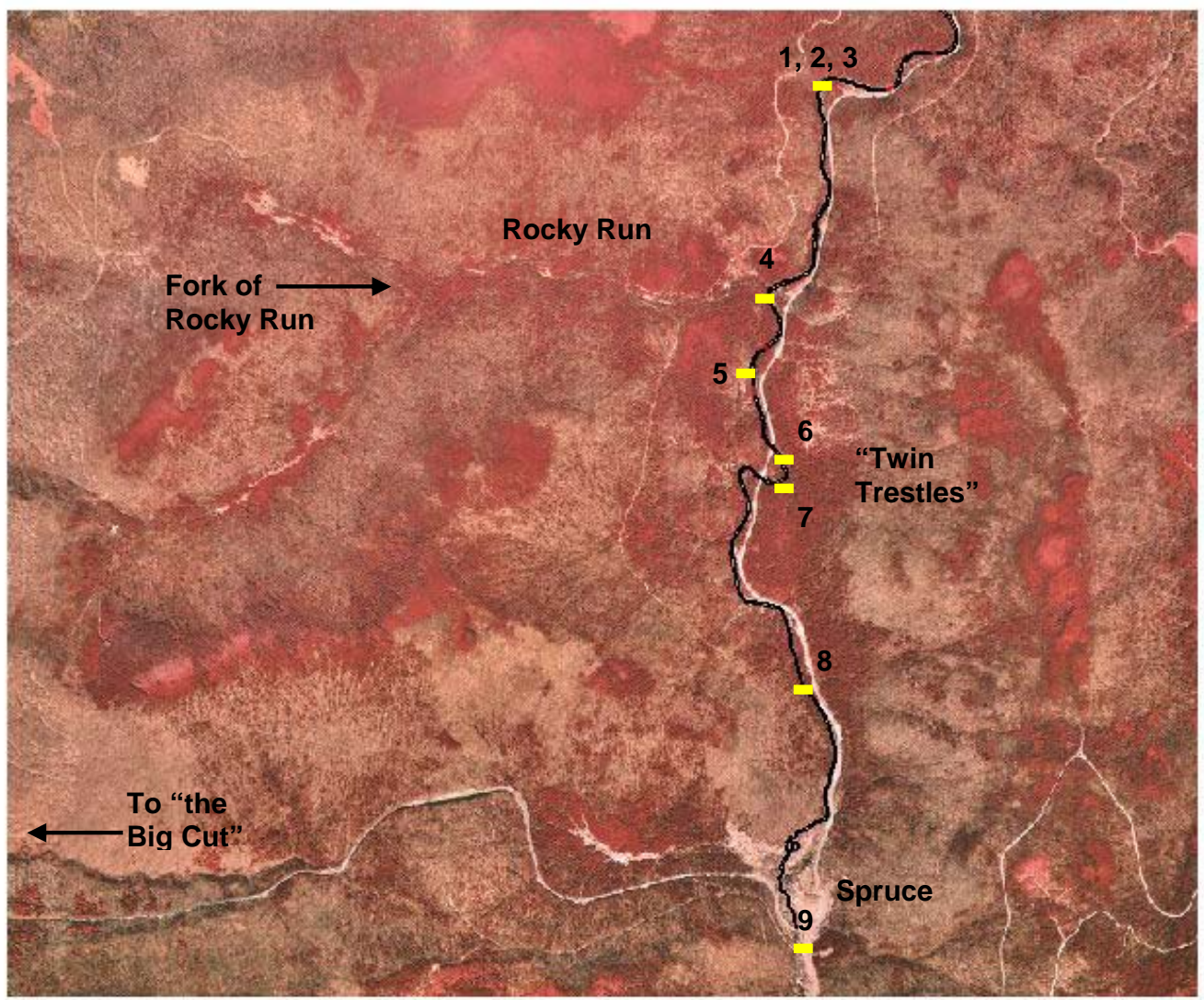

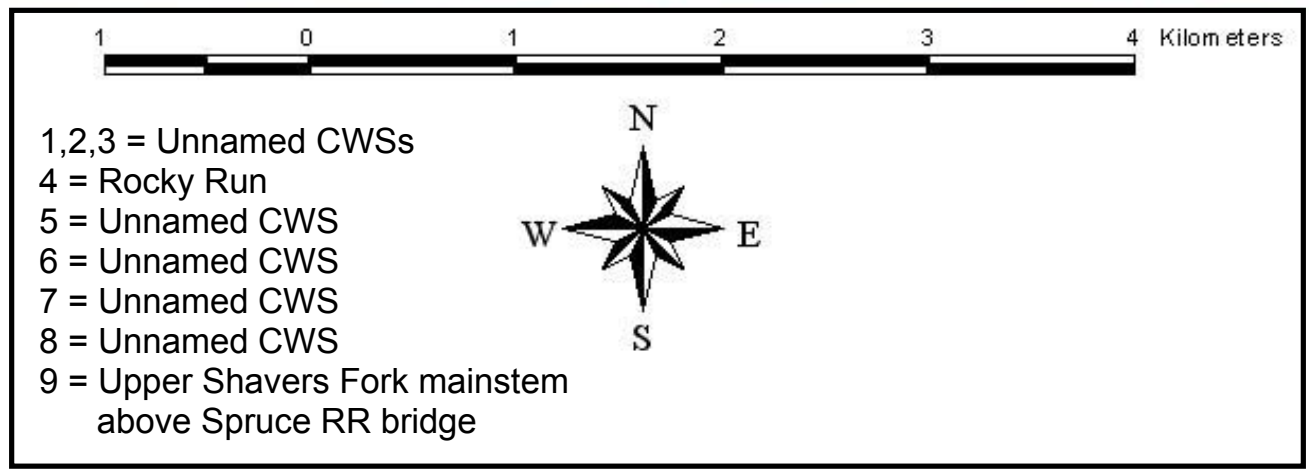


Figure 11. Hydraulic channel unit (HCU) use by trout and availability in Rocky Run and Shavers Fork, spring/summer 2000 (PW = pocket water, Riffle $/$ Run = riffle run complex). Also present are results of $X^{2}$ analysis comparing use to availability.
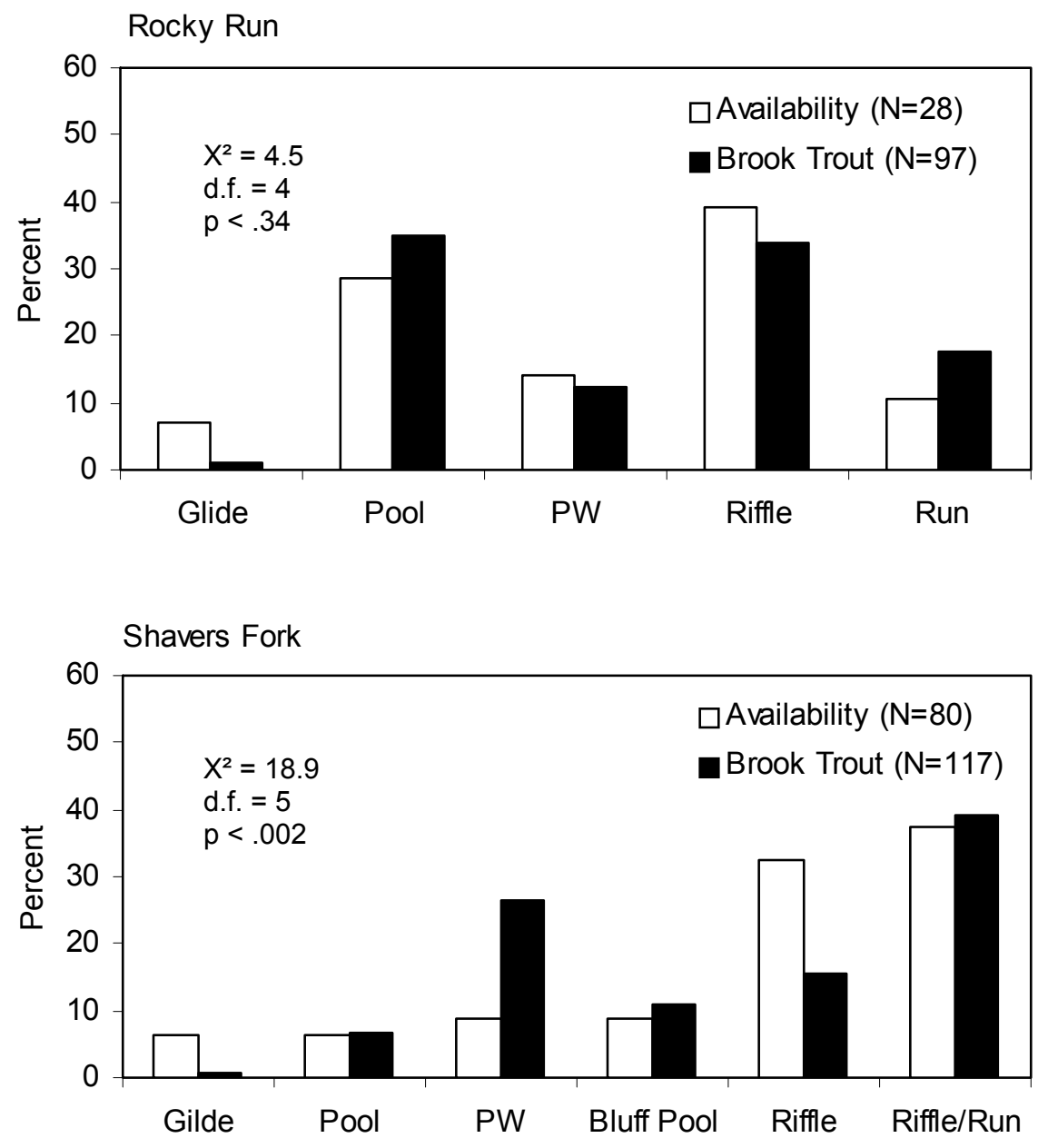
Figure 12. Hydraulic channel unit (HCU) use by trout and availability in Rocky Run and Shavers Fork, spring/summer 2001 (PW = pocket water, Riffle $/$ Run = riffle run complex). Also present are results of $X^{2}$ analysis comparing use to availability.
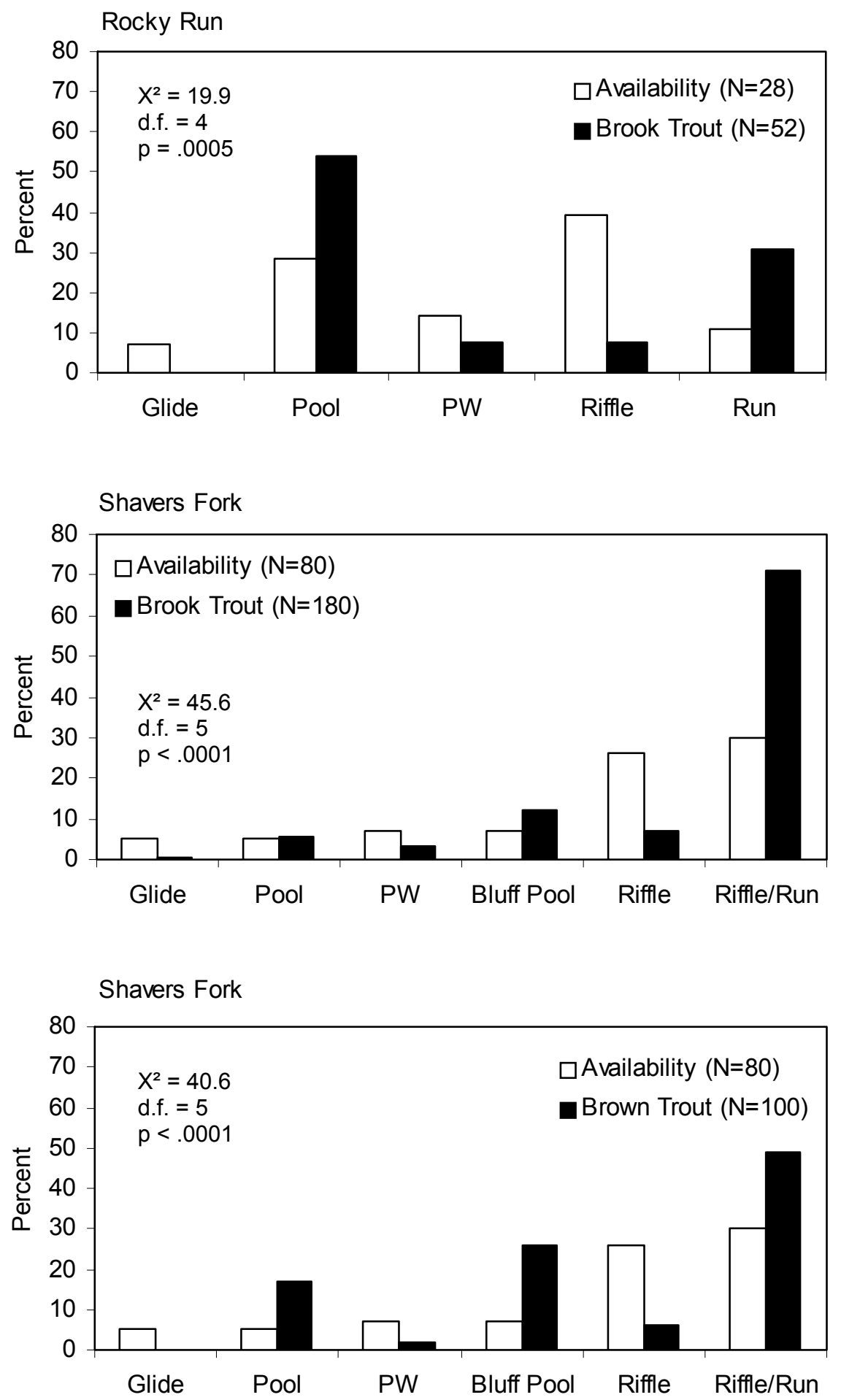
Figure 13. Hydraulic channel unit (HCU) use by trout and availability in Rocky Run and Shavers Fork, fall 2000 (PW = pocket water, Riffle /Run = riffle run complex). Also present are results of $\mathrm{X}^{2}$ analysis comparing use to availability.
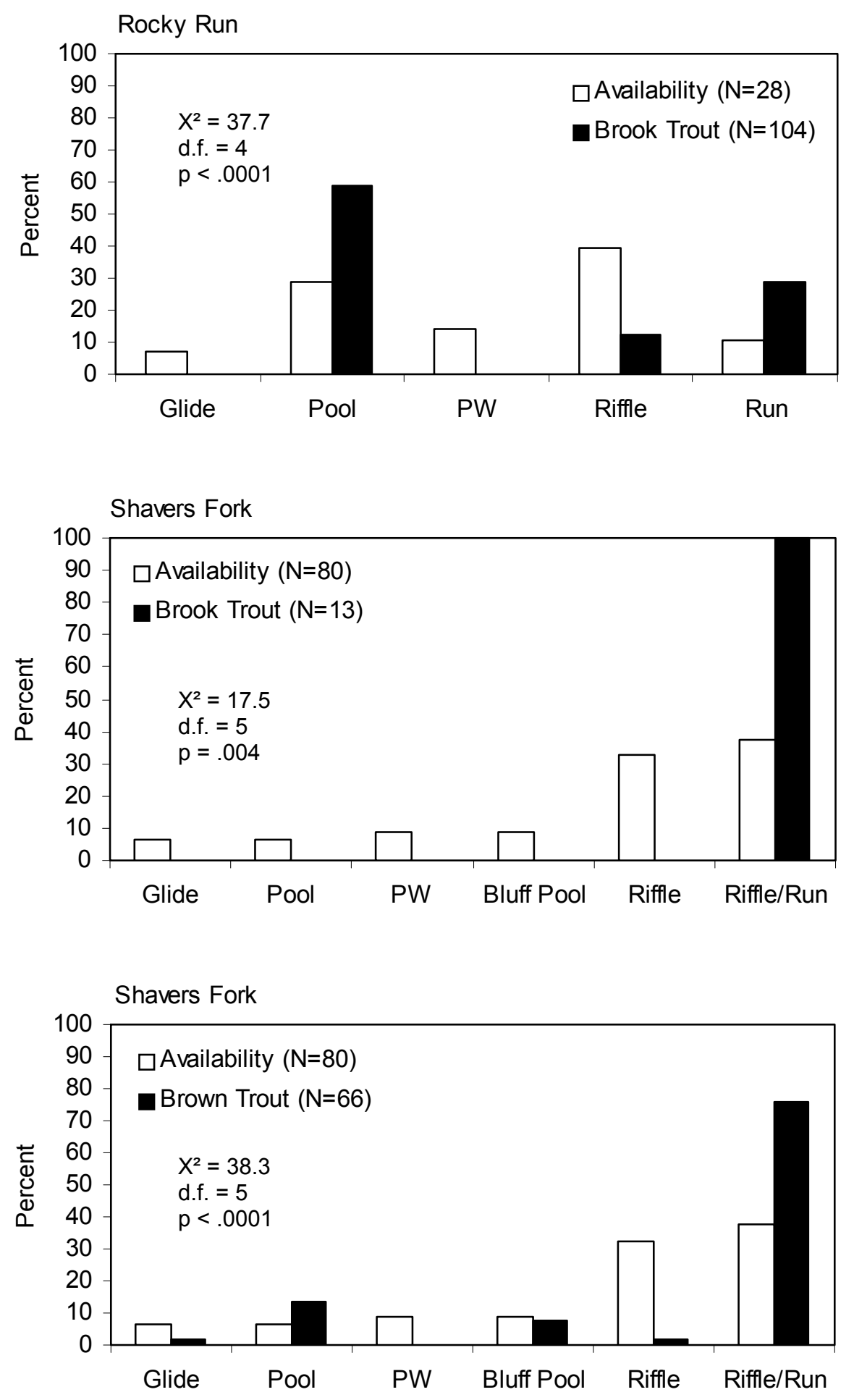
Figure 14. Microhabitat use by trout and availability of water depth (D) in Rocky Run and Shavers Fork, spring/summer 2000. The arrow refers to the mean depth used, the asterisk refers to mean availability. Also present are results of $X^{2}$ analysis comparing use to availability.
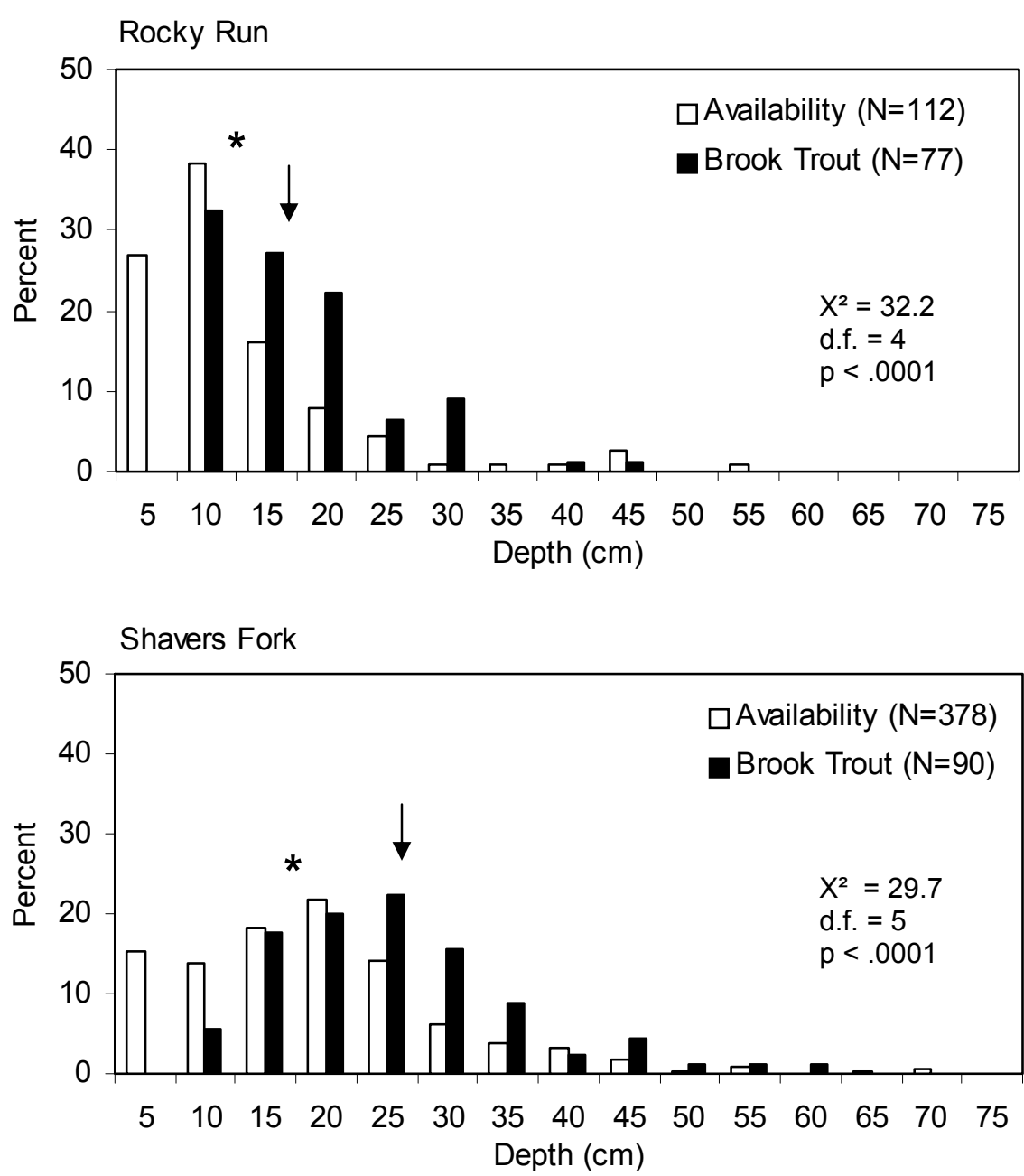
Figure 15. Microhabitat use by trout and availability of water depth (D) in Rocky Run and Shavers Fork, spring/summer 2001. The arrow refers to the mean depth used, the asterisk refers to mean availability. Also present are results of $X^{2}$ analysis comparing use to availability.
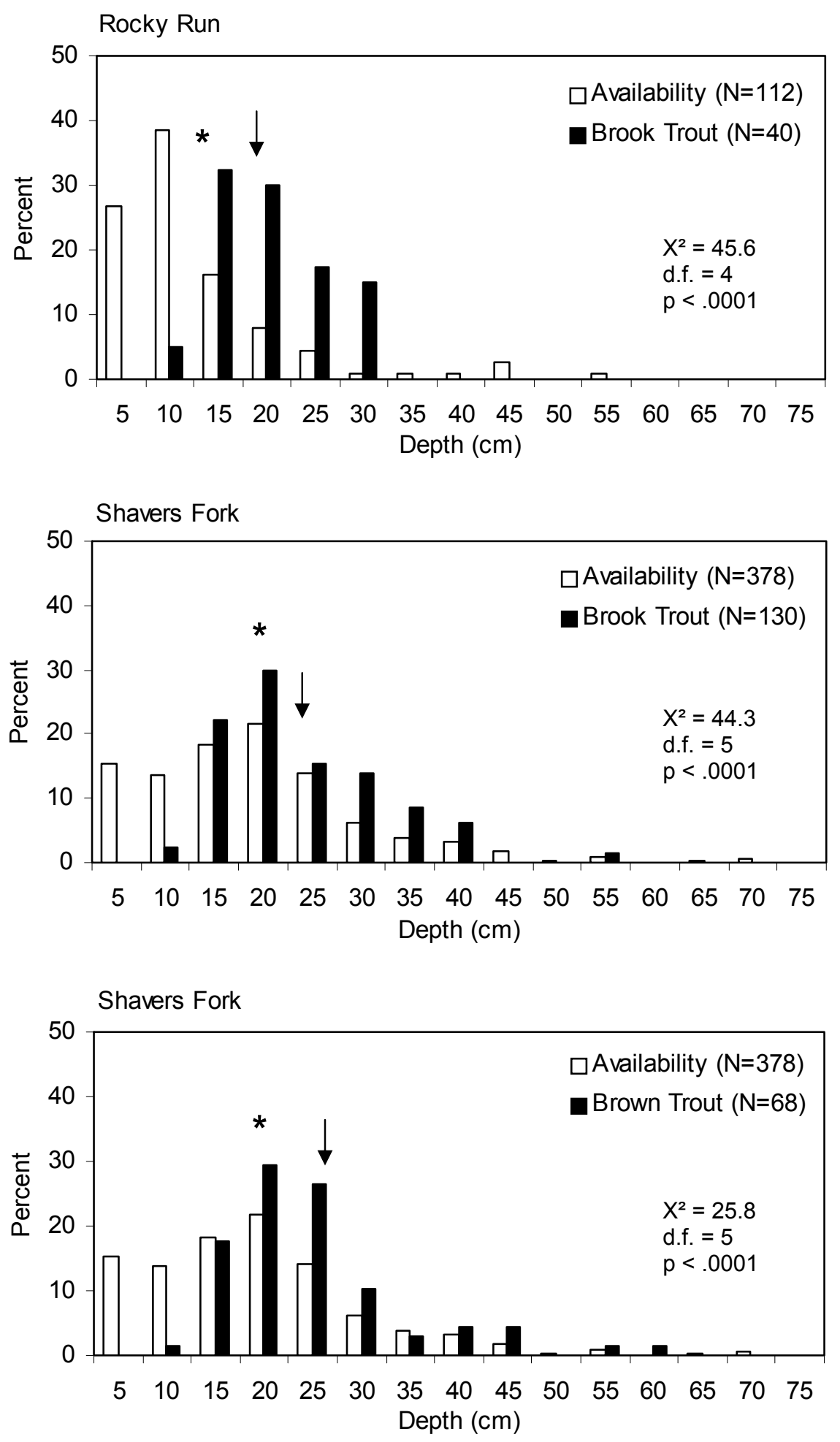
Figure 16. Microhabitat use by trout and availability of water depth (D) in Rocky Run and Shavers Fork, fall 2000. The arrow refers to the mean depth used, the asterisk refers to mean availability. Also present are results of $X^{2}$ analysis comparing use to availability.
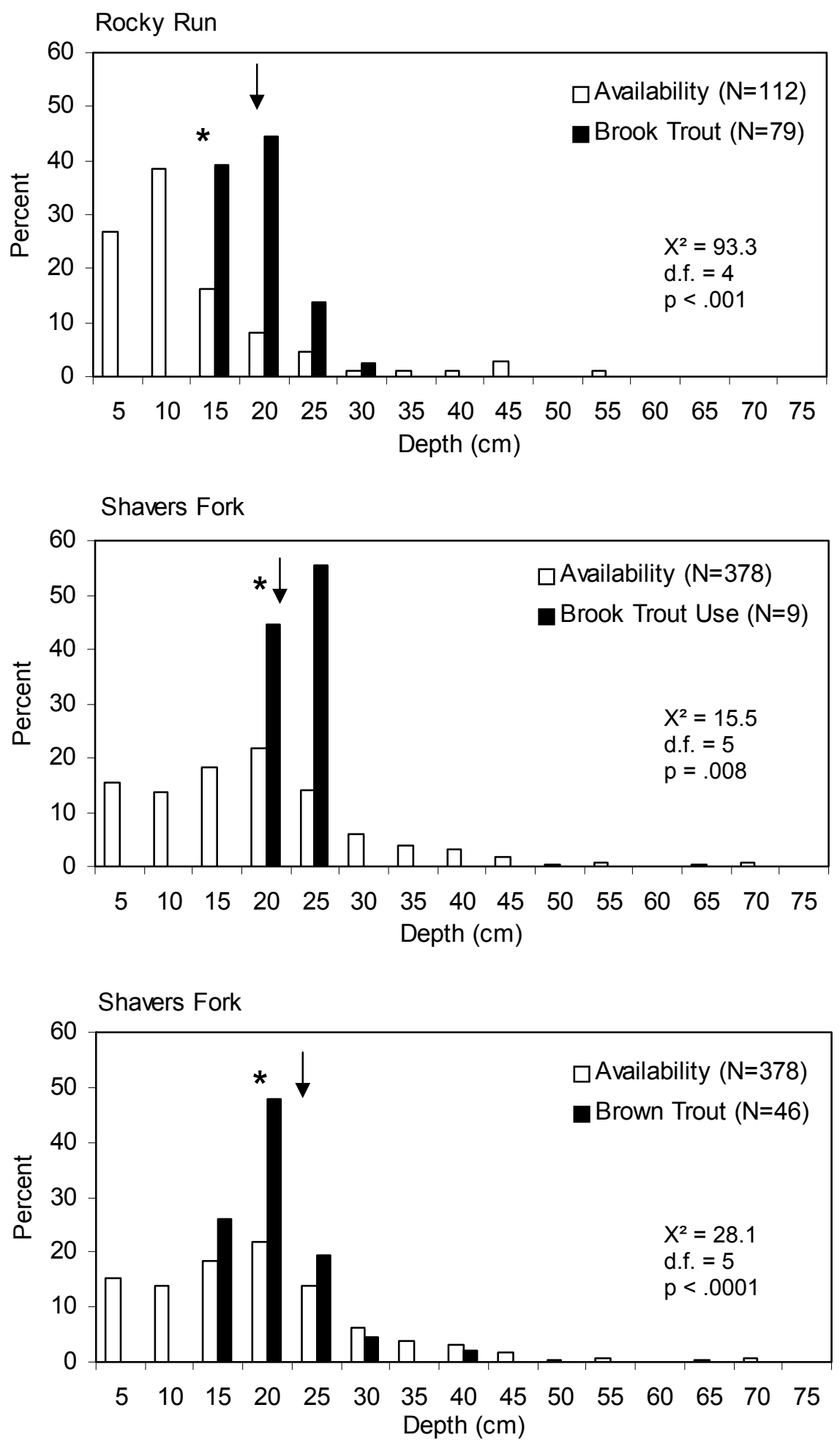
Figure 17. Microhabitat use by trout and availability of average current velocity (ACV) in Rocky Run and Shavers Fork, spring/summer 2000. The arrow refers to the mean average current velocity used, the asterisk refers to mean availability. Also present are results of $X^{2}$ analysis comparing use to availability.
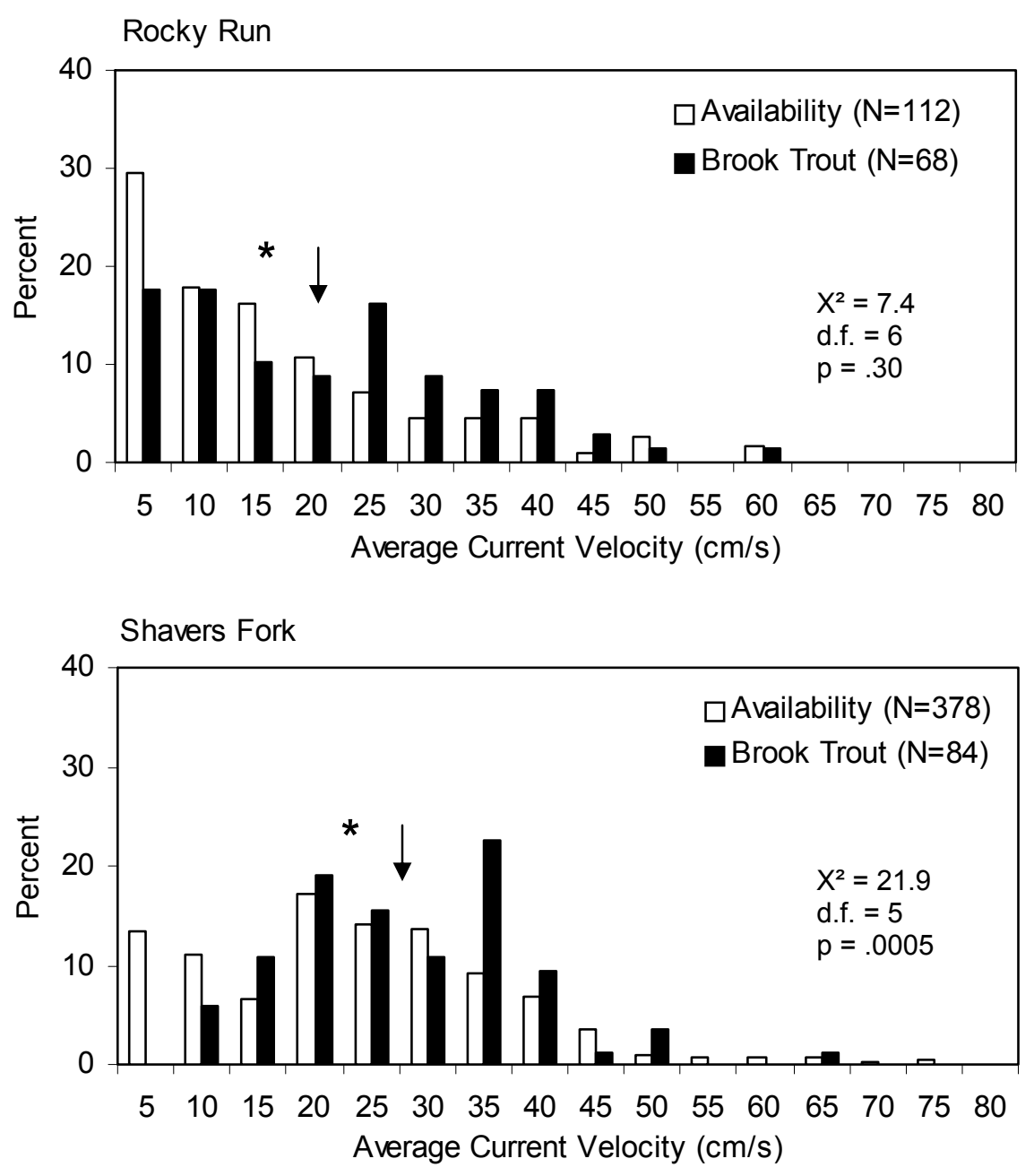
Figure 18. Microhabitat use by trout and availability of average current velocity (ACV) in Rocky Run and Shavers Fork, spring/summer 2001. The arrow refers to the mean average current velocity used, the asterisk refers to mean availability. Also present are results of $X^{2}$ analysis comparing use to availability.
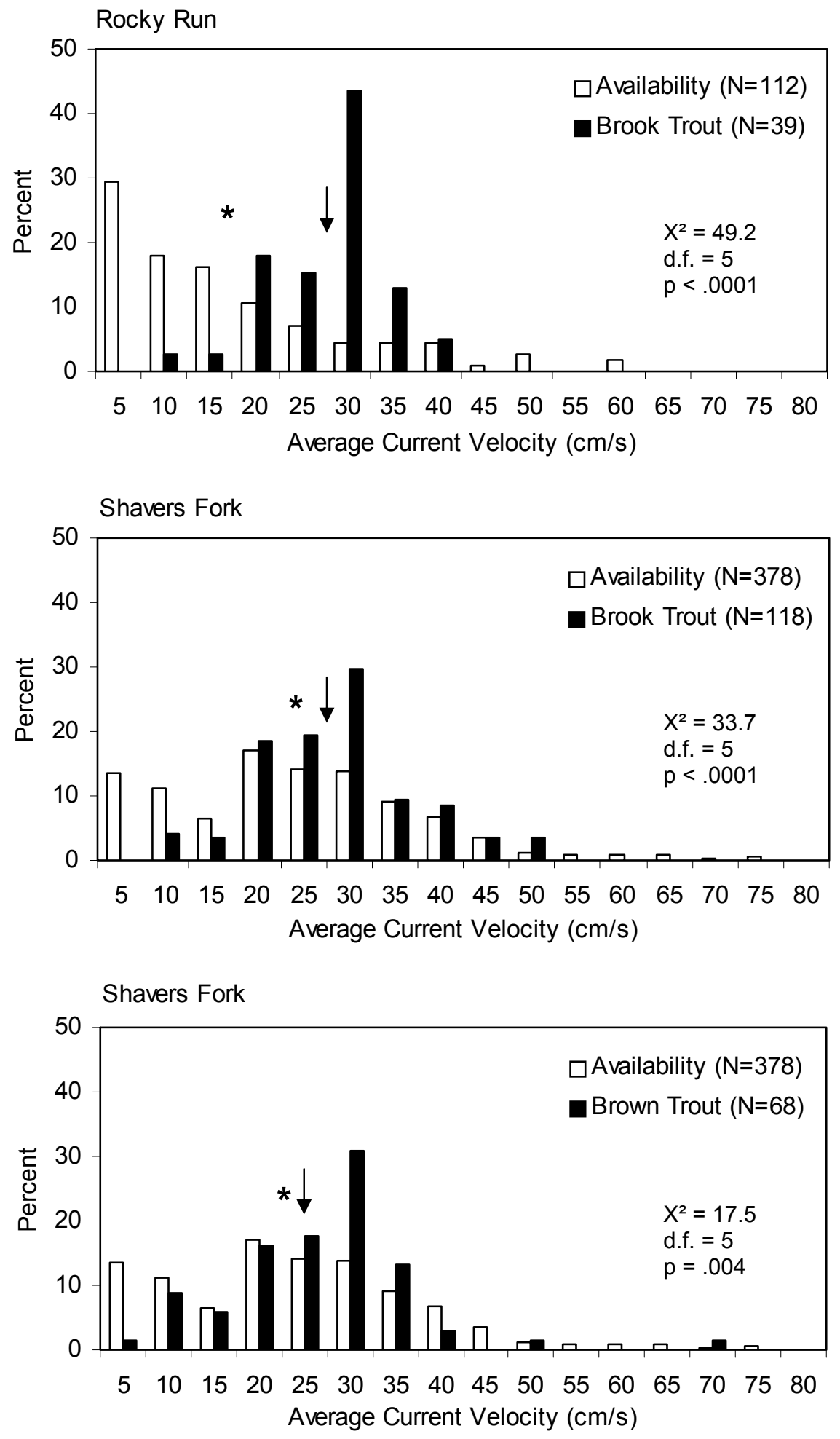
Figure 19. Microhabitat use by trout and availability of average current velocity (ACV) in Rocky Run and Shavers Fork, fall 2000. The arrow refers to the mean average current velocity used, the asterisk refers to mean availability. Also present are results of $X^{2}$ analysis comparing use to availability.
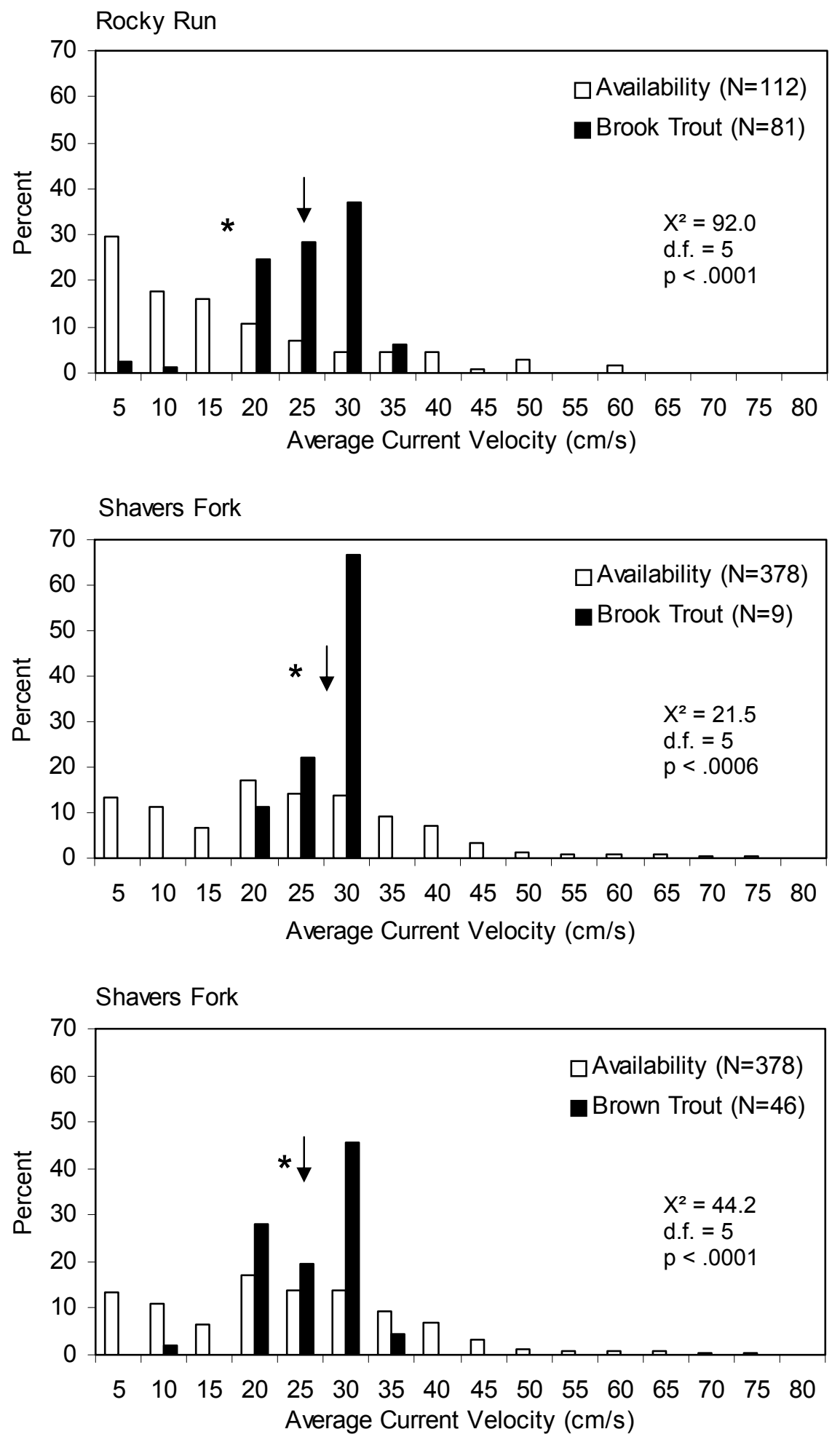
Figure 20. Microhabitat use by trout and availability of focal point current velocity (FPCV) in Rocky Run and Shavers Fork, spring/summer 2000. The arrow refers to the mean focal point current velocity used (availability was not taken).
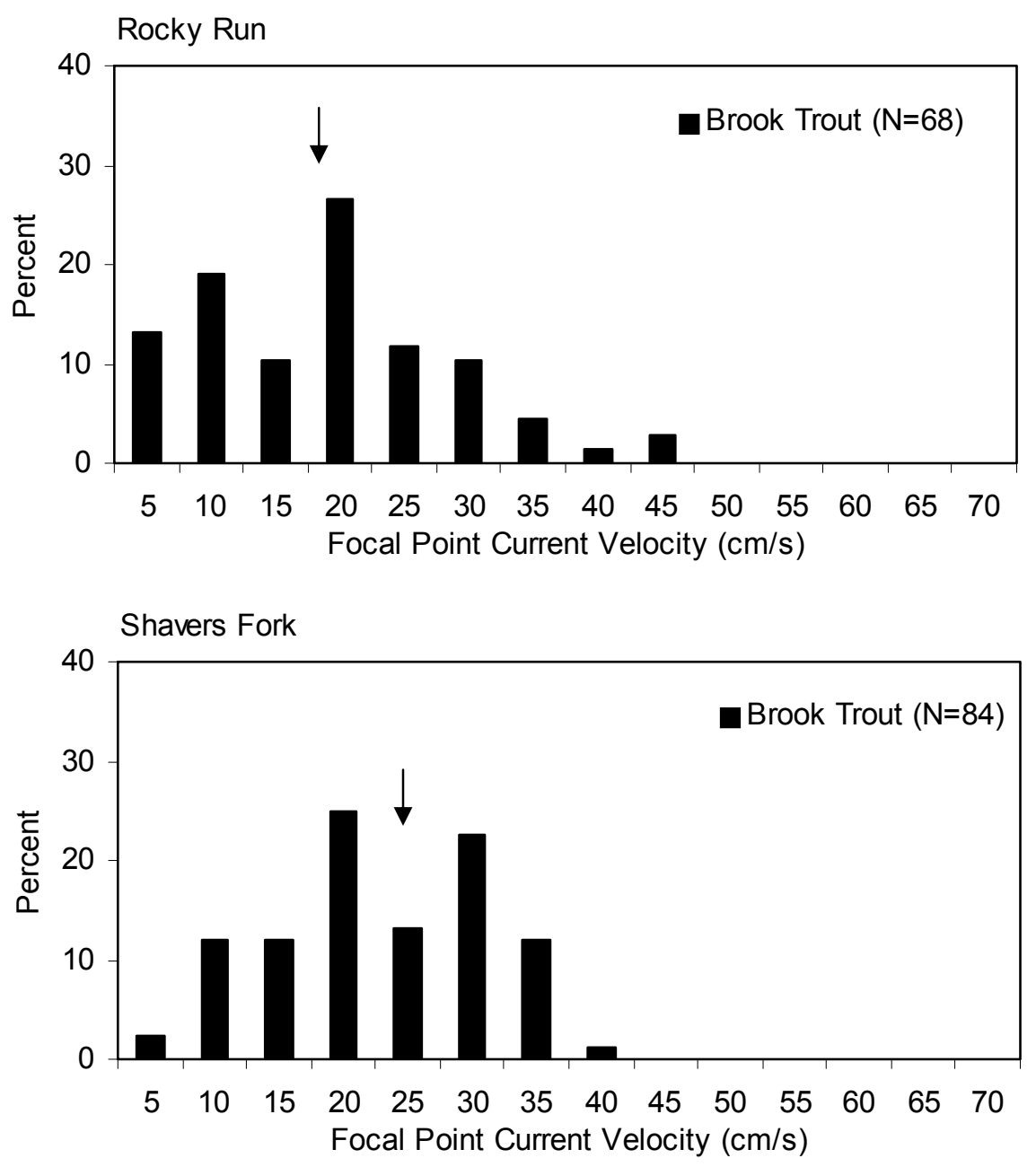
Figure 21. Microhabitat use by trout and availability of focal point current velocity (FPCV) in Rocky Run and Shavers Fork, spring/summer 2001. The arrow refers to the mean focal point current velocity used (availability was not taken).
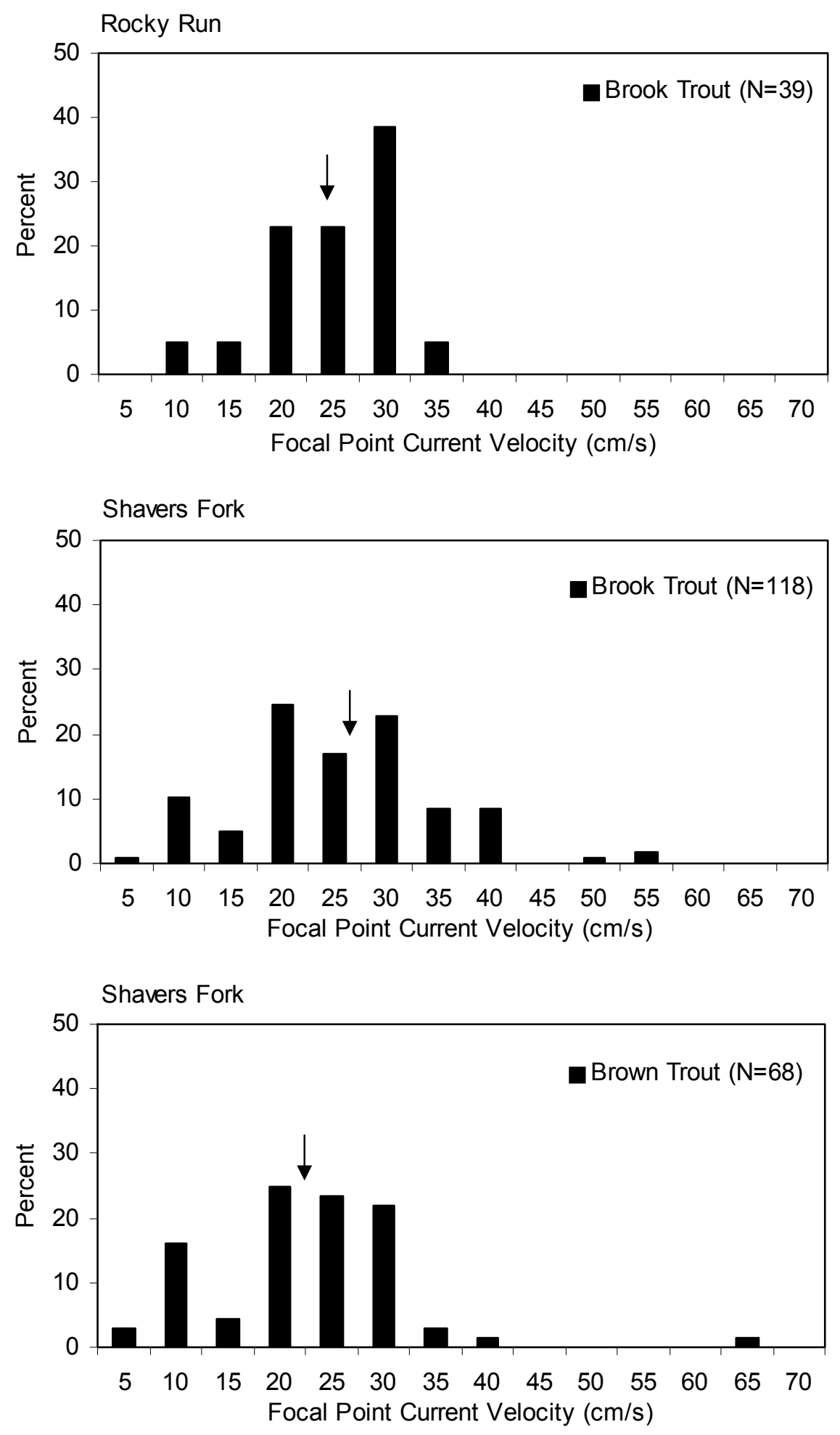
Figure 22. Microhabitat use by trout and availability of focal point current velocity (FPCV) in Rocky Run and Shavers Fork, fall 2000. The arrow refers to the mean focal point current velocity used (availability was not taken).
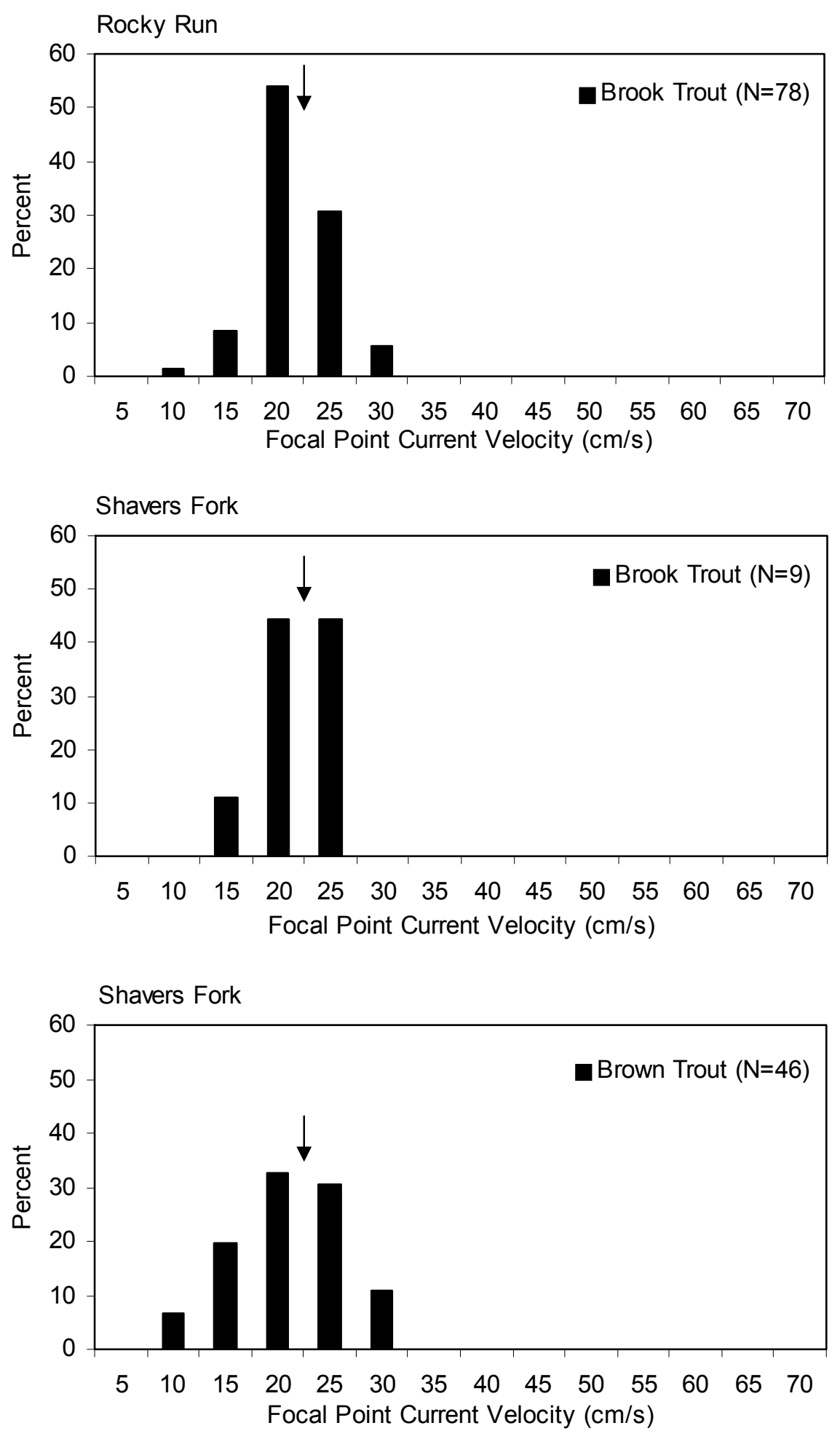
Figure 23. Microhabitat use by trout and availability of maximum current velocity (MCV) in Rocky Run and Shavers Fork, spring/summer 2000. The arrow refers to the mean maximum current velocity used (availability was not taken).
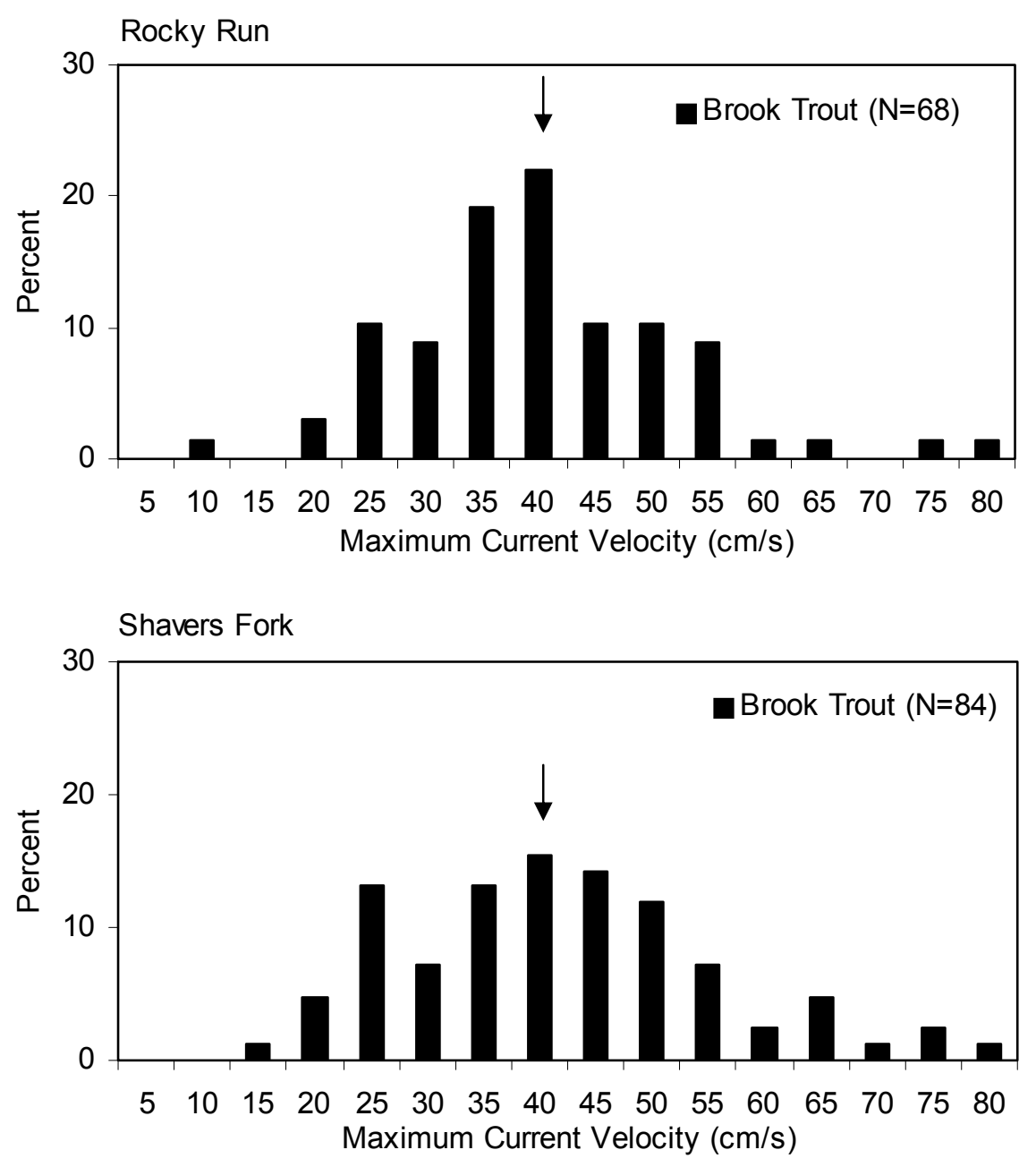
Figure 24. Microhabitat use by trout and availability of maximum current velocity (MCV) in Rocky Run and Shavers Fork, spring/summer 2001. The arrow refers to the maximum current velocity used (availability was not taken).
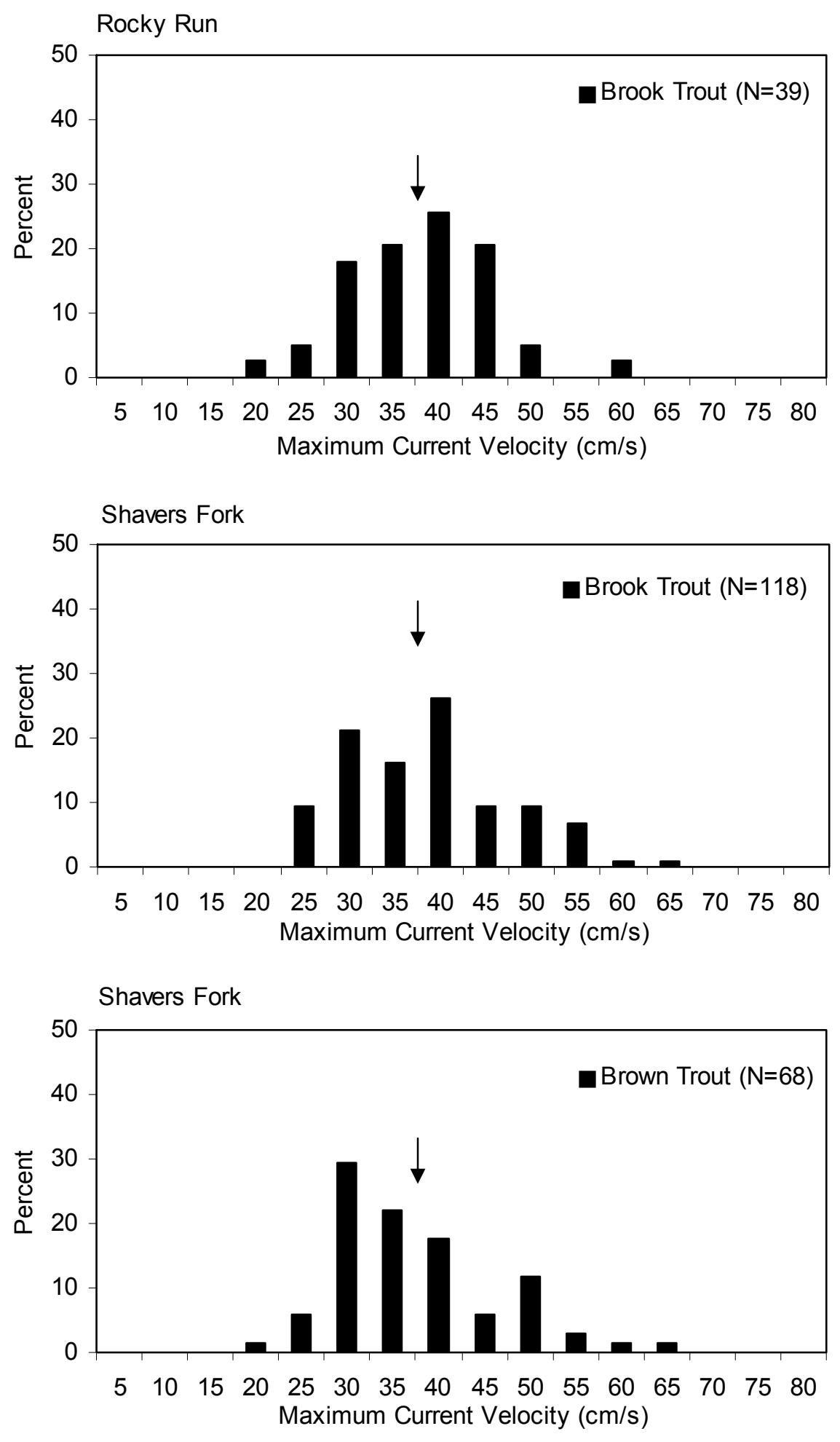
Figure 25. Microhabitat use by trout and availability of maximum current velocity (MCV) in Rocky Run and Shavers Fork, fall 2000. The arrow refers to the mean maximum current velocity used (availability was not taken).
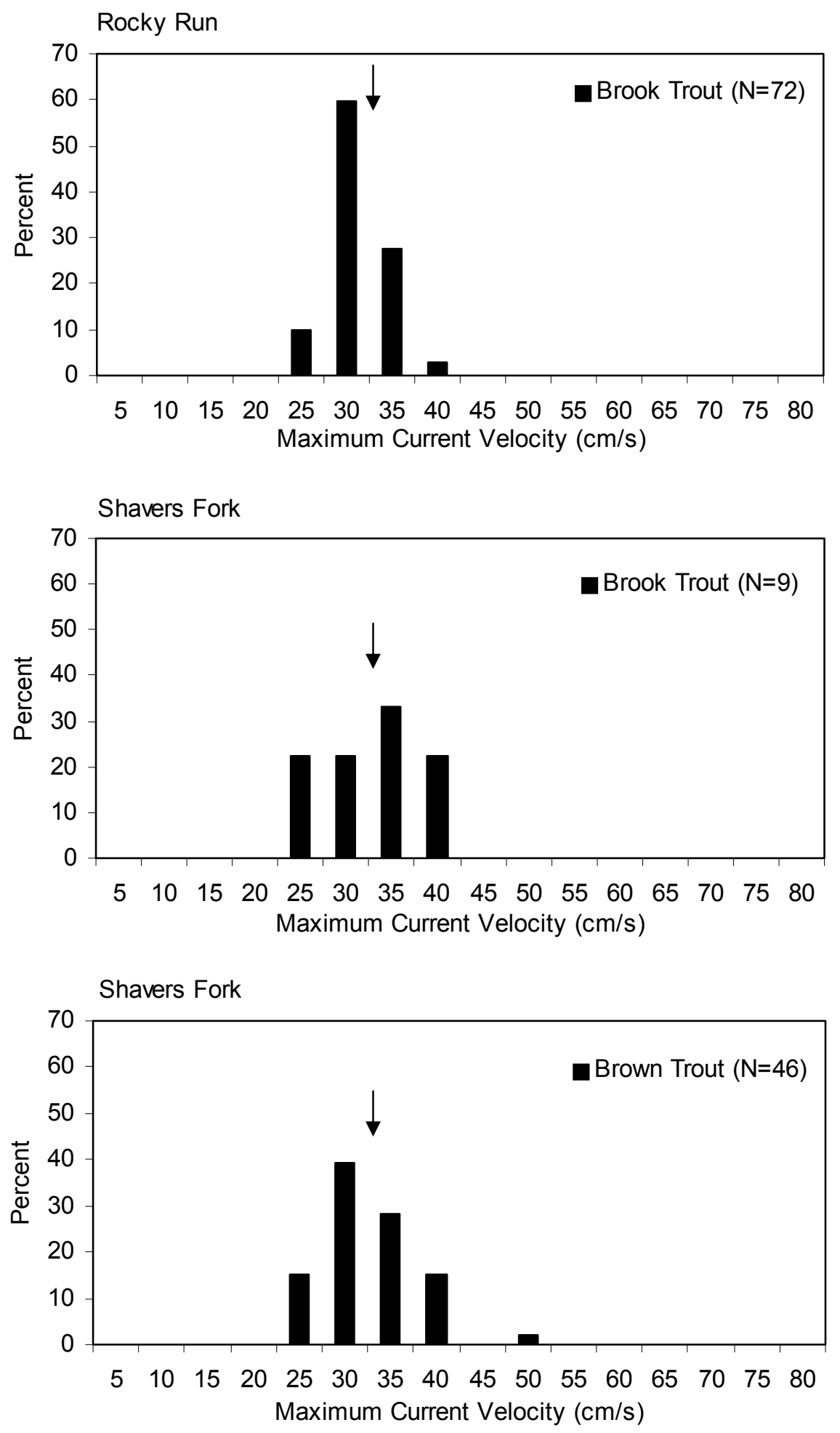
Figure 26. Microhabitat use by trout and availability of distance to cover (D_cov) in Rocky Run and Shavers Fork, spring/summer 2000. The arrow refers to the mean distance to cover used, the asterisk refers to mean availability. Also present are results of $X^{2}$ analysis comparing use to availability.
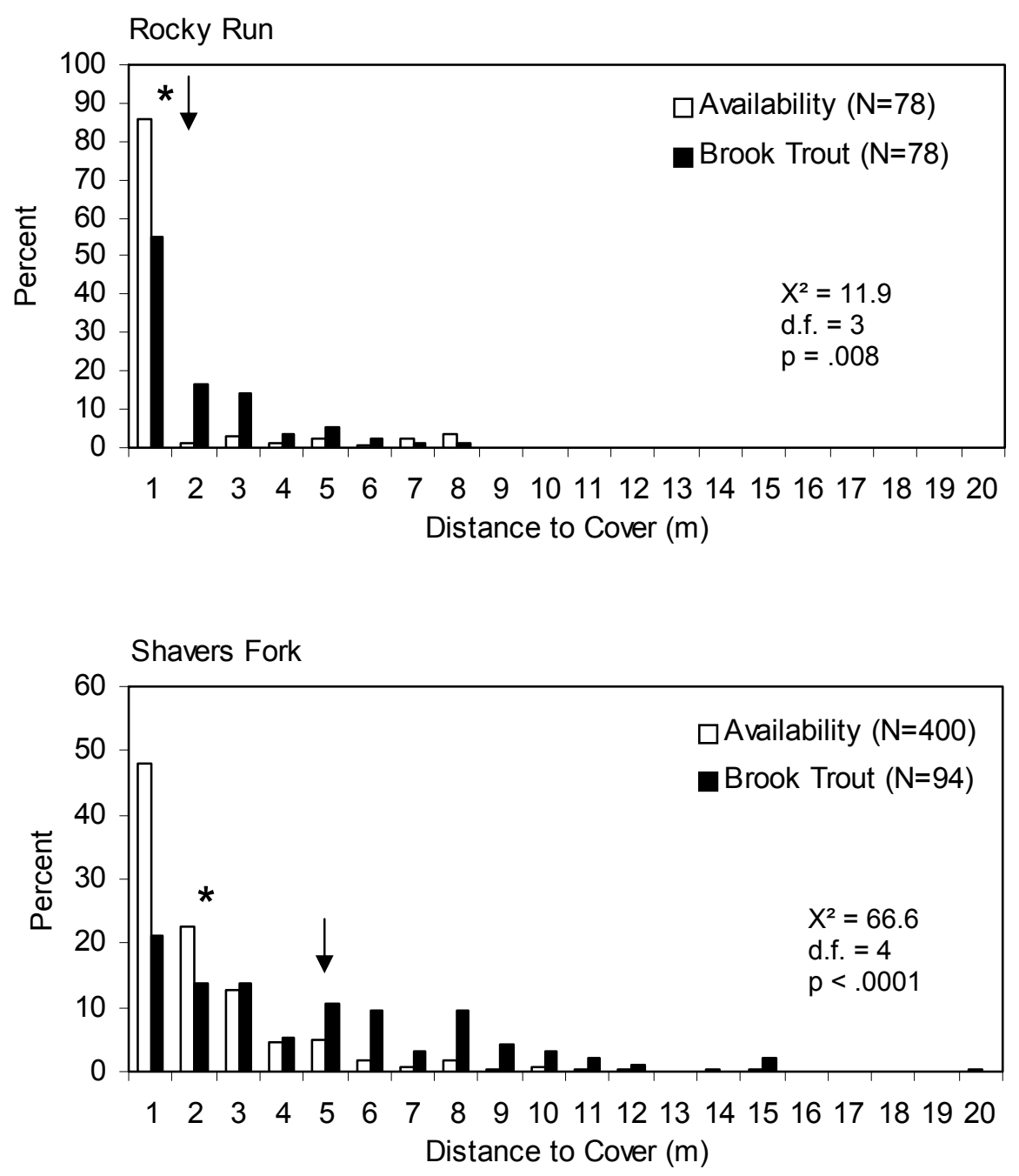
Figure 27. Microhabitat use by trout and availability of distance to cover (D_cov) in Rocky Run and Shavers Fork, spring/summer 2001. The arrow refers to the mean distance to cover used, the asterisk refers to mean availability. Also present are results of $X^{2}$ analysis comparing use to availability.
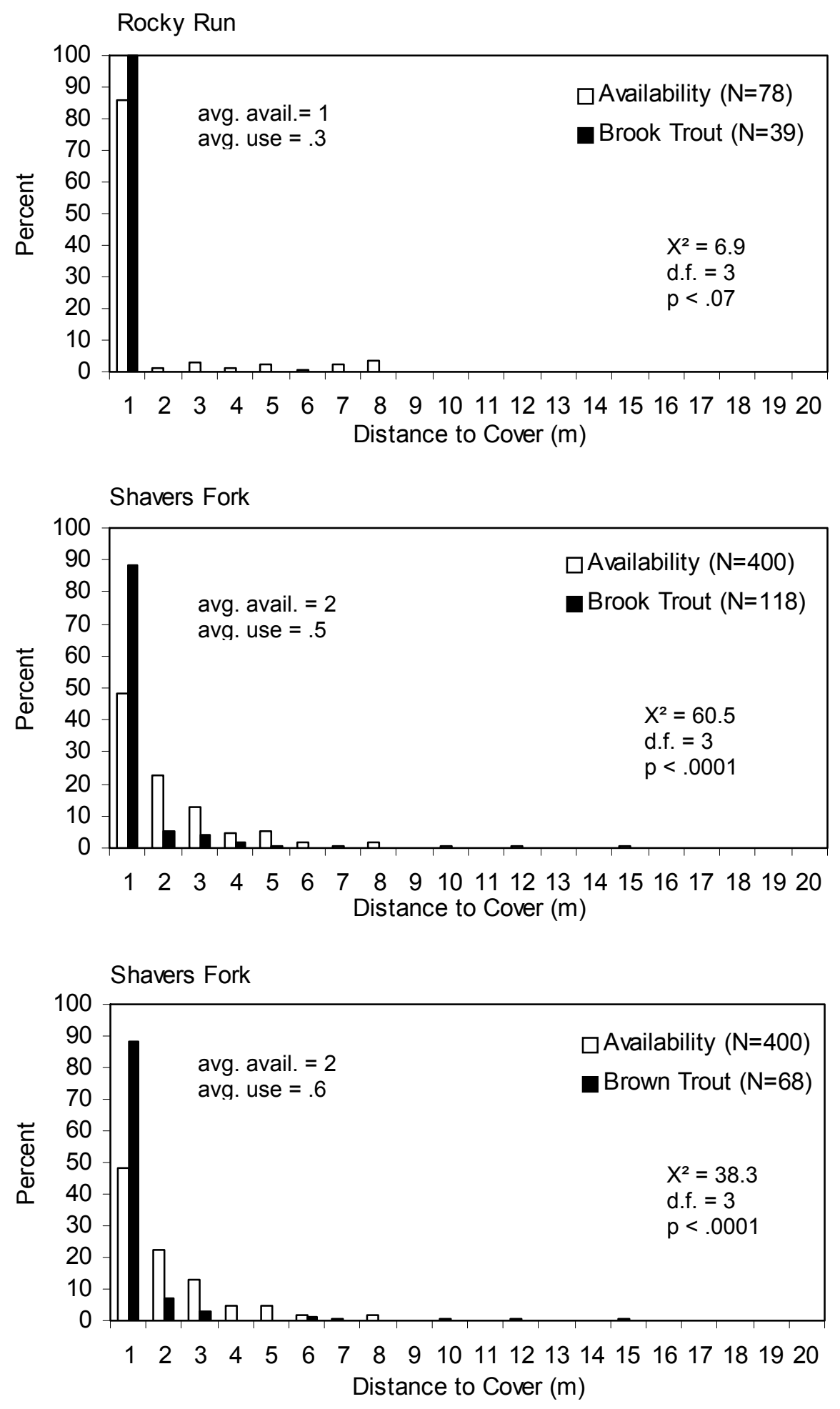
Figure 28. Microhabitat use by trout and availability of distance to cover (D_cov) in Rocky Run and Shavers Fork, fall 2000. The arrow refers to the mean distance to cover used, the asterisk refers to mean availability. Also present are results of $\mathrm{X}^{2}$ analysis comparing use to availability.
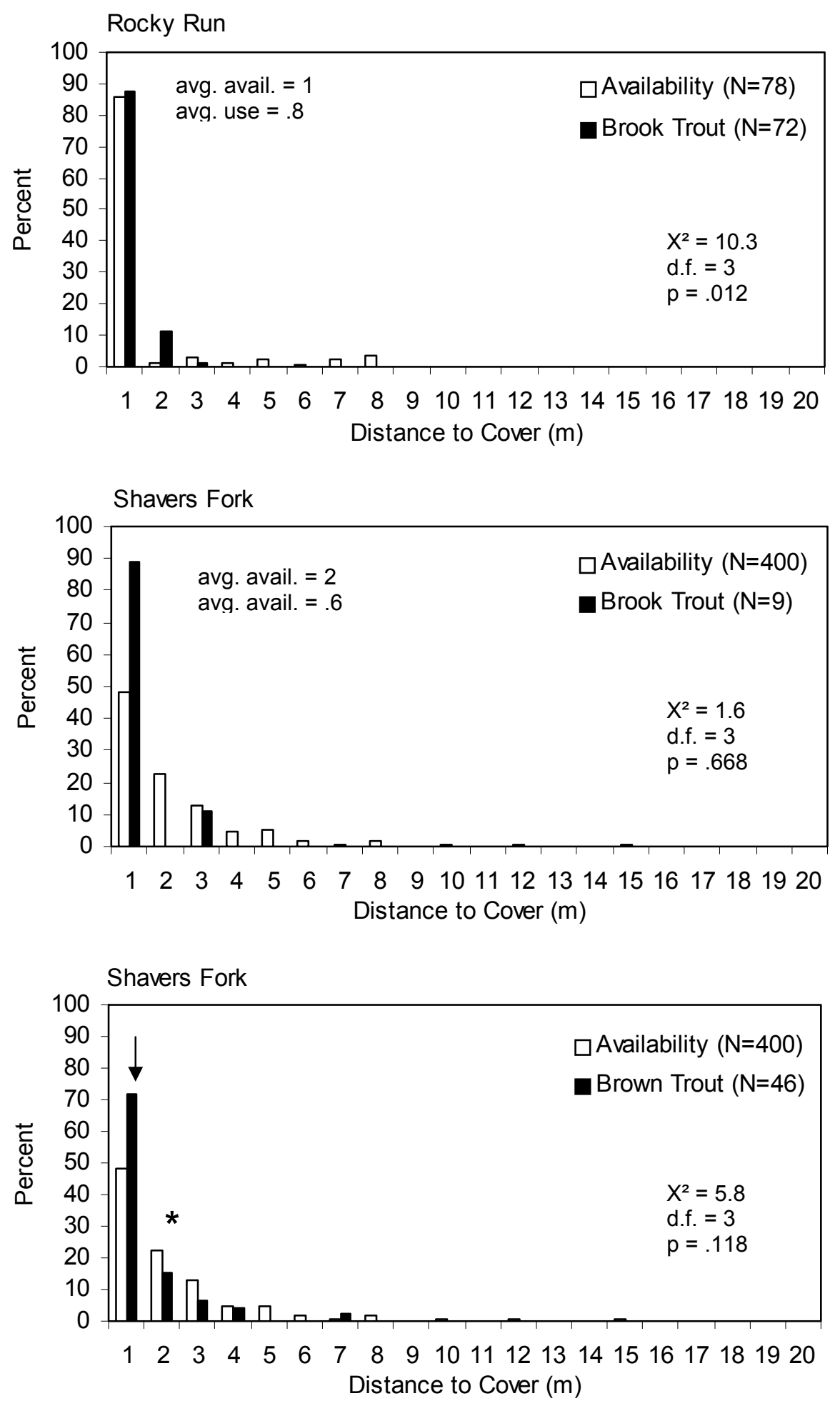
Figure 29. Focal point current velocity (FPCV) versus maximum current velocity (MCV) for spring/summer 2000.
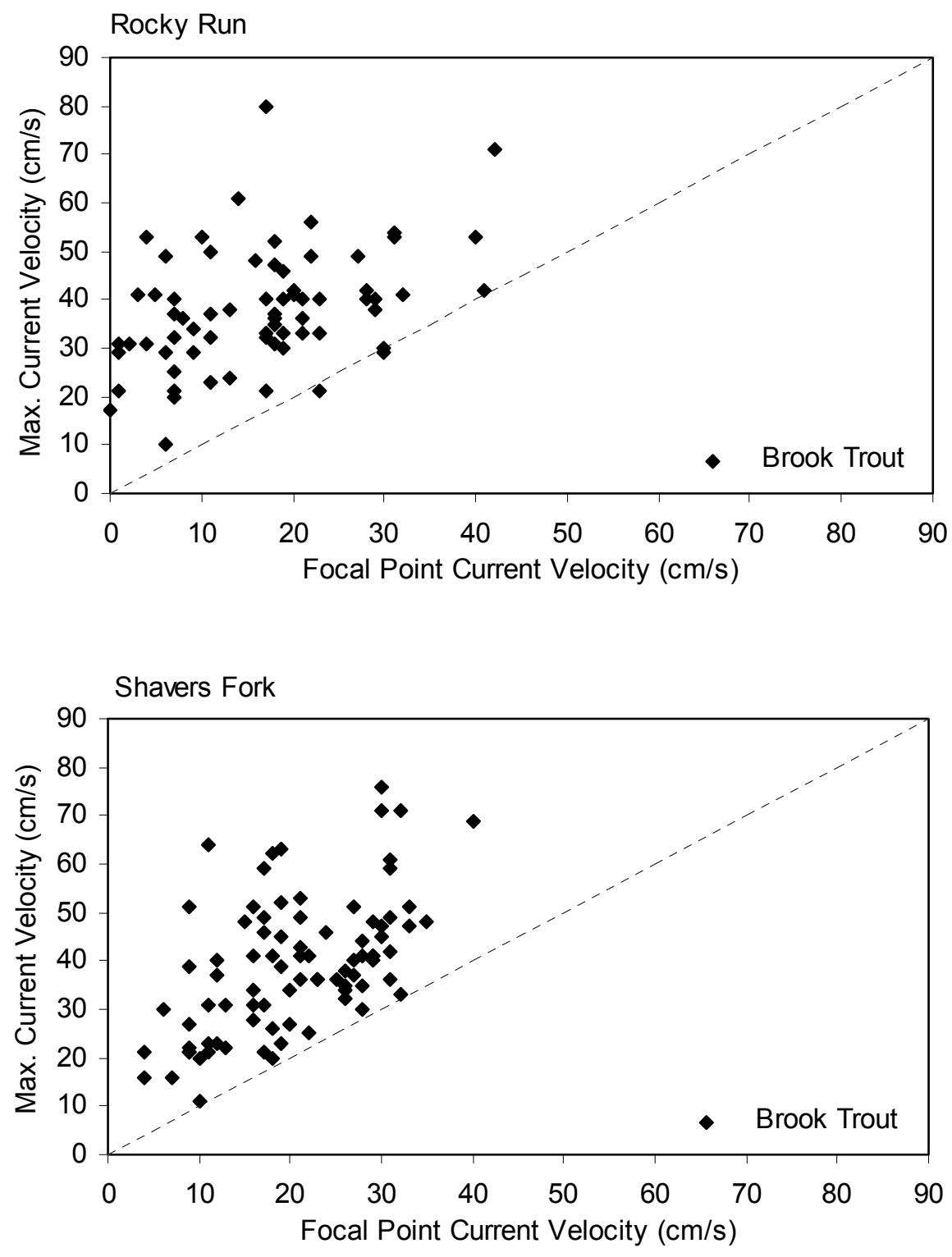
Figure 30. Focal point current velocity (FPCV) versus maximum current velocity (MCV) for spring/summer 2001.
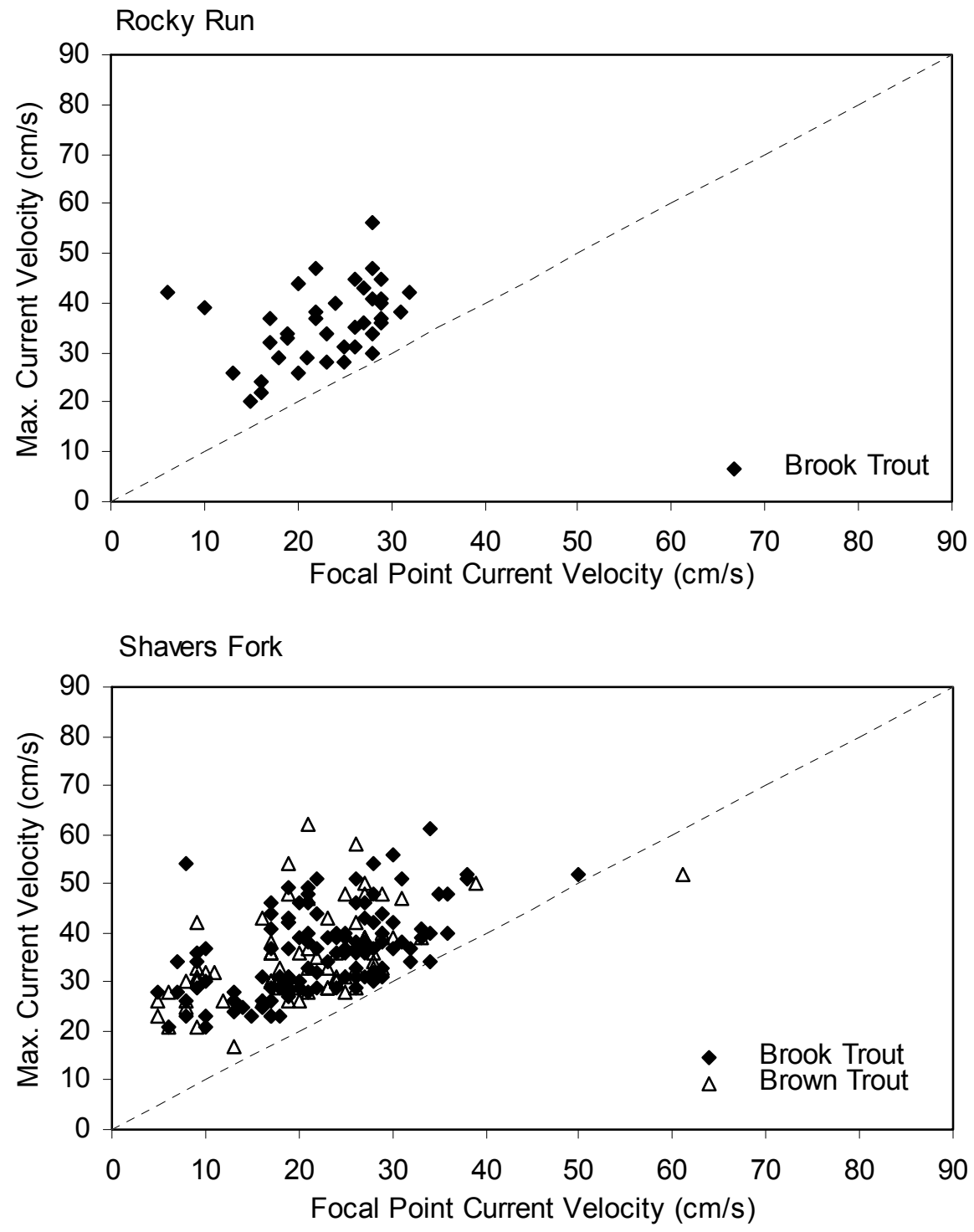
Figure 31. Focal point current velocity (FPCV) versus maximum current velocity (MCV) for fall 2000.
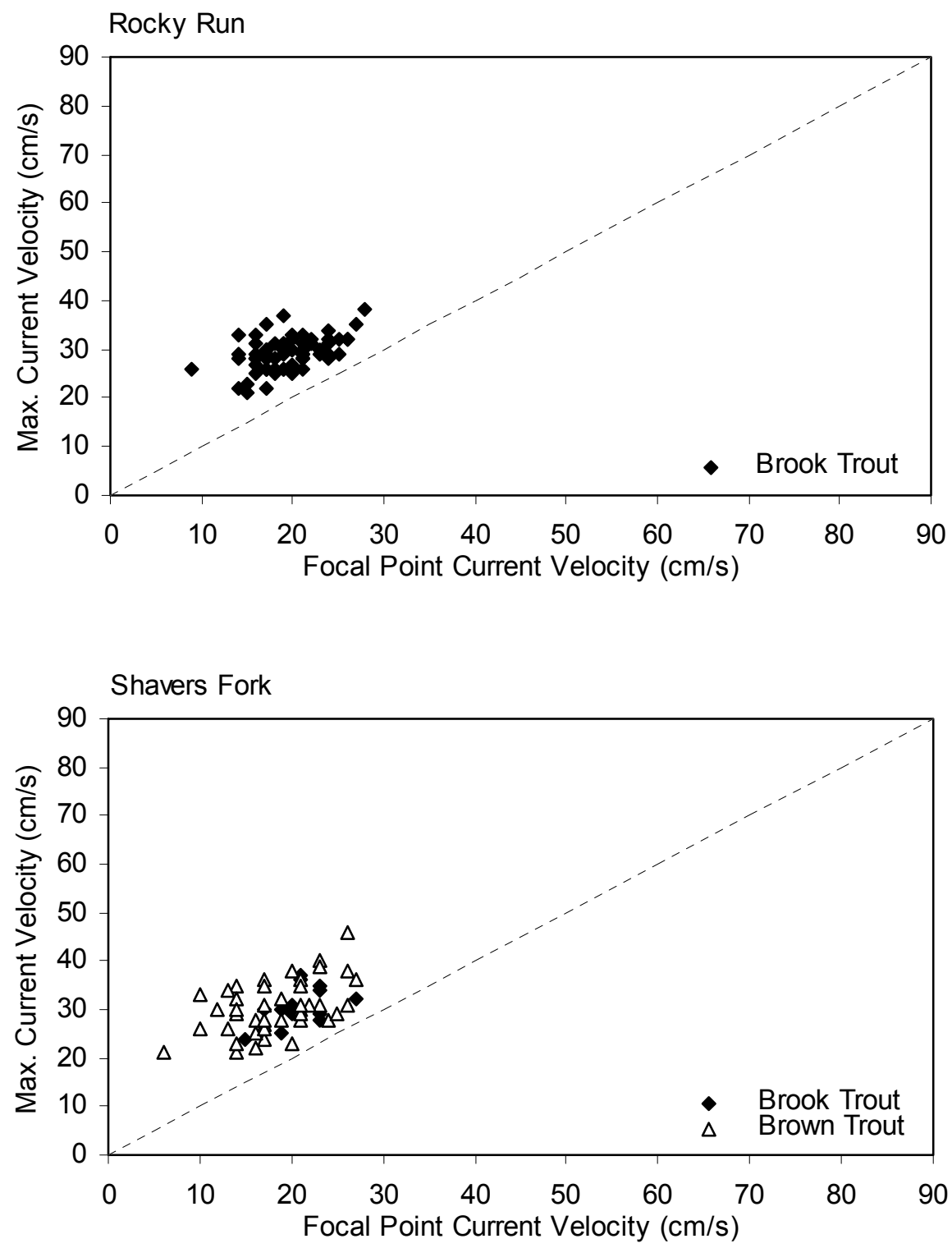
Figure 32. Relationship between focal point temperature (FPT) and ambient water temperature for spring/summer 2000-01, and fall 2000.
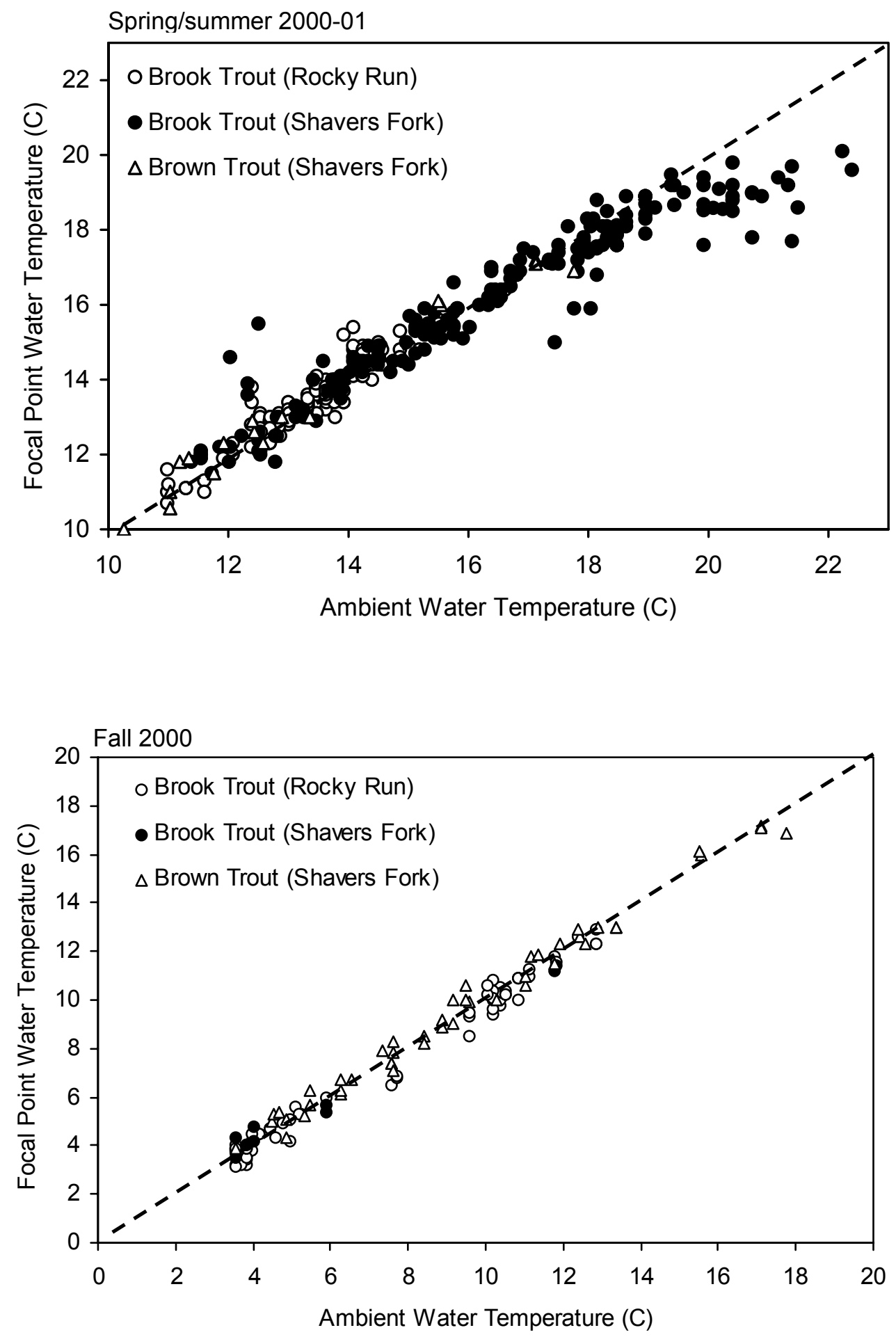
Figure 33. Variation in the difference between focal point temperature (FPT) and ambient water temperature as a function of ambient water temperature for spring/ summer 2000-01 (note brook and brown trout are separate series). Numbers denote temperature group divisions (1-6) based on temperature thresholds and a difference $\pm 1^{\circ} \mathrm{C}$ between recorded focal and ambient temperature levels.

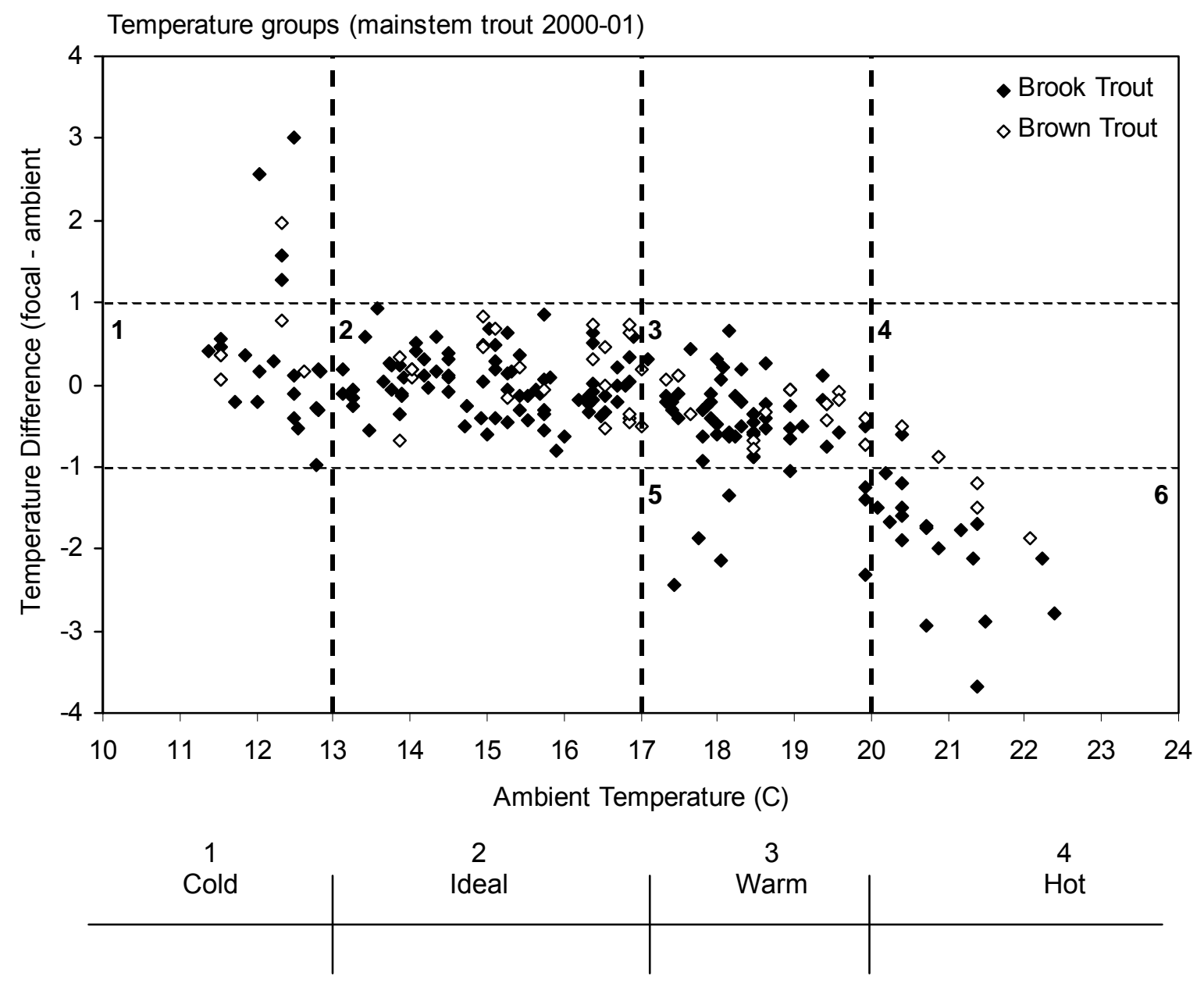


Figure 34. Cumulative frequency histograms showing the use of water depth (D), and average current velocity (ACV) by mainstem brook trout by temperature group divisions (1-6) for spring/summer 2000-01.
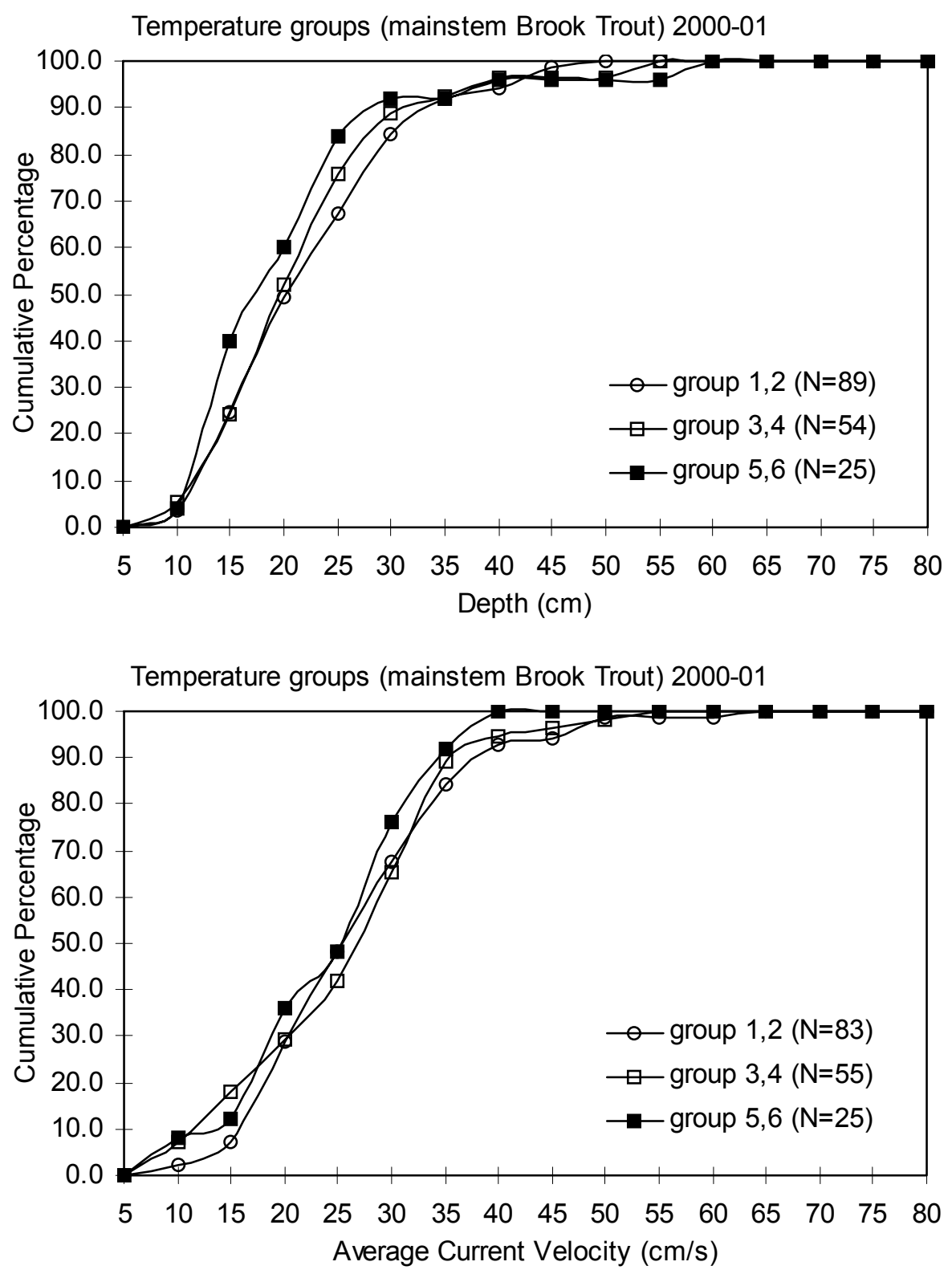
Figure 34 (cont'd). Cumulative frequency histograms showing the use of focal point current velocity (FPCV), and maximum current velocity (MCV) within $60 \mathrm{cms}$ by mainstem brook trout by temperature group divisions (1-6) for spring/summer 2000-01.

Temperature groups (mainstem Brook Trout) 2000-01

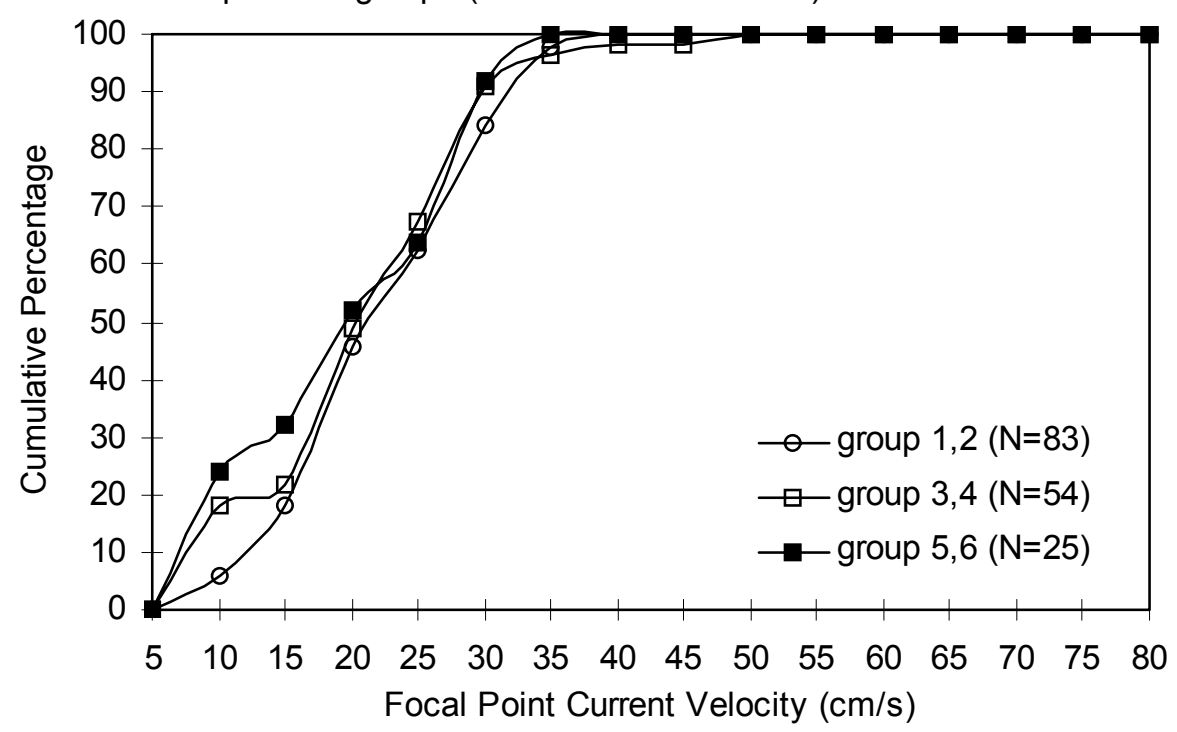

Temperature groups (mainstem Brook Trout) 2000-01

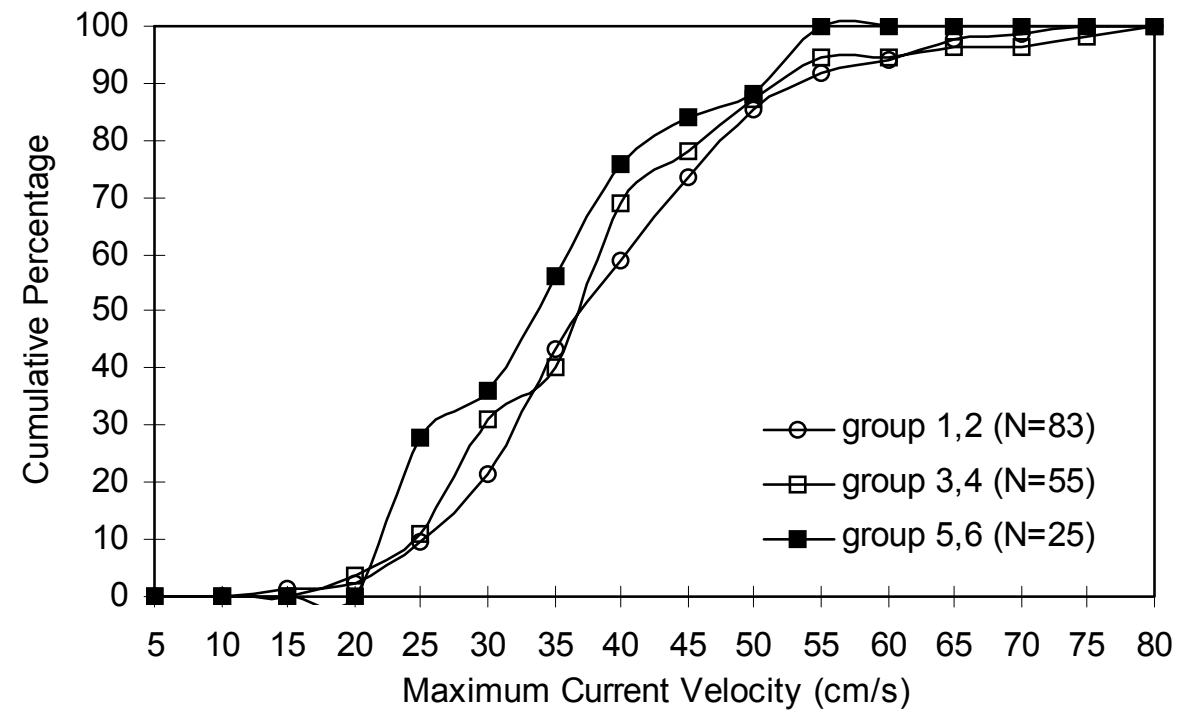


Figure 34 (cont'd). Cumulative frequency histograms showing the distance to cover (D_cov) used by mainstem brook trout by temperature group divisions (16) for spring/summer 2000-01.

Temperature groups (mainstem Brook Trout) 2000-01

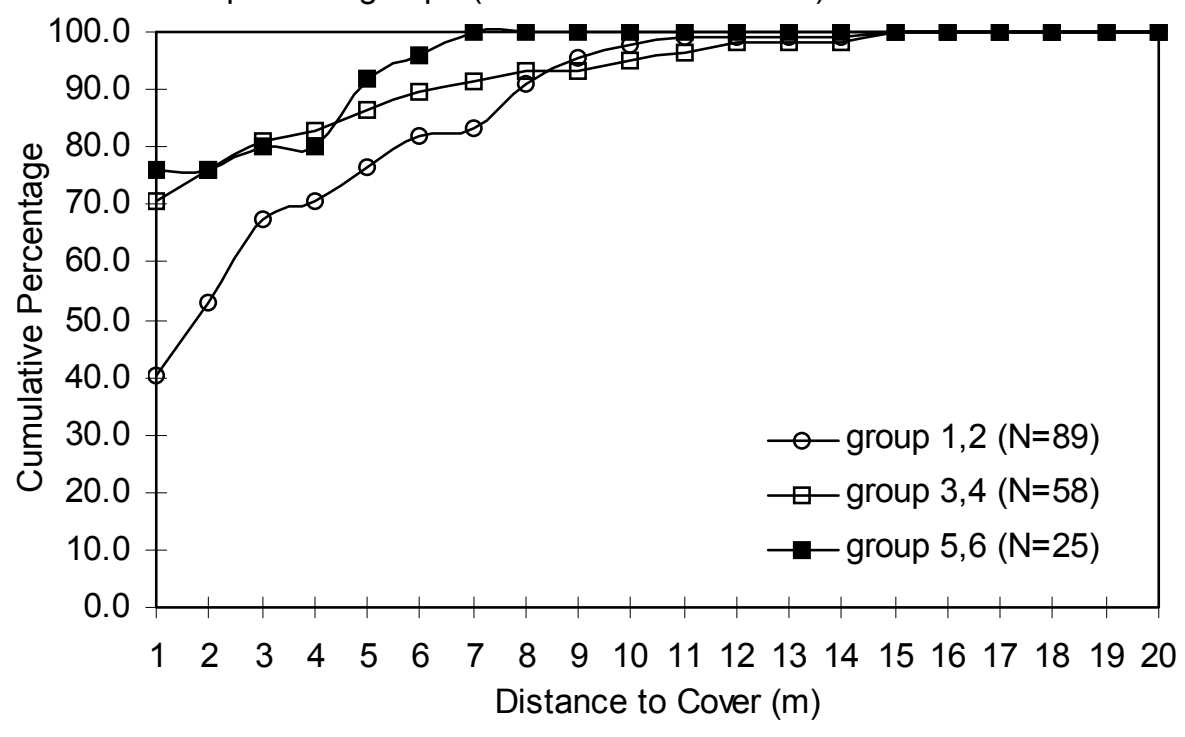


Figure 35. Map showing representative trout movement over spring/summer 2001 tracking period. The focus area of this map is approximately $5-\mathrm{km}$ below Spruce. Brook trout \#64 was implanted with a transmitter and placed back in the Shavers Fork mainstem and eventually entered the tributary Rocky Run, moving almost 2-km upstream throughout the tracking period. Numbers (and dates) missing from the track sequence were due to bad weather, diel sampling, or equipment problems.

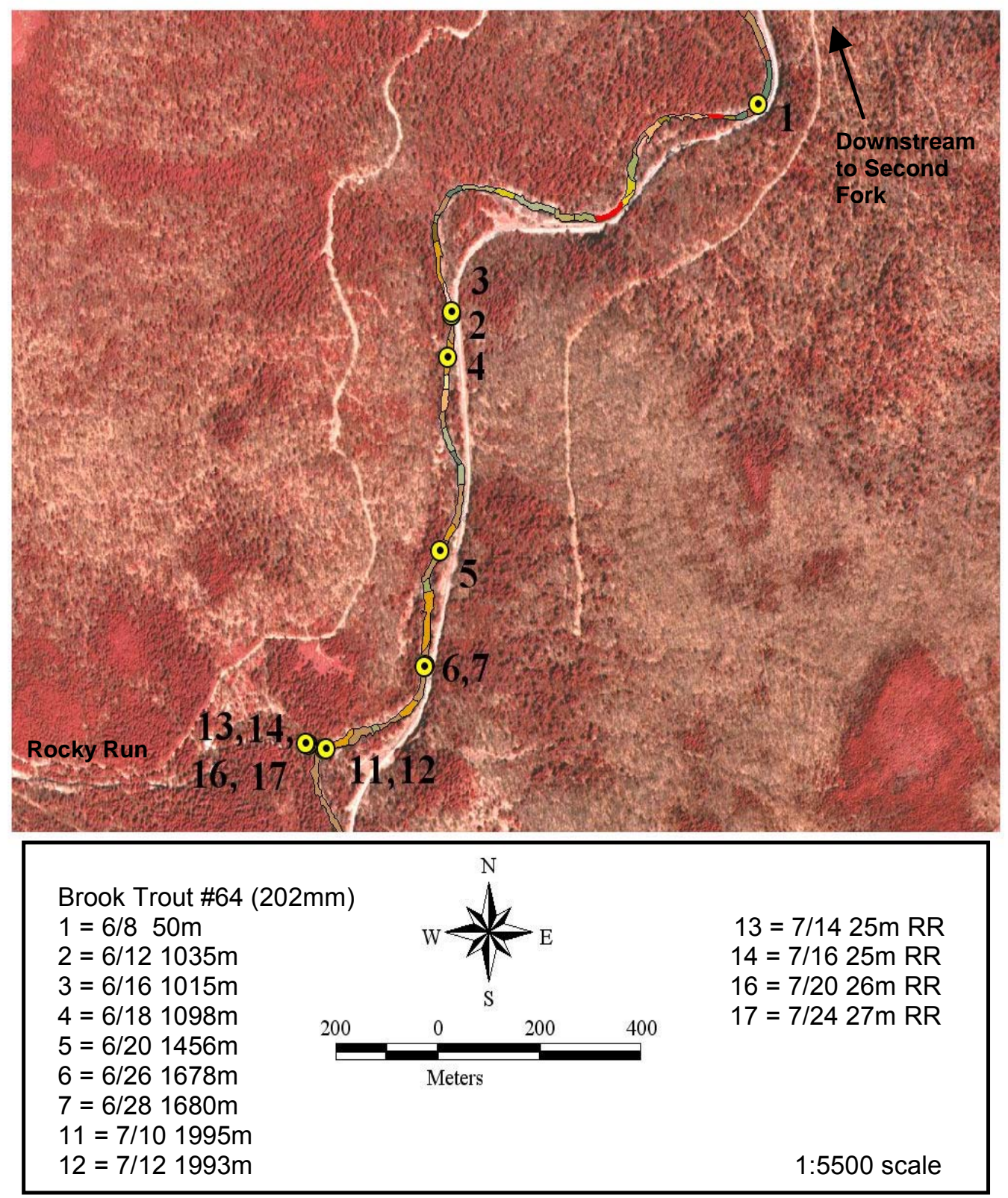


Figure 36. Map showing representative trout movement over spring/summer 2000 tracking period. The focus area of this map is approximately $5 \mathrm{kms}$ below Spruce. Brook trout \#2 was implanted with a transmitter and placed back in Rocky Run and exhibited little to no overall movement throughout the tracking period. Numbers (and dates) missing from the track sequence were due to bad weather, diel sampling, or equipment problems.
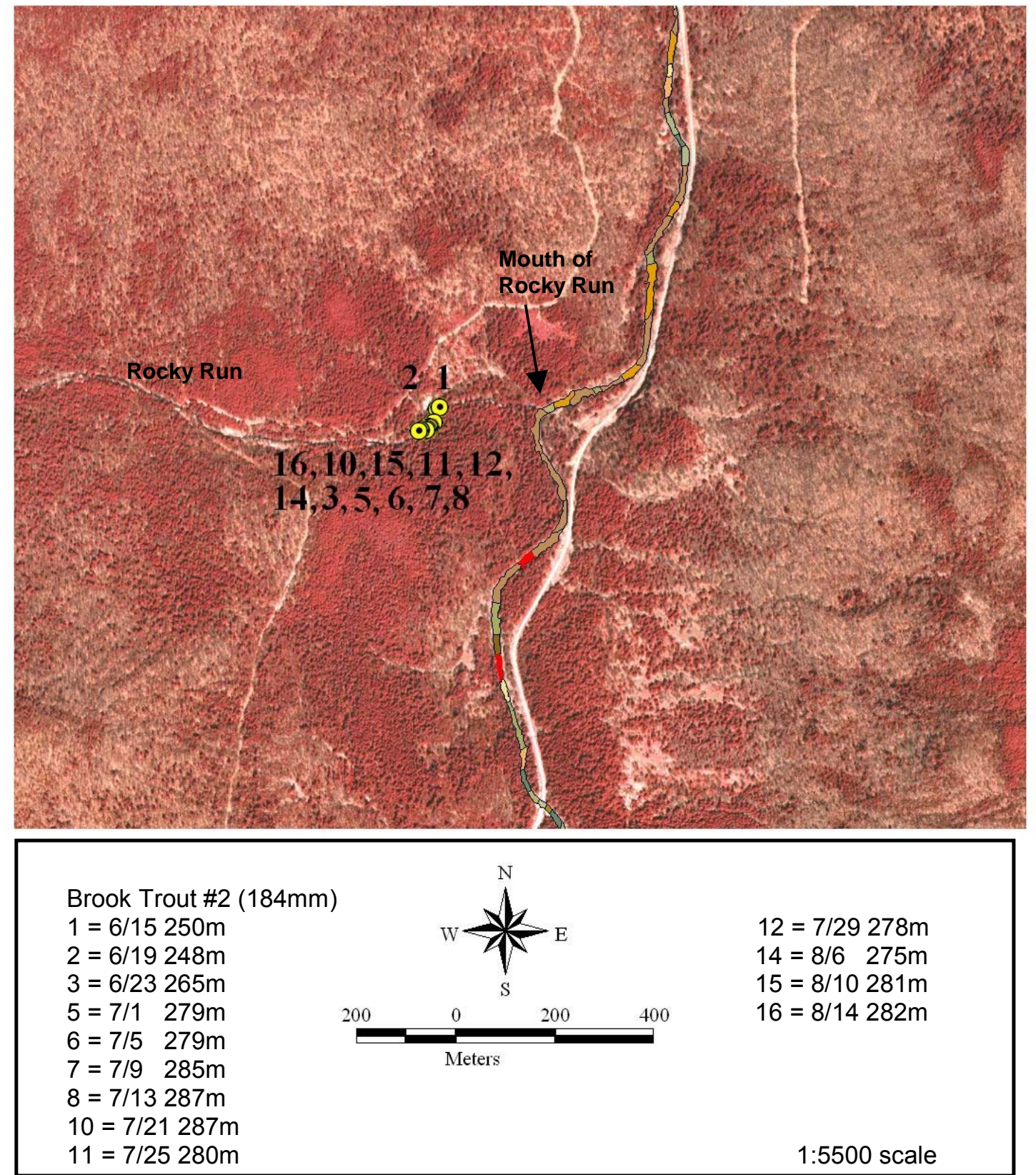
Figure 37. Map showing representative trout movement over fall 2000 tracking period. The focus area of this map is the tributary Rocky Run with the Shavers Fork mainstem to the right. Brook trout \#34 was implanted with a transmitter and placed back in the extreme left fork of Rocky Run with minimal movement recorded throughout the entire tracking period. The left fork of Rocky Run was used extensively by many tagged brook trout for spawning besides this particular individual. Numbers (and dates) missing from the track sequence were due to bad weather, diel sampling, or equipment problems.

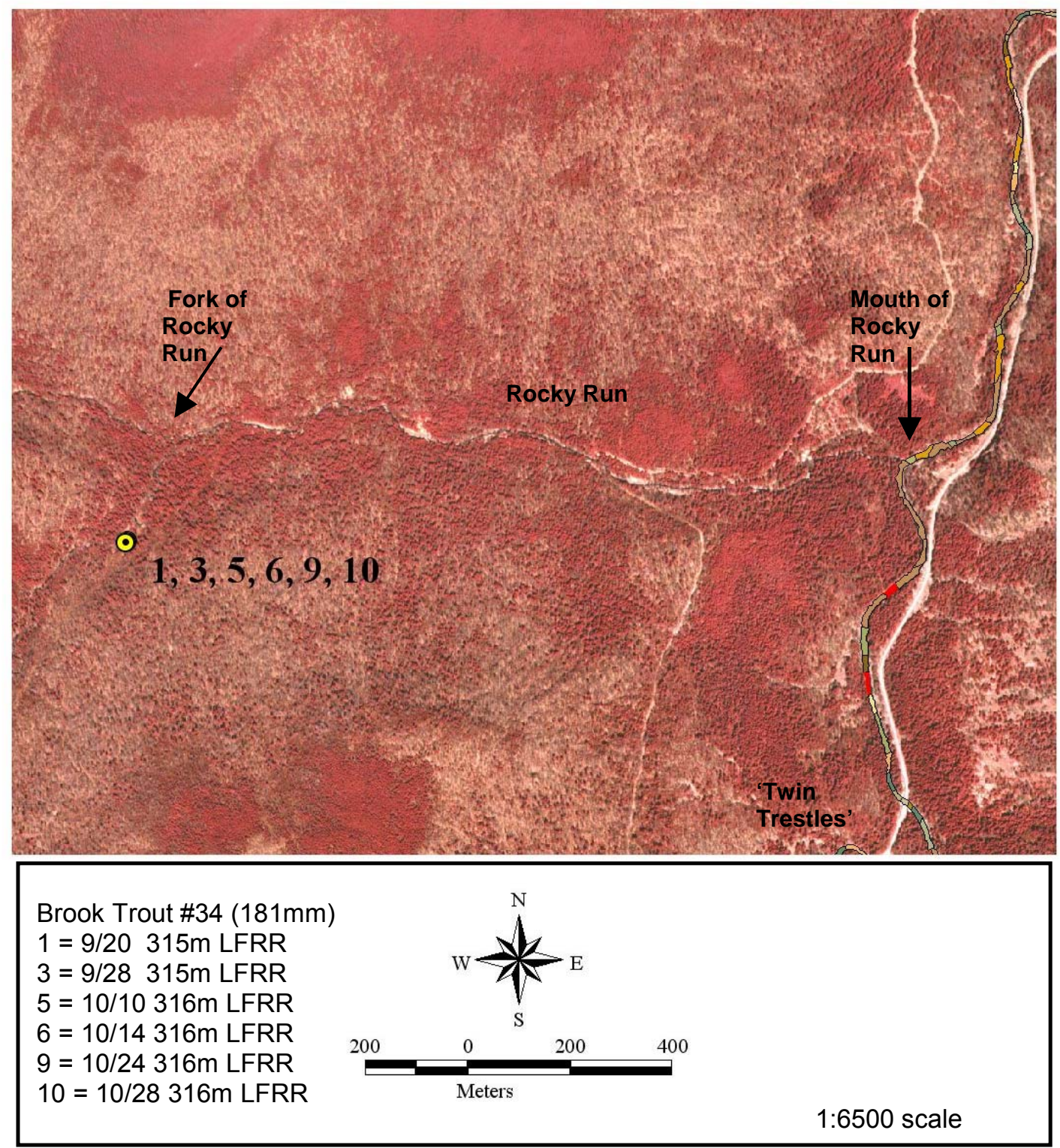


Figure 38. Frequency histograms of trout movement rates in spring/summer 2000. Total dispersal rate refers to the absolute value of the distance moved by individual trout.
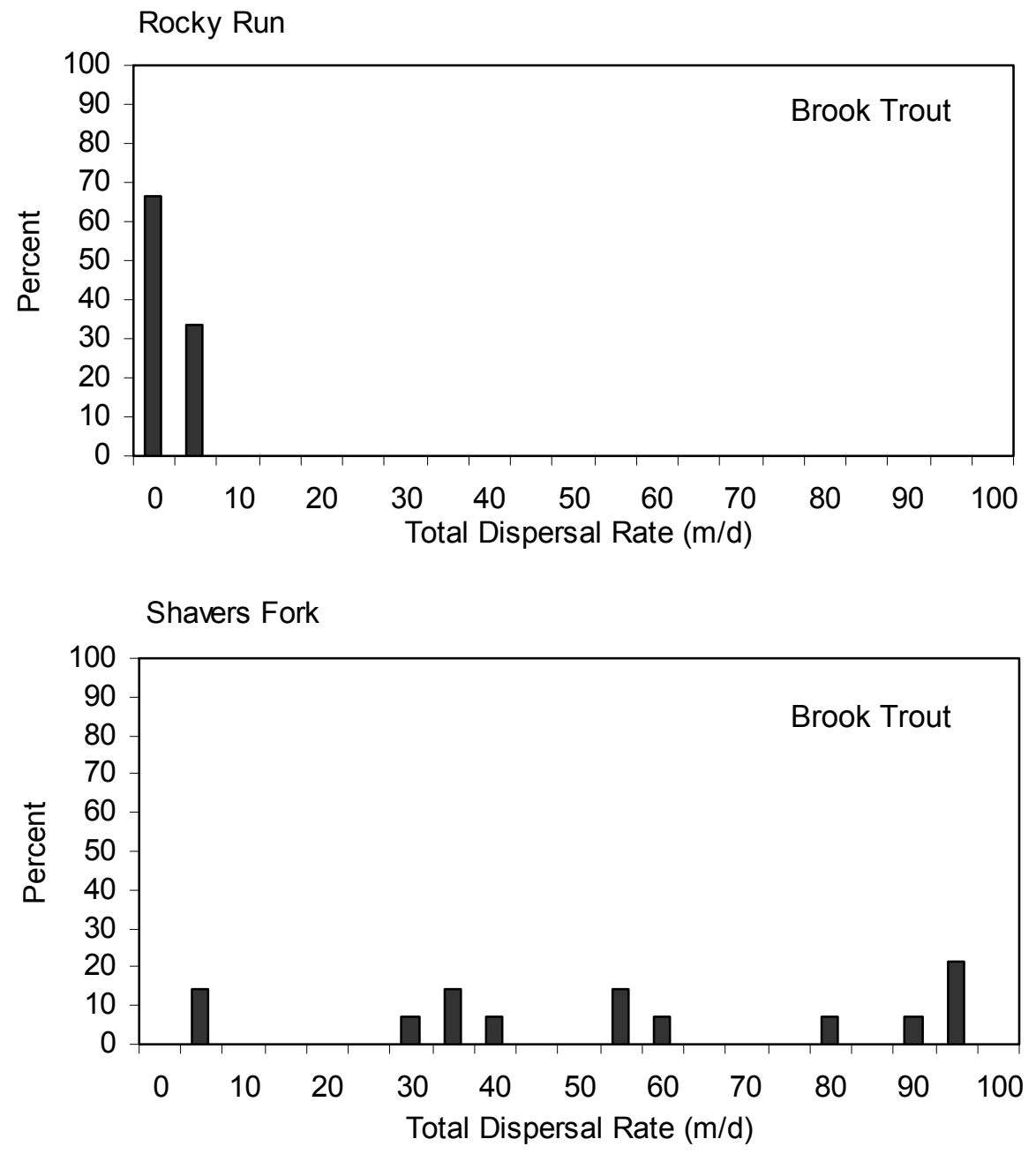
Figure 39. Frequency histograms of trout movement rates in spring/summer 2001. Total dispersal rate refers to the absolute value of the distance moved by individual trout.
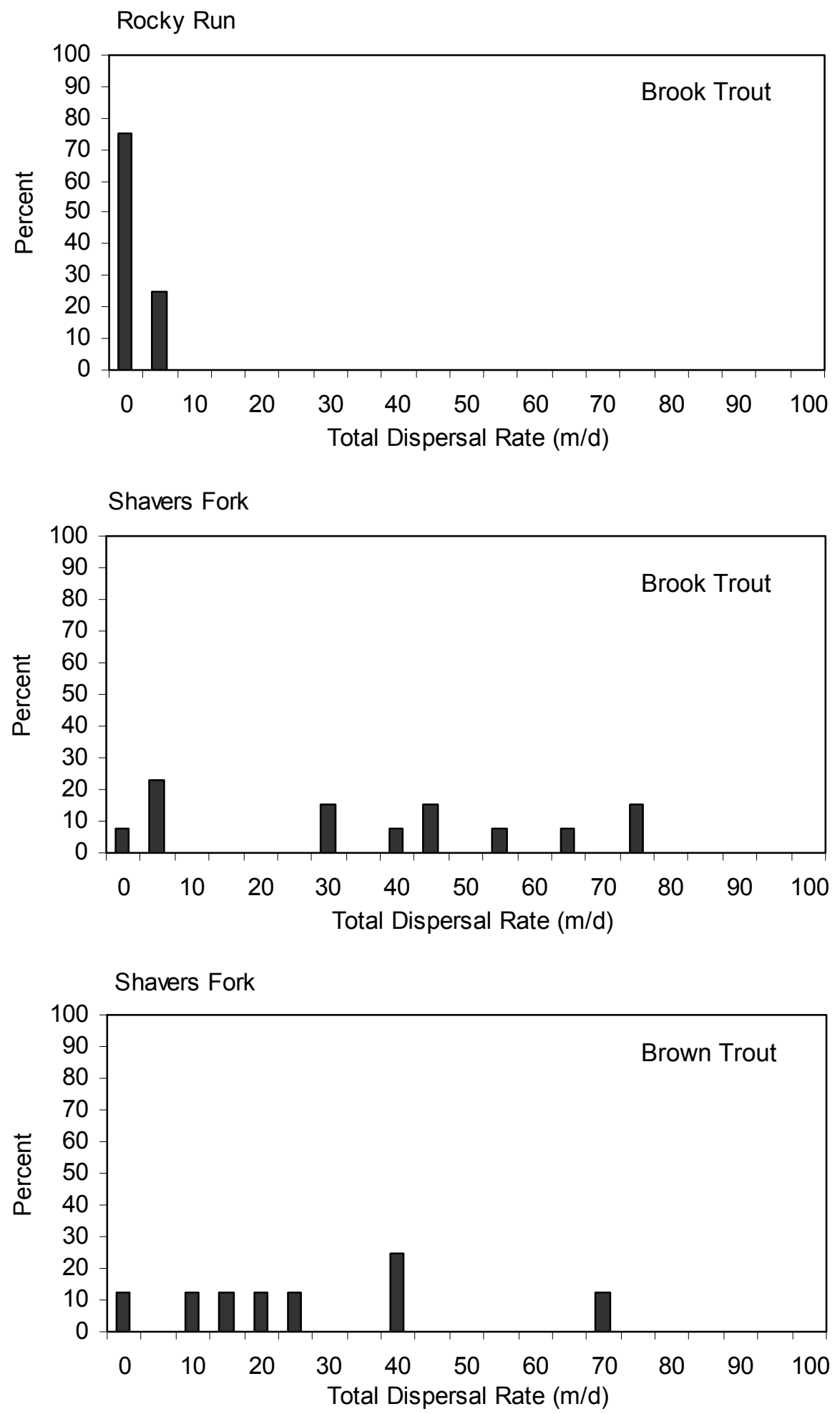
Figure 40. Frequency histograms of trout movement rates in fall 2000. Total dispersal rate refers to the absolute value of the total distance moved by individual trout
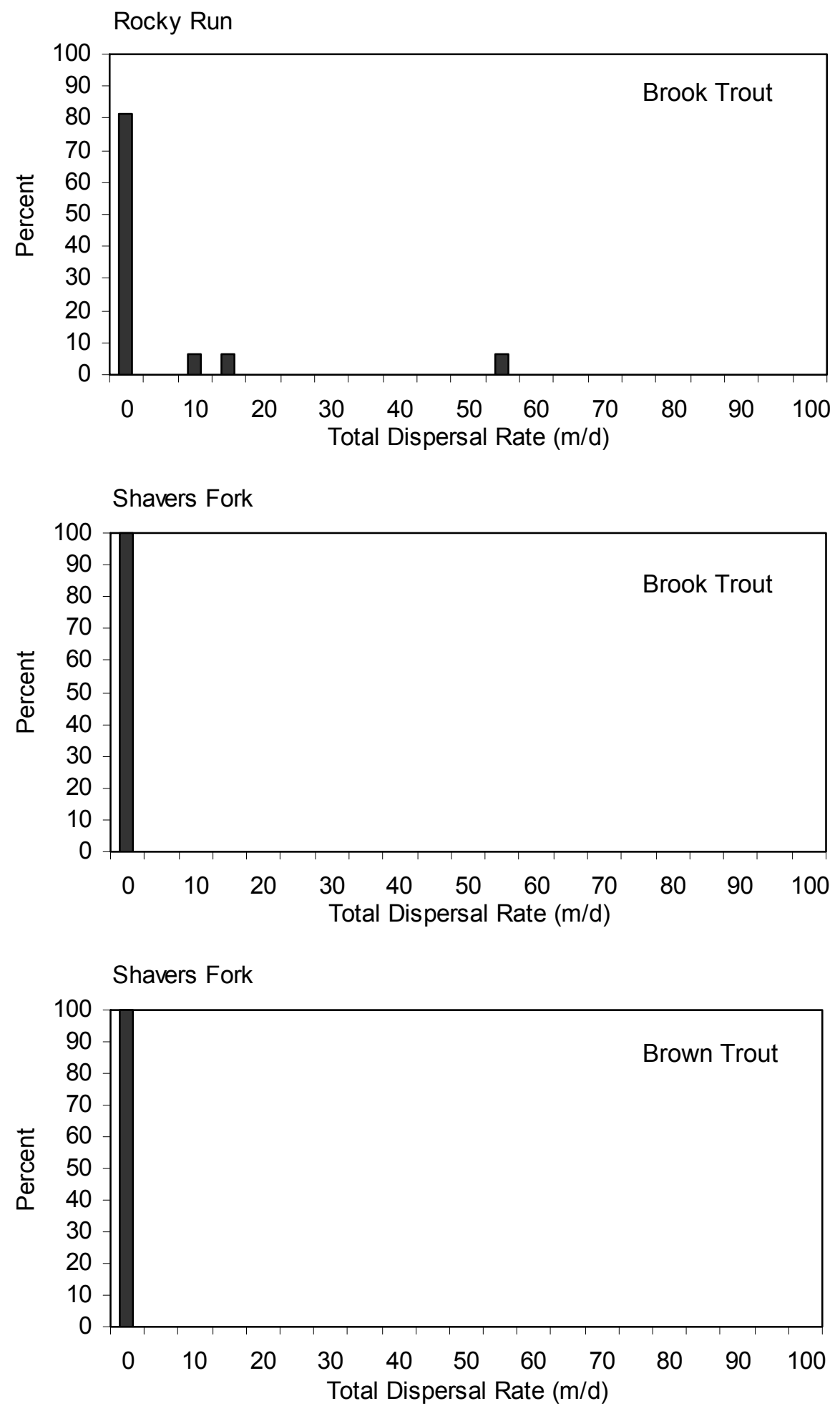
Figure 41. Frequency histograms of trout movement rates in spring/summer 2000. Net dispersal rate refers to the directional value of the total distance moved by trout.
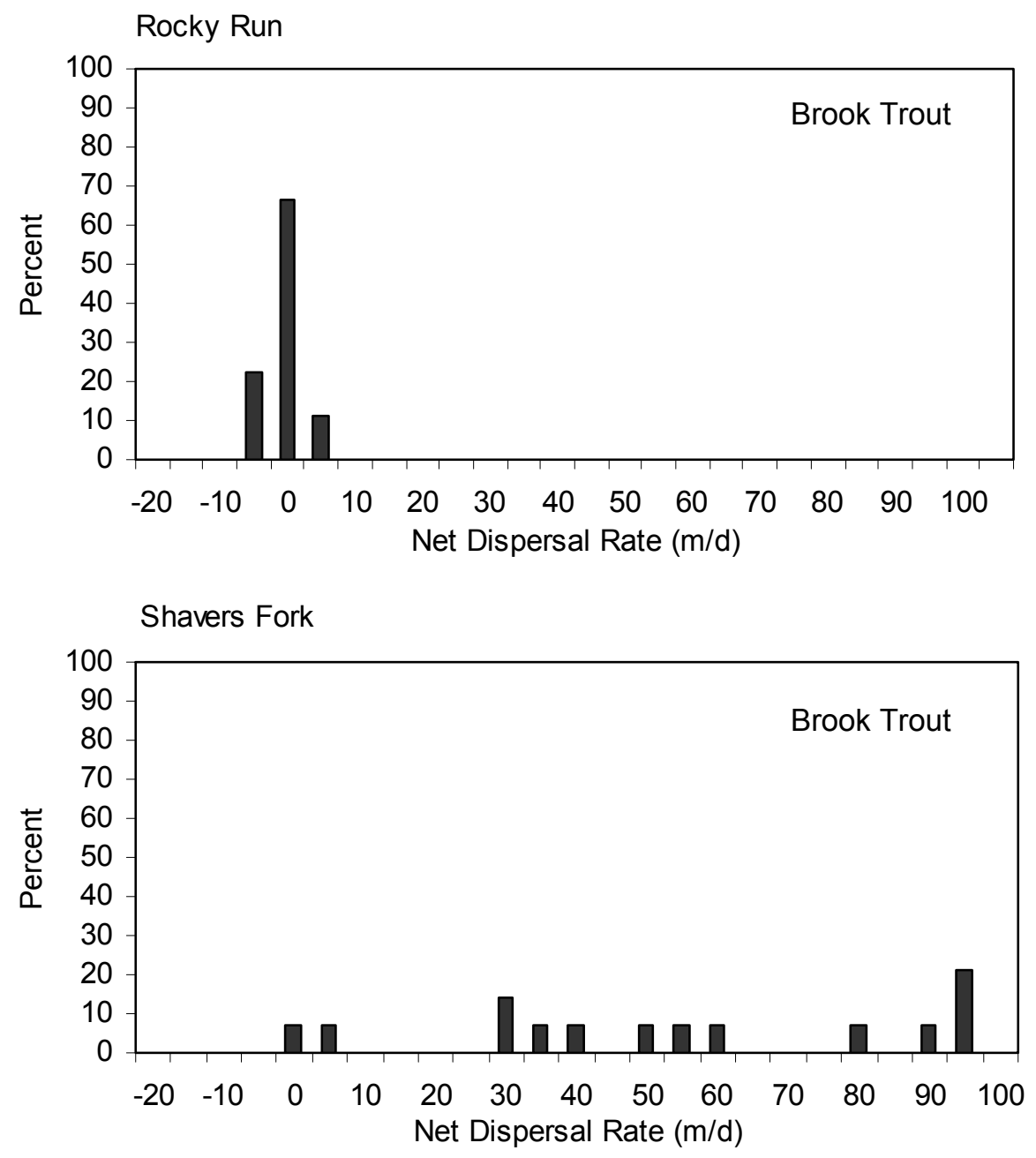
Figure 42. Frequency histograms of trout movement rates in spring/summer 2001. Net dispersal rate refers to the directional value of the total distance moved by trout.
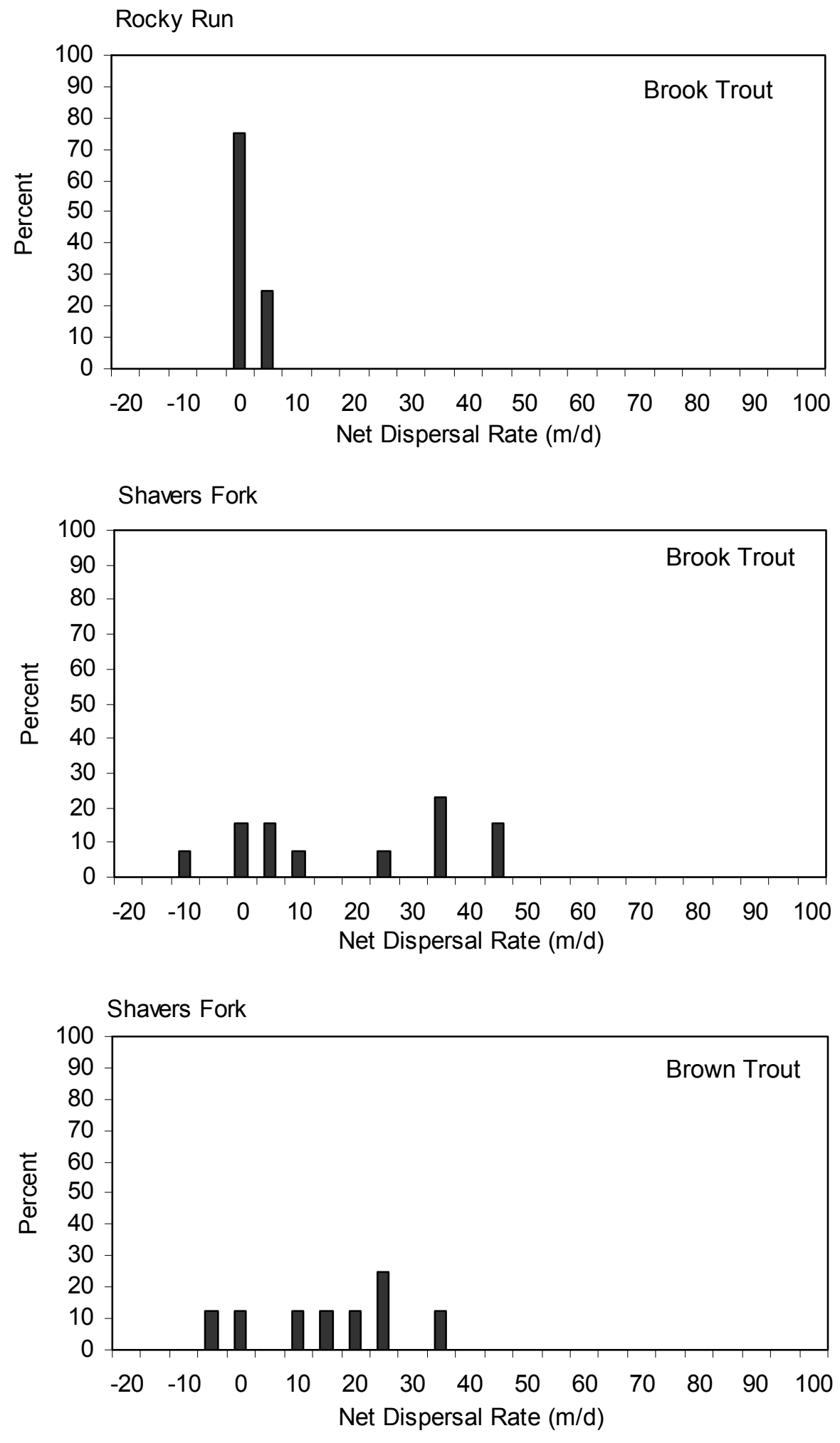
Figure 43. Frequency histograms of trout movement rates in fall 2000. Net dispersal rate refers to the directional value of the total distance moved by trout.
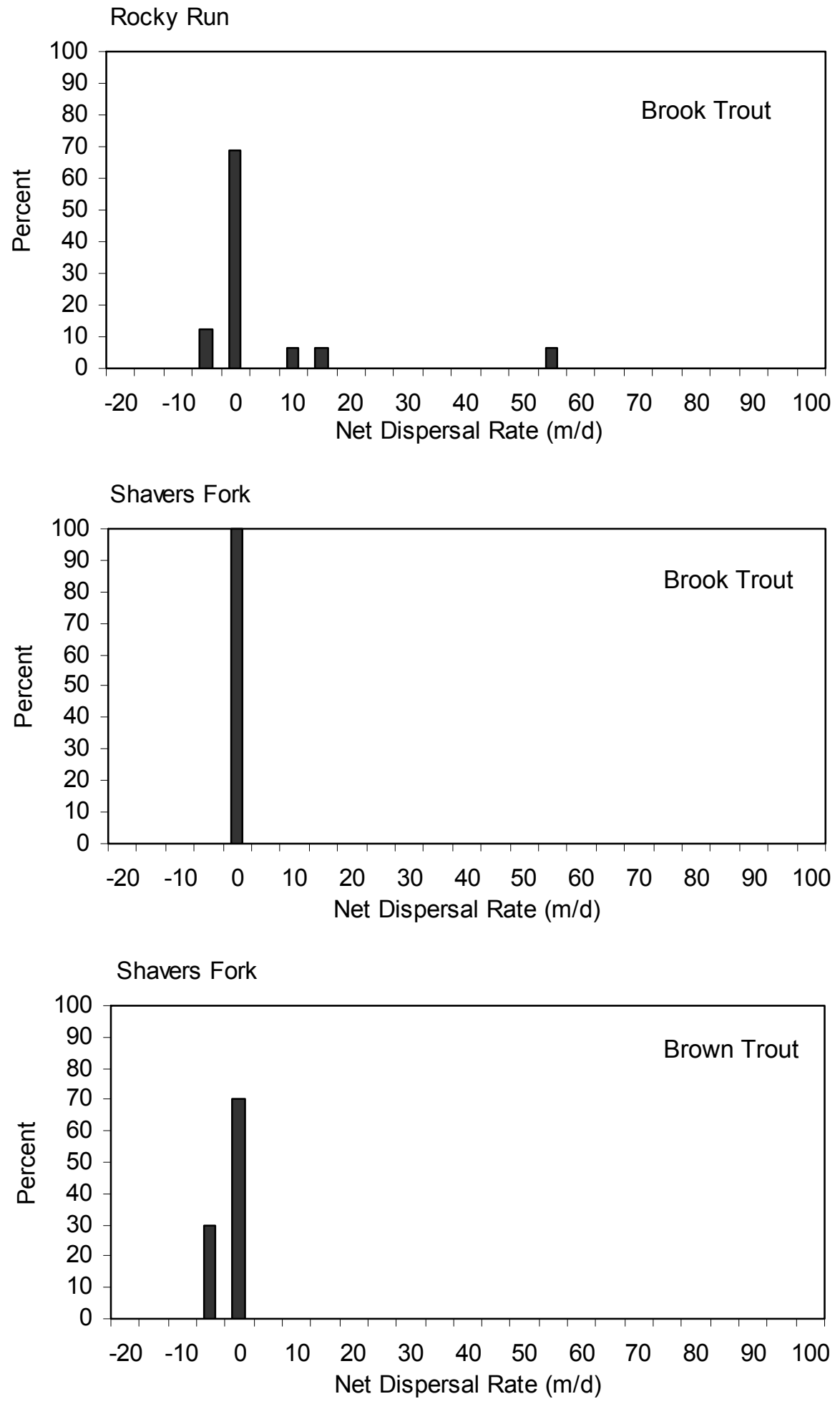
Figure 44. Mean ( \pm SE) total dispersal rate of brook trout (BRK) and brown trout (BRN) inhabiting Rocky Run (RR) and the mainstem (SH) of the upper Shavers Fork watershed. Arrows indicate rates that were significantly lower (i.e., $p<0.05$ ) than others in that particular season for that particular species/ stream group. "ND" refers to no data for brown trout in spring/summer 2000.

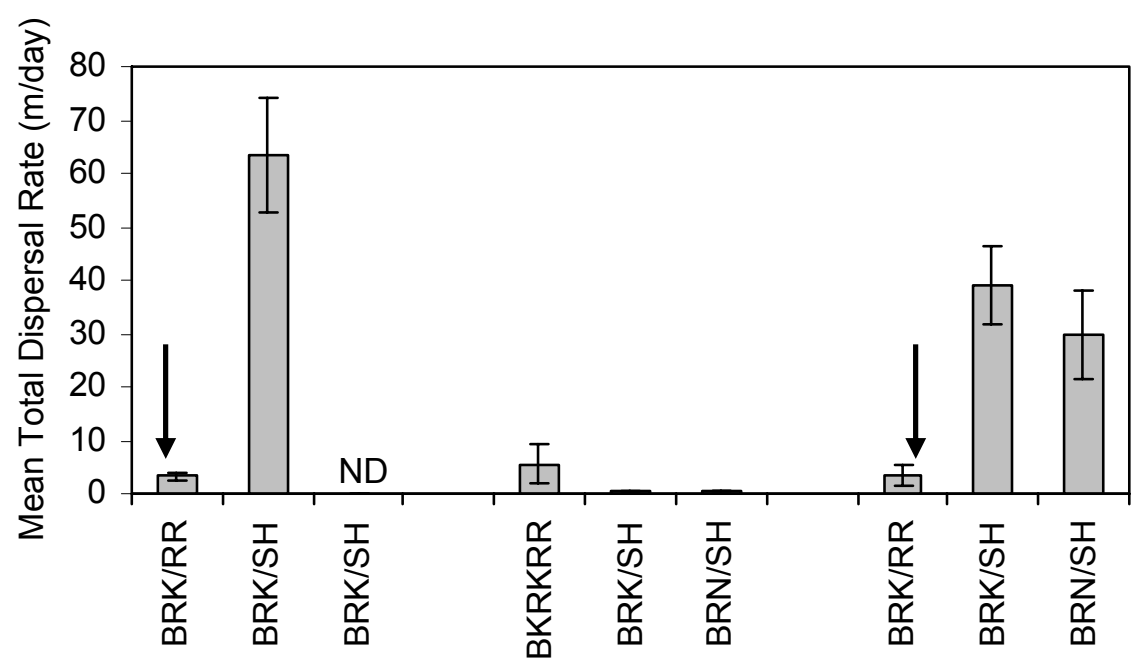

Spring 2000

Fall 2000

Spring 2001

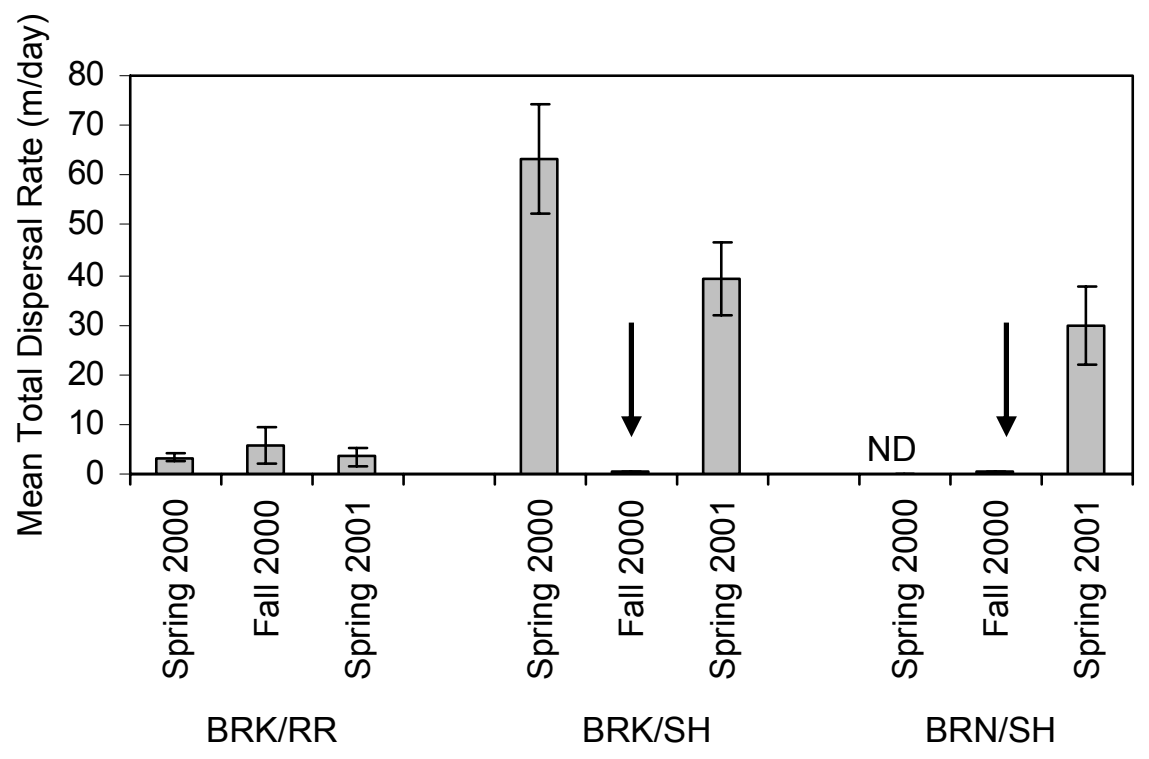


Figure 45. Relationship between brook trout movement rate and the maximum ambient water temperature of the Shavers Fork mainstem. Data are presented separately for spring/summer 2000 and 2001 . Open squares represent patterns during "cool" periods (i.e., Maximum Temperature $<18^{\circ} \mathrm{C}$ ). Black diamonds represent patterns during "warm" periods (i.e., Maximum Temperature $>18^{\circ} \mathrm{C}$ ). A "cool" period did not occur in 2001.
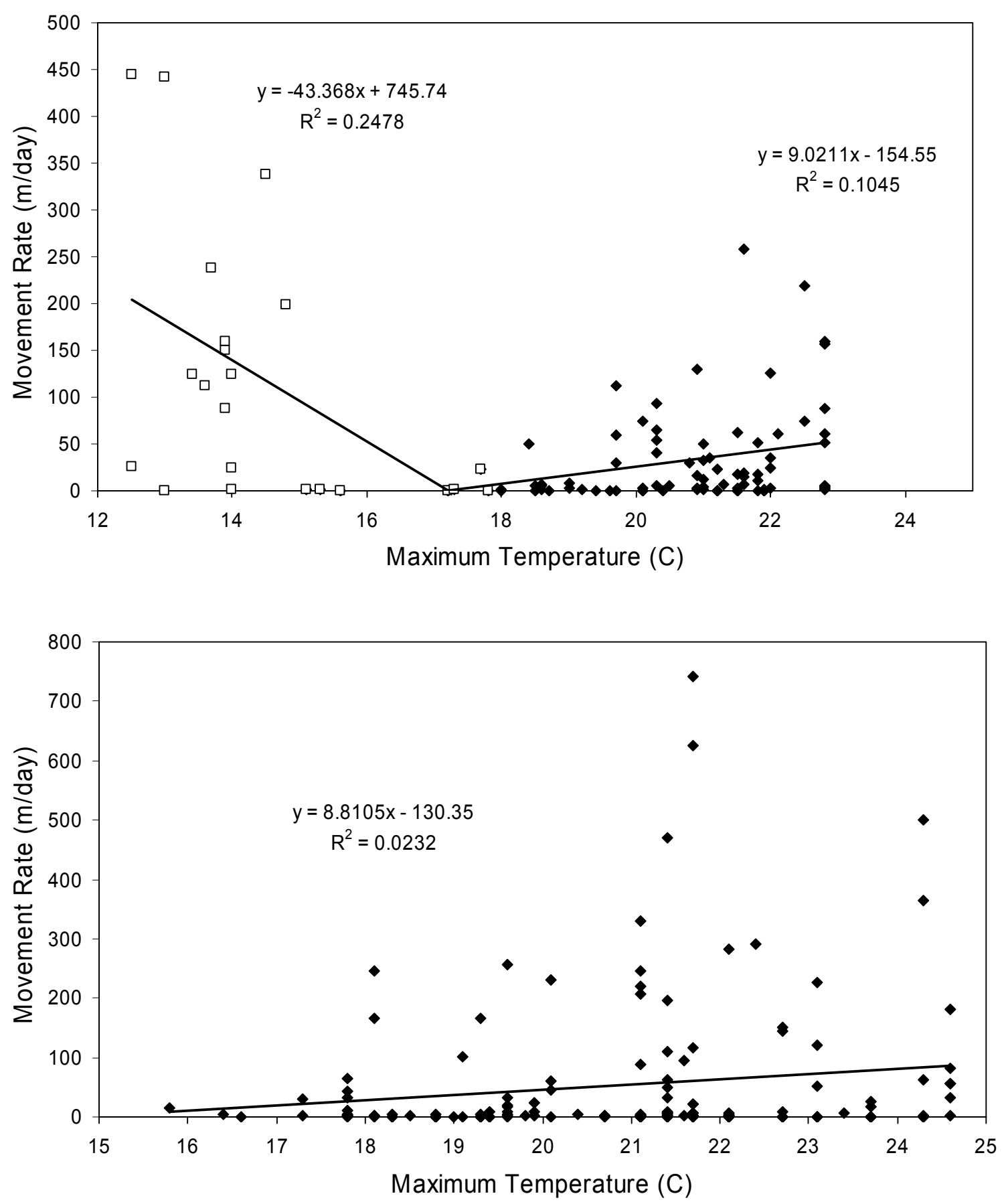
Figure 46. Relationship between brook trout movement rates and distance to known CWSs (Cold Water Sources) in the Shavers Fork mainstem. Data are presented separately for spring/summer 2000 and 2001.
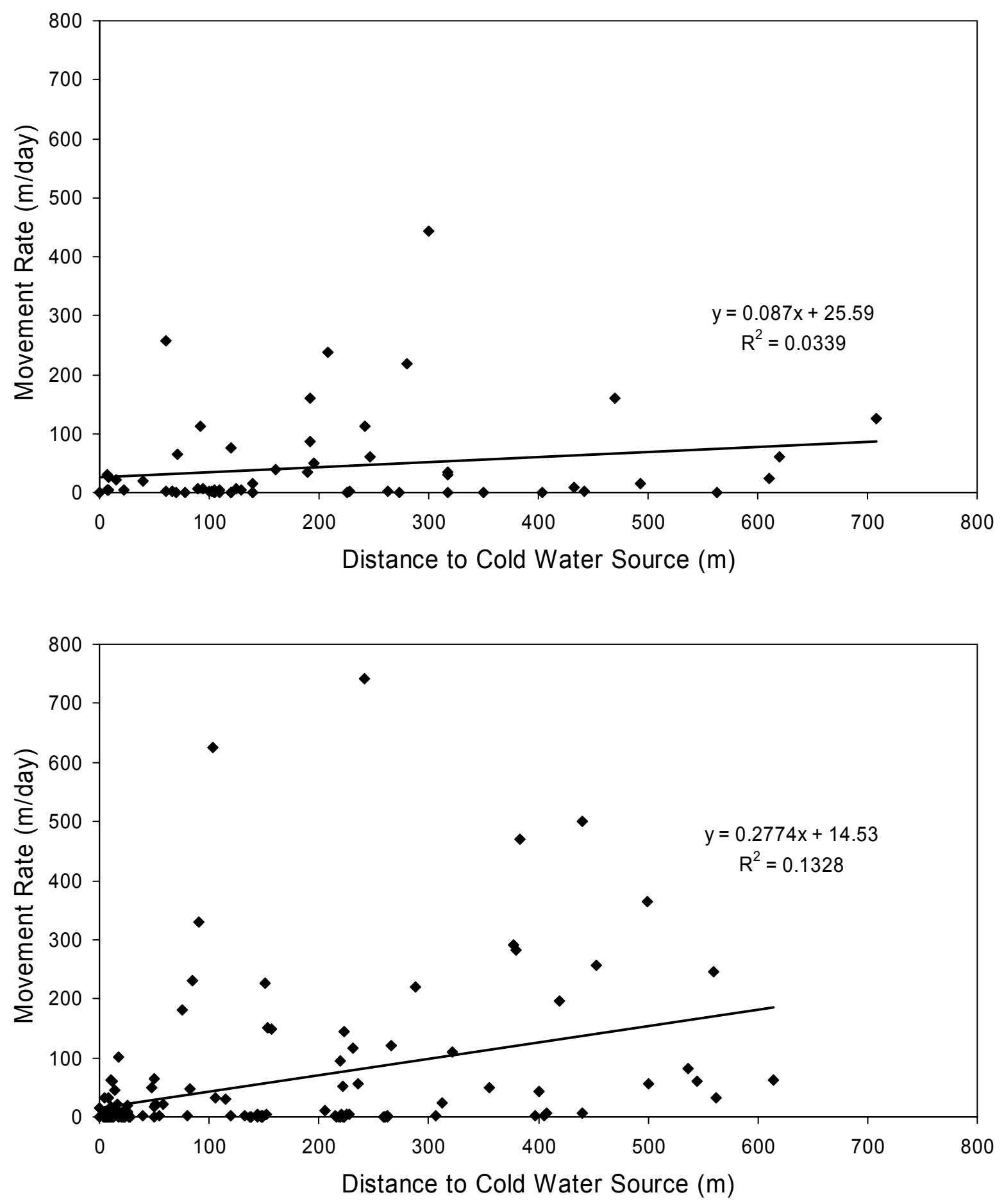


\section{Appendix}

Summary of implanted (tagged) trout data for all seasons $(B R K=$ brook, BRN $=$ brown, RR = Rocky Run, SF = Shavers Fork mainstem). Values indicated for "days at large" do not include the initial seven day post-surgery non-tracking period used to minimize handling effects, etc.

\begin{tabular}{|c|c|c|c|c|c|c|c|}
\hline Season & Fish No. & $\mathrm{SL}(\mathrm{mm})$ & Wt. (g) & Sp. & Days at Large & No. of Tracks & Release Location \\
\hline \multirow[t]{28}{*}{ Spr./Summer 2000} & 1 & 196.0 & 115.0 & BRK & 23 & 6 & SF \\
\hline & 2 & 184.0 & 76.2 & BRK & 65 & 14 & SF \\
\hline & 3 & 213.4 & 128.0 & BRK & 56 & 13 & SF \\
\hline & 4 & 182.2 & 72.0 & BRK & 40 & 9 & SF \\
\hline & 5 & 225.4 & 149.6 & BRK & 40 & 9 & SF \\
\hline & 6 & 190.4 & 82.2 & BRK & 44 & 10 & SF \\
\hline & 7 & 174.8 & 78.0 & BRK & 40 & 9 & SF \\
\hline & 8 & 225.4 & 146.9 & BRK & 36 & 10 & SF \\
\hline & 9 & 230.0 & 160.6 & BRK & 8 & 3 & SF \\
\hline & 10 & 202.4 & 99.6 & BRK & 1 & 1 & SF \\
\hline & 11 & 192.3 & 91.4 & BRK & 28 & 4 & SF \\
\hline & 12 & 198.7 & 101.3 & BRK & 28 & 4 & SF \\
\hline & 13 & 194.1 & 90.2 & BRK & 47 & 10 & SF \\
\hline & 14 & 198.7 & 93.8 & BRK & 40 & 7 & SF \\
\hline & 15 & 218.0 & 120.2 & BRK & 31 & 7 & SF \\
\hline & 16 & 204.2 & 114.2 & BRK & 36 & 8 & SF \\
\hline & 17 & 179.4 & 81.6 & BRK & 44 & 7 & SF \\
\hline & 18 & 211.6 & 132.7 & BRK & 36 & 7 & SF \\
\hline & 19 & 196.9 & 127.0 & BRK & 40 & 7 & SF \\
\hline & 20 & 195.0 & 94.6 & BRK & 61 & 18 & SF \\
\hline & 21 & 188.6 & 90.6 & BRK & 28 & 6 & SF \\
\hline & 22 & 190.4 & 88.9 & BRK & 36 & 6 & SF \\
\hline & 23 & 174.8 & 75.0 & BRK & 20 & 5 & SF \\
\hline & 24 & 218.0 & 170.4 & BRK & 36 & 8 & $\mathrm{RR}$ \\
\hline & 25 & 224.5 & 145.1 & BRK & 48 & 11 & RR \\
\hline & 26 & 220.8 & 134.0 & BRK & 43 & 9 & $\mathrm{RR}$ \\
\hline & 27 & 198.7 & 85.7 & BRK & 40 & 9 & $\mathrm{RR}$ \\
\hline & 28 & 187.7 & 84.2 & BRK & 12 & 3 & $\mathrm{RR}$ \\
\hline \multirow[t]{10}{*}{ Fall 2000} & 29 & 211.6 & 127.8 & BRK & 30 & 8 & $\mathrm{RR}$ \\
\hline & 30 & 216.2 & 149.3 & BRK & 40 & 7 & $\mathrm{RR}$ \\
\hline & 31 & 220.8 & 125.9 & BRK & 34 & 6 & RR \\
\hline & 32 & 205.2 & 120.8 & BRK & 40 & 6 & $\mathrm{RR}$ \\
\hline & 33 & 169.3 & 75.0 & BRK & 34 & 5 & RR \\
\hline & 34 & 181.2 & 77.0 & BRK & 48 & 6 & $\mathrm{RR}$ \\
\hline & 35 & 285.2 & 208.0 & BRK & 30 & 6 & $\mathrm{RR}$ \\
\hline & 36 & 187.7 & 94.6 & BRK & 38 & 6 & RR \\
\hline & 37 & 178.5 & 78.9 & BRK & 38 & 6 & $\mathrm{RR}$ \\
\hline & 38 & 192.3 & 100.0 & BRK & 38 & 7 & RR \\
\hline
\end{tabular}


Appendix (cont'd)

\begin{tabular}{|c|c|c|c|c|c|c|c|}
\hline Season & Fish No. & $\mathrm{SL}(\mathrm{mm})$ & Wt. (g) & Sp. & Days at Large & No. of Tracks & Release Location \\
\hline Fall 2000 & 39 & 179.4 & 99.0 & BRK & 26 & 6 & RR \\
\hline \multirow[t]{17}{*}{ (cont'd) } & 40 & 188.6 & 101.4 & BRK & 52 & 8 & RR \\
\hline & 41 & 204.2 & 115.0 & BRK & 38 & 6 & $\mathrm{RR}$ \\
\hline & 42 & 193.2 & 102.0 & BRK & 45 & 7 & $\mathrm{RR}$ \\
\hline & 43 & 188.6 & 99.1 & BRK & 45 & 7 & RR \\
\hline & 44 & 184.0 & 97.0 & BRK & 45 & 7 & $\mathrm{RR}$ \\
\hline & 45 & 161.9 & 72.5 & BRK & 40 & 6 & SF \\
\hline & 46 & 163.8 & 73.2 & BRK & 54 & 7 & SF \\
\hline & 47 & 219.0 & 238.0 & BRN & 34 & 5 & SF \\
\hline & 48 & 167.4 & 193.2 & BRN & 34 & 6 & SF \\
\hline & 49 & 175.7 & 191.0 & BRN & 34 & 6 & SF \\
\hline & 50 & 146.0 & 158.7 & BRN & 34 & 5 & SF \\
\hline & 51 & 150.1 & 183.5 & BRN & 54 & 8 & SF \\
\hline & 52 & 231.7 & 251.8 & BRN & 38 & 7 & SF \\
\hline & 53 & 227.8 & 253.5 & BRN & 28 & 9 & SF \\
\hline & 54 & 128.2 & 139.4 & BRN & 24 & 8 & SF \\
\hline & 55 & 128.9 & 140.1 & BRN & 34 & 5 & SF \\
\hline & 56 & 119.2 & 129.6 & BRN & 52 & 7 & SF \\
\hline \multirow[t]{23}{*}{ Spr./Summer 2001} & 57 & 254.0 & 225.7 & BRN & 20 & 11 & SF \\
\hline & 58 & 243.0 & 204.3 & BRN & 46 & 13 & SF \\
\hline & 59 & 178.0 & 73.0 & BRK & 36 & 10 & SF \\
\hline & 60 & 193.0 & 85.1 & BRK & 56 & 14 & SF \\
\hline & 61 & 218.0 & 145.2 & BRK & 46 & 12 & SF \\
\hline & 62 & 211.0 & 164.0 & BRK & 46 & 13 & SF \\
\hline & 63 & 137.0 & 155.0 & BRK & 34 & 9 & SF \\
\hline & 64 & 202.0 & 160.0 & BRK & 46 & 13 & SF \\
\hline & 65 & 279.0 & 362.0 & BRN & 56 & 16 & SF \\
\hline & 66 & 195.0 & 110.0 & BRK & 46 & 12 & SF \\
\hline & 67 & 279.0 & 375.0 & BRN & 42 & 11 & SF \\
\hline & 68 & 184.0 & 96.4 & BRK & 46 & 13 & SF \\
\hline & 69 & 184.0 & 99.2 & BRK & 20 & 7 & SF \\
\hline & 70 & 171.0 & 93.3 & BRK & 48 & 13 & SF \\
\hline & 71 & 185.0 & 108.7 & BRK & 64 & 16 & SF \\
\hline & 72 & 222.0 & 169.7 & BRK & 48 & 13 & SF \\
\hline & 73 & 198.0 & 124.4 & BRK & 54 & 14 & SF \\
\hline & 74 & 184.0 & 109.7 & BRN & 50 & 14 & SF \\
\hline & 75 & 193.0 & 112.0 & BRK & 12 & 5 & SF \\
\hline & 76 & 191.0 & 106.8 & BRK & 46 & 12 & SF \\
\hline & 77 & 226.0 & 212.4 & BRN & 36 & 11 & SF \\
\hline & 78 & 231.0 & 221.6 & BRN & 46 & 13 & SF \\
\hline & 79 & 213.0 & 148.5 & BRN & 36 & 11 & SF \\
\hline
\end{tabular}




\section{Appendix (cont'd)}

\begin{tabular}{cccccccc}
\hline Season & Fish No. & SL $(\mathrm{mm})$ & Wt. $(\mathrm{g})$ & Sp. & Days at Large & No. of Tracks & Release Location \\
\hline Spr./Summer 2001 & 80 & 195.0 & 116.0 & BRK & 38 & 11 & RR \\
(cont'd) & 81 & 203.0 & 129.0 & BRK & 38 & 11 & RR \\
& 82 & 212.0 & 150.2 & BRK & 28 & 9 & RR \\
& 83 & 198.0 & 128.1 & BRK & 38 & 10 & RR \\
& 84 & 180.0 & 80.3 & BRK & 60 & 15 & RR \\
\hline **avg., range & & 197.4 & 132.0 & & $1-65$ & $1-15$
\end{tabular}

